\title{
Evaluation of Lentil Genepool for Yield and Some Yield Related Attributes
}

\author{
Anam Nourin', Aysha Kiran", Sadia Kaukab,", Aziz ur Rehman², Muhammad Sajjad Saeed², \\ Aqsa Tahir ${ }^{2}$,Gulfam Riasat ${ }^{2}$, Ehsan Khan ${ }^{2}$ \\ ${ }^{1}$ Department of Botany, University of Agriculture, Faisalabad, Pakistan \\ ${ }^{2}$ Pulses Research Institute, Ayub Agricultural Research Institute (AARI), Faisalabad, Pakistan
}

Copyright $\odot 2019$ by authors, all rights reserved. Authors agree that this article remains permanently open access under the terms of the Creative Commons Attribution License 4.0 International License

\begin{abstract}
Lentil is an important pulse crop in Pakistan which is used in combination with cereals to balance the diet. Lentil area and production is declining for the last ten year. The current study is devised to evaluate lentil germplasm for the high yield performance at the Ayub Agricultural Research Institute, Faisalabad. Hundred accessions of lentil germplasm (Lens culinaris L.) were estimated for morphological and yield related attributes. Field performance results showed that lentil lines indicated major differences for their morphological studied factors. AARI-L-540, AARI-L-302, AARI-L- 411, AARI-L-562, AARI-L-454, AARI-L-417, AARI-L- 650, AARI-L-701, AARI-L-284, AARI-L-124, AARI-L-234, AARI-L-318, AARI-L-530, AARI-L-550, AARI-L-272, genotype analyzed the maximum plant biomass, highest seed yield, 1000 seed weight, number of pods, plant height at maturity and flowering, length of reproductive phase, days to flowering and maturity, harvest index, Degree of indetermination, primary and secondary branches of plant, No of pods/plant, seed per pod, canopy temp, internode distance, no of nodes and leaves were calculated respectively. Principal component analysis statistically applied on these traits. First eight principal component analyses (PCA) expressed $88.52 \%$ of total variation in which PC I, PC II, PC III, PC IV, PC V, PC VI, PC VII \& PC VIII accounted for $19.12 \%, 11.24 \%, 610.05 \%, 29.66 \%$, $7.19 \%, 36.75 \%, 75.88 \%$, $5.58 \%$ of total variation. The data was statistically analyzed to find out the superior genotype for the above mentioned character.
\end{abstract}

Keywords Germplasm, Yield, AARI

\section{Introduction}

Lens culinaris Medik, is an important Rabi-pulse crop which is mainly cultivated in rain fed areas. In Pakistan lentil is cultivated on 14.2 thousand ha with overall production 6.4 thousand tons and yield is $5.23 \mathrm{~kg} / \mathrm{ha}$ in 2016-17 which is far less than other countries. In the previous years lentil area has been drastically decreased which happen due to low economic return of lentil as compared to other Rabi crops. The main reason is low yield potential of lentil varieties, in the past no serious effort have been made for genetic improvement of lentil crop. The available lentil germplasm have not been evaluated for yield and yield related traits in Pakistan while great genetic variability have been reported in literature, generally lentil germplasm grown in India is categorized as small seed, early flowering and maturing, short duration and low biological yield Erksine $^{[3]}$ 1998. Whereas several genotypes in micro-sperma lentil are available that are grown in long day environment with bold seed and upright growth habit Majumdar 2011, Tickoo et al, 2005 ${ }^{[7,12]}$. Seed yield is decreased with low number of pods/ plant and seeds/ pod Singh et al. ${ }^{[10]}$ 2009. The varieties of small seeded lentil are more healthy in dry conditions and varieties of bold seeded lentil show better performance in cold environment Erksine ${ }^{[2]}$ 1996. The lentil genotypes both micro and macro-sperma have different contribution of characters involved in yield potential. Ahamed et al. ${ }^{[1]}$ 2014 reported less variation in plant height, days to flowering, days to maturity and 100 seed weight both at genotypic and phenotypic level. They reported positive correlation between grain yield and plant height. Rehman et al. ${ }^{[9]}$ 2013, reported different levels of degree of indetermination in lentil germplasm. Goa ${ }^{\left[4^{\prime}\right]}$ 2015, observed significant yield difference among lentil genotypes. Kumar et al. ${ }^{[6]}$ 2015, explained maximum variation in seed yield, plant biomass, length of reproductive phase, degree of indetermination and seeds/pod. Khatun et al. ${ }^{[5]}$ 2016, showed differential in various agro-morphological characters of lentil, like harvest index, seed yield, maturity period, plant height and pods/ plant. 


\section{Material and Methods}

One hundred lines of lentil germplasm accession were planted at experimental area of Pluses Research Institute, Ayub Agricultural Research Institute, and (AARI) Faisalabad on 15-11-2016. Standard agronomic methods and cultural operations i.e., hoeing, weeding, irrigation, fertilizers were applied from sowing till reaping the crops in order to reduce the experimental error. Each entry was sown on $2.5 \mathrm{~m}$ long row to distance of $30 \mathrm{~cm}$.

Ten equally competent plants were selected and labeled in order to record data

\section{$50 \%$ flowering}

Data regarding days to blossoming was calculated from the date of seeding to the appearance of $50 \%$ flower.

\section{0\% maturity}

Data regarding times to maturity was calculated since date of seeding to the date when pods were $90 \%$ ripened in all plants.

\section{Reproductive phase length}

Reproductive phase length was counted by directly subtracting the days of $50 \%$ flowering from the days to $90 \%$ maturity of each replicate.

\section{Canopy temperature}

Canopy temperature was measured on the bright sunny day in ${ }^{0} \mathrm{C}$ by infrared $6^{\text {th }}$ sense thermometer while data regarding total of main and subordinate branches was calculated by directly counting the main and subordinate branches of ten plants and then their mean value was considered.

\section{Pods/plant and seeds/plant}

Pods/plant seeds/plant, leaves and nodes on the main branches of all plants were counted for each plant and regular data was calculated.

\section{Internode length}

Internode length was calculated by computing the distance between two internodes of the mid of the main branches and taking the average value.

\section{0 seed weight}

1000 seed produced in each row were counted and weighed on the electronic balance.

\section{Plant biomass}

Plant biomass (in grams) was measure by weighing the plant debris of the whole row after harvesting and drying. Similarly, Seed yield of the whole row was measured in grams using the digital electric balance.

Length of reproductive phase $=$ Days to maturity-Days to flowering

\section{Degree of indetermination}

Degree of indetermination was calculated by the formula following Rehman et al. ${ }^{[9]} 2013$.

Degree of indetermination

$$
=\frac{\text { Height at maturity-Height at flowering }}{\text { Height at maturity }} \times 100
$$

\section{Harvest index}

Harvest index (HI) is the ratio of economic yield to total biological yield. Harvest index was calculated by the formula following by Rehman et al. ${ }^{[8]} 2009$.

$$
\text { Harvest index }=\frac{\text { Seed Yield }}{\text { Plant biomass }} \times 100
$$

\section{Disease rating scale}

Lentil rust was scored 0 and 1 with 1 indicating the attack of disease and 0 marked the absence of disease. Lentil blight incidence was scored from 1-5 as described by Singh and Sandhu ${ }^{[11]} 1988$ as: $1=$ resistant, 3= temperately resistant, $5=$ temperately susceptible, $7=10$ susceptible, $9=$ extremely susceptible.

The data were statistically analyzed by Principal Component analysis in order to find out the superior genotype for the above discussed characters

\section{Results and Discussion}

\subsection{Multivariate Analysis Principal Component Analysis}

Principle component analysis (PCA) was carried out to obtain the sources of variance in lentil genotypes and $75.4 \%$ of the total variation was assessed in first eight axes of gathered 20 morphological characters. The top most Eigenvalues were secured in initial eight PCs.

Table 1. Eigen values and percentage of variation for corresponding 8 component characters in 100 lentil genotypes

\begin{tabular}{|c|c|c|c|c|c|c|c|c|}
\hline Variables & F1 & F2 & F3 & F4 & F5 & F6 & F7 & F8 \\
\hline Eigenvalue & 3.63 & 2.13 & 1.91 & 1.83 & 1.36 & 1.28 & 1.11 & 1.06 \\
\hline Variability (\%) & 19.12 & 11.24 & 10.05 & 9.66 & 7.19 & 6.75 & 5.88 & 5.58 \\
\hline Cumulative \% & 19.12 & 30.36 & 40.41 & 50.08 & 57.27 & 64.03 & 69.91 & 75.49 \\
\hline
\end{tabular}




\subsection{Contribution of Characteristics to Divergence of Genotype}

Lentil genotypes show significant differences in agro morphological and yield attributes (Table2). The foremost principle component (PC1) proved 19.12\% of the aggregate variation in first generation and affiliated positively with characters of plant biomass, plant height at maturity, length of reproductive phase, harvest index, no of pod/plant, 1000 grain weight, biological yield, degree of indetermination, no of seed per pod , internodes distance, no of nodes, no of leaves(main branch) traits.

Whereas, PC2 regarded for $11.24 \%$ of whole fluctuation that associated with characters as like days to maturity and flowering, reproductive phase length, degree of indetermination, canopy temperature, internodes distance, no of nodes, no of leaves (main branch).

The third principle component explore $10.05 \%$ of the entire variation and associated with plant biomass, seed harvest, 1000 carnal mass, yield Index, days to maturity, length of reproductive phase, degree of indetermination, primary branches of plant, no of pods/plant, seed/Pod, canopy temperature traits. The fourth principle component (PC4) showed $9.66 \%$ of the cumulative variation and related positively with characters of 1000 seeds/plant, length of reproductive phase, maturity duration, flowering elevation, tallness of maturity, no of pod/plant, seeds/pod, no of leaves (main branch), lentil rust traits. Whereas, the fifth principle component (PC5) proved for $7.19 \%$ of the aggregate variation that associated with parameter of harvest index, days to blooming plus maturity, length of reproductive phase, plant height at flowering, primary branches of plant, secondary branches of plant, canopy temperature, internodes distance, no of nodes, no of leaves(main branch), lentil rust traits.

The sixth principle component (PC6)exhibited 6.75\% of the total variation and related with 1000/ weight, harvest index, length of reproductive phase, degree of indetermination, plant height at maturity, primary twigs of plant, secondary twigs, pods no per plant, grain/Pod, canopy temperature, internodes distance, no of leaves(main branch), lentil rust traits.

The seventh principle component (PC7) exhibited $5.88 \%$ of the whole variation and associated with 1000/spore mass, crop Index, days to maturity as well as flowering, seed yield, no of pods/plant, seed per pod, plant height at flowering, no of leaves(main branch), lentil rust traits.

Whereas, the eight principle component (PC8) proved for $5.58 \%$ of the entire variation that associated to traits like harvest index, 1000/seed weight, blooming time, maturity duration, full bloom height, primary and secondary brushwood of plant, degree of indetermination, pods no of every plant traits.

Table:2. Relative contributions of the 19 characteristics to the total divergence in lentil germplasm

\begin{tabular}{|l|c|c|c|c|c|c|c|c|}
\hline \multicolumn{1}{|c|}{ Characters } & F1 & F2 & F3 & F4 & F5 & F6 & F7 & F8 \\
\hline Plant Biomass & 0.296 & -0.266 & 0.358 & -0.169 & -0.105 & -0.207 & -0.207 & -0.088 \\
\hline Seed Yield & 0.280 & -0.277 & 0.416 & -0.293 & -0.026 & -0.173 & 0.002 & -0.039 \\
\hline 1000/seed weight & 0.062 & -0.094 & 0.062 & 0.175 & -0.073 & 0.394 & 0.024 & 0.467 \\
\hline Harvest Index & 0.066 & -0.111 & 0.262 & -0.387 & 0.157 & 0.012 & 0.462 & 0.138 \\
\hline Days to Maturity & -0.003 & 0.453 & 0.328 & 0.177 & 0.347 & -0.095 & 0.133 & 0.097 \\
\hline Days to flowering & -0.061 & 0.343 & -0.218 & -0.423 & 0.052 & -0.150 & 0.223 & 0.260 \\
\hline Length of reproductive phase & 0.041 & 0.162 & 0.457 & 0.469 & 0.277 & 0.023 & -0.041 & -0.101 \\
\hline Plant height at maturity & 0.433 & -0.074 & -0.137 & 0.138 & -0.003 & 0.031 & -0.103 & 0.233 \\
\hline plant height at flowering & -0.003 & -0.401 & -0.186 & 0.226 & 0.287 & -0.306 & 0.218 & -0.010 \\
\hline Degree of in determination & 0.404 & 0.162 & 0.002 & -0.016 & -0.197 & 0.246 & -0.238 & 0.223 \\
\hline Primary branches of plant & -0.091 & -0.173 & 0.107 & -0.142 & 0.472 & 0.235 & -0.229 & 0.319 \\
\hline Secondary branches of plant & -0.195 & -0.153 & -0.083 & -0.176 & 0.299 & 0.248 & -0.196 & 0.145 \\
\hline No of pods/plant & 0.100 & -0.018 & 0.092 & 0.067 & -0.069 & 0.208 & 0.555 & 0.147 \\
\hline Seed per Pod & 0.036 & -0.069 & 0.069 & 0.005 & -0.171 & 0.559 & 0.298 & -0.426 \\
\hline Canopy Temp & -0.110 & 0.177 & 0.119 & -0.339 & 0.173 & 0.283 & -0.248 & -0.362 \\
\hline Internode Distance (cm) & 0.377 & 0.073 & -0.179 & -0.082 & 0.078 & 0.046 & -0.018 & -0.029 \\
\hline No of nodes & 0.338 & 0.098 & -0.228 & -0.101 & 0.391 & -0.004 & 0.080 & -0.239 \\
\hline No of leaves(main branch) & 0.375 & 0.115 & -0.231 & 0.079 & 0.244 & 0.039 & 0.043 & -0.185 \\
\hline Lentil rust & -0.059 & -0.414 & -0.158 & 0.105 & 0.207 & 0.170 & 0.047 & -0.112 \\
\hline
\end{tabular}


The plot displayed by the PC1 and PC2 differentiate eighteen sets of traits (Fig. 1, 2). The initial set was positively related along with leaves number, internodes distance, degree of indetermination, length of reproductive phase, number of nodes. Plant height at maturity, pods no,1000 grain mass, yield index, seed/pod, biomass of plant, seed output was adversely associated to axis two (PC2), in contrary to flowering duration, time of maturation and canopy temperature represented third group was negatively correlated to axis one (PC1). First twigs, second brushwood, lentil rust, plant height at flowering were inversely affiliated to two axes. This may helpful in selection of genotypes for construction of varieties based on PC values for high elastic capacity. The outcome of analysis also determines the significance of those characters for evolution of high yielding varieties.

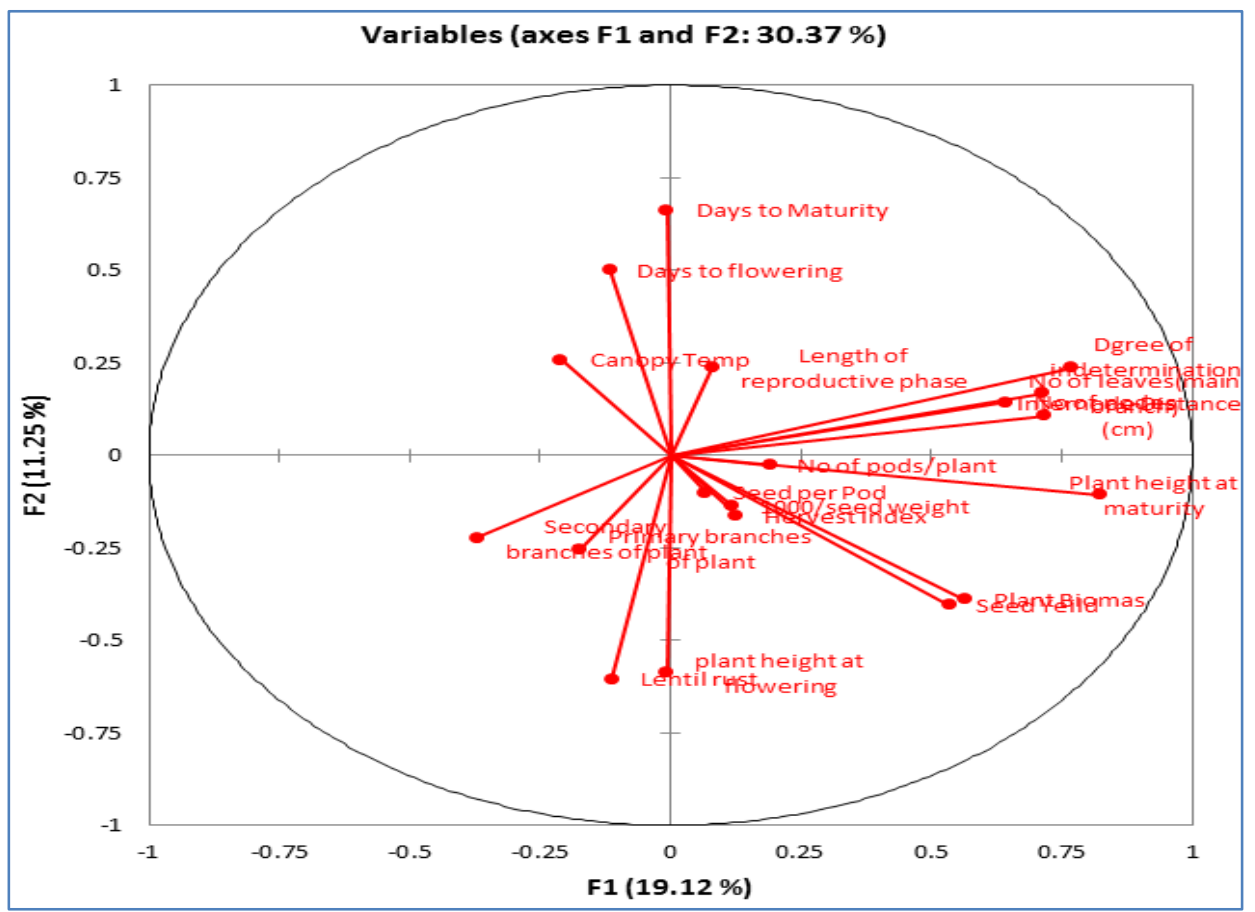

Figure1. Correlation between the characters of two variables F1 and F2.

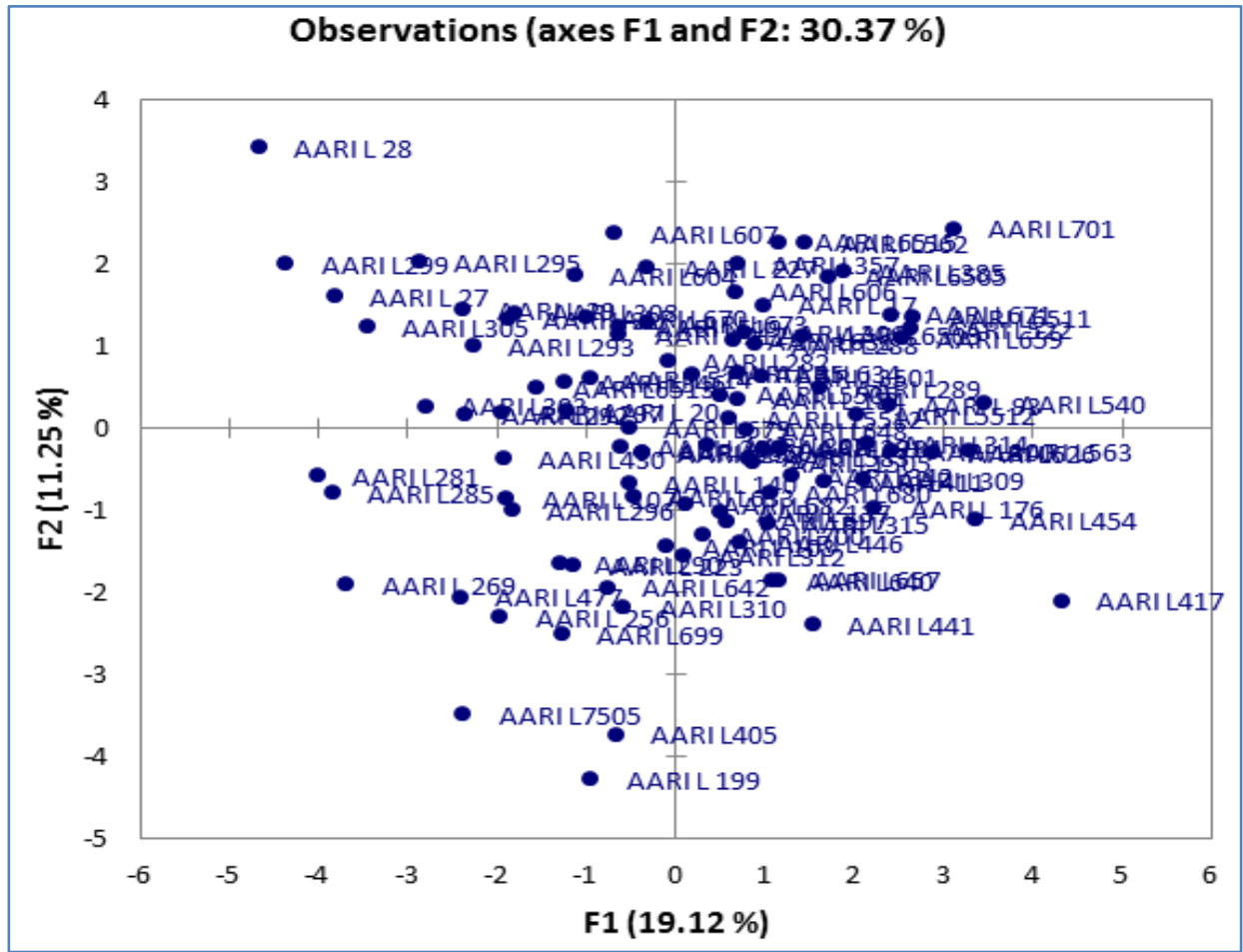

Figure 2. Two-dimensional ordination of 19 agro-morphological characters in genotypes of lentil germplasm on principal component axes. 
The design showed PC1 and PC2 identify eighteen classes of traits (Fig.3,4). The initial category was completely associated together with length of reproductive phase, harvest index, maturity duration, seed yield, plant biomass, degree of indetermination, 1000/seed weight, seed/pod, amount of pods/plant traits. Plant height at maturity, Internodes distance, number of leaves (main branch), was inversely associated to axis two (PC2), in comparison, primary branches of plant, and canopy temperature exhibited the third group was adversely to axis one (PC1). Secondary branches of plant, height at blooming, flowering period as well as lentil rust was fatalistic correlated to two axes. This may helpful in selection of genotypes for construction of varieties based on PC values for high elastic capacity. The outcome of analysis also determines the significance of those characters for evolution of high yielding varieties.

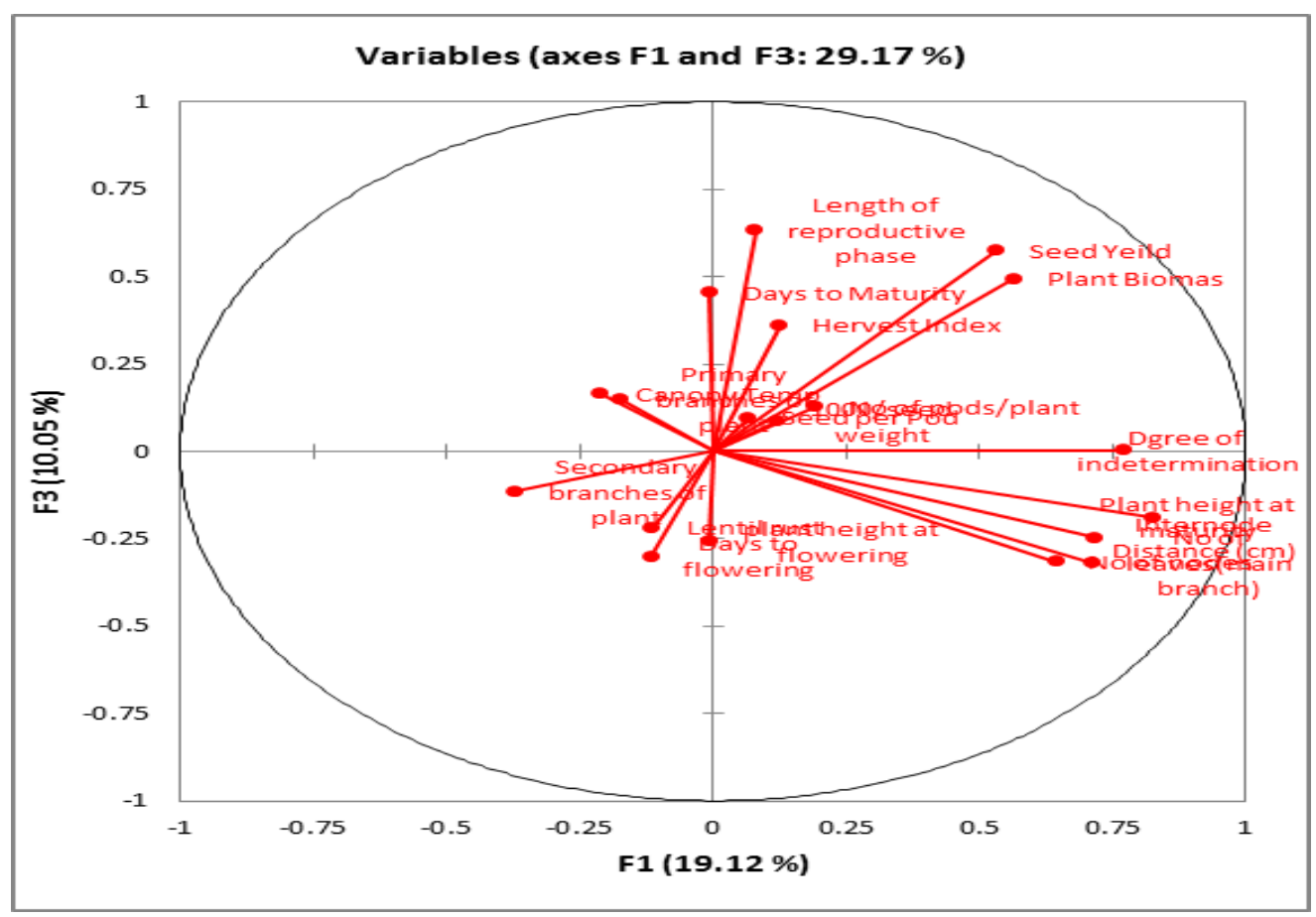

Figure 3. The graph shows the correlation between the characters of two variables. Each dot in this cloud shows a particular character.

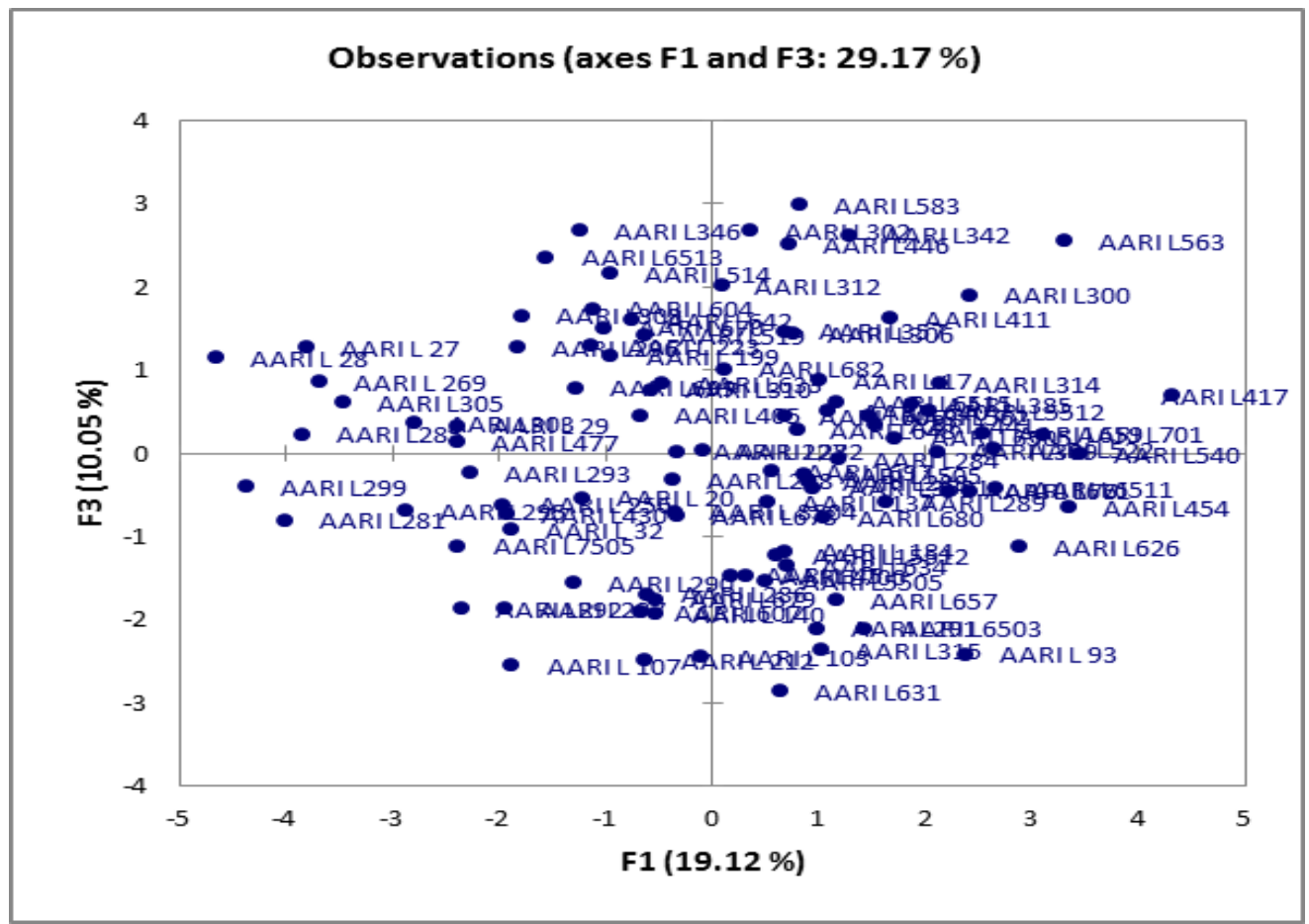

Figure 4. Two-dimensional ordination of 19 agro morphological traits in genotypes of lentil germplasm on principal component axes. 
The design explained by the principal component 1 and 2 distinguished eighteen collection traits (Fig.5,6). The original assembly was definitely linked along with length of reproductive phase, time to development, elevation at blossoming, 1000 inkling influence, pods quantity, particle/pod, and altitude at maturity, leaves numeral (main branch) traits. Degree of indetermination, plant biomass, number of nodes, internodes distance. Harvest index and seed yield was detrimental related to axis two (PC2), in contrary, lentil rust, showed the third group was fatalistic associated to axis one (PC1). Primary branches of plant, secondary branches of plant; canopy temperature and maturity duration was inversely related to two axes. . This may helpful in selection of genotypes for construction of varieties based on PC values for high elastic capacity.

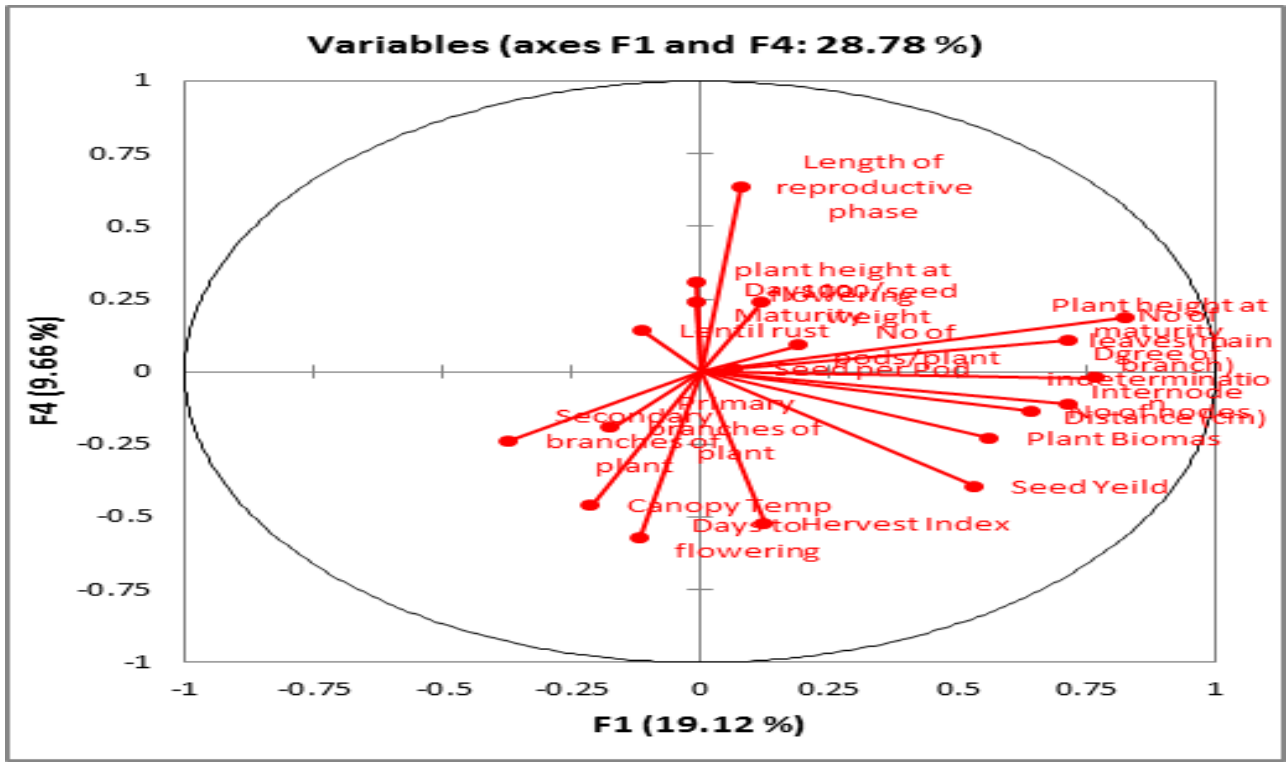

Figure 5. Correlation between the characters of two variables F1 and F4.

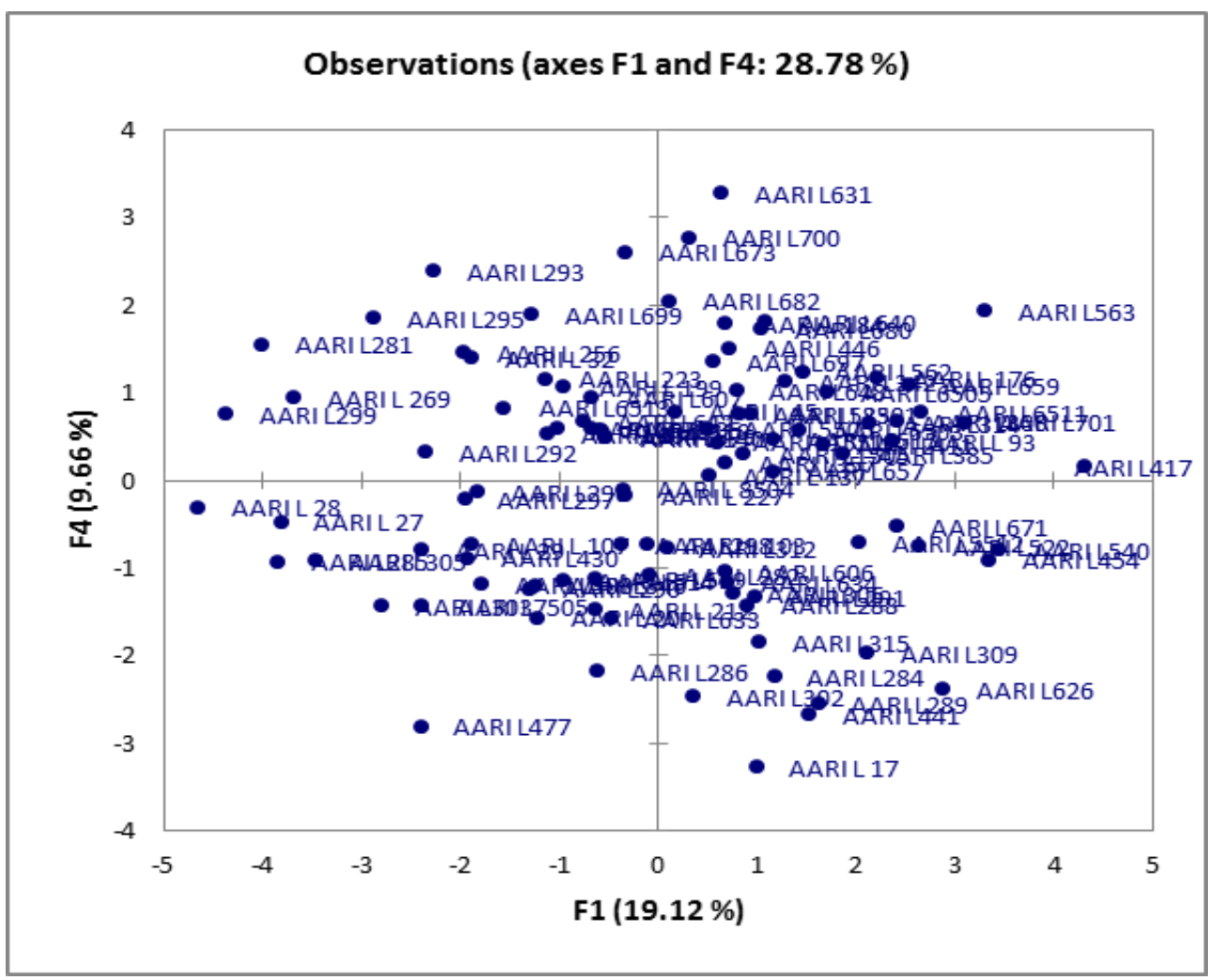

Figure 6. Two-dimensional ordination of 19 agro-morphological characters in genotypes of lentil germplasm on principal component axes. 
The plot showed by the PC1 and PC2 differences among eighteen classes of traits (Fig.7,8). The first one was positively linked towards the nodes quantity, number of leaves (main branch), maturity time, internodes distance, length of reproductive phase, days to maturity, harvest index and flowering altitude. Degree of indetermination, pods quantity ,1000 grain mass, kernel in pods, plant biomass, seed crop was fatalistic associated to axis two (PC2), in comparison, primary branches of plant, secondary branches of plant, lentil rust and canopy temperature exhibited the third class was adversely related to axis one (PC1). No character was inversely associated to two axes. This may helpful in selection of genotypes for construction of varieties based on PC values for high elastic capacity. The outcome of analysis also determines the significance of those characters for evolution of varieties with greater yield potential.

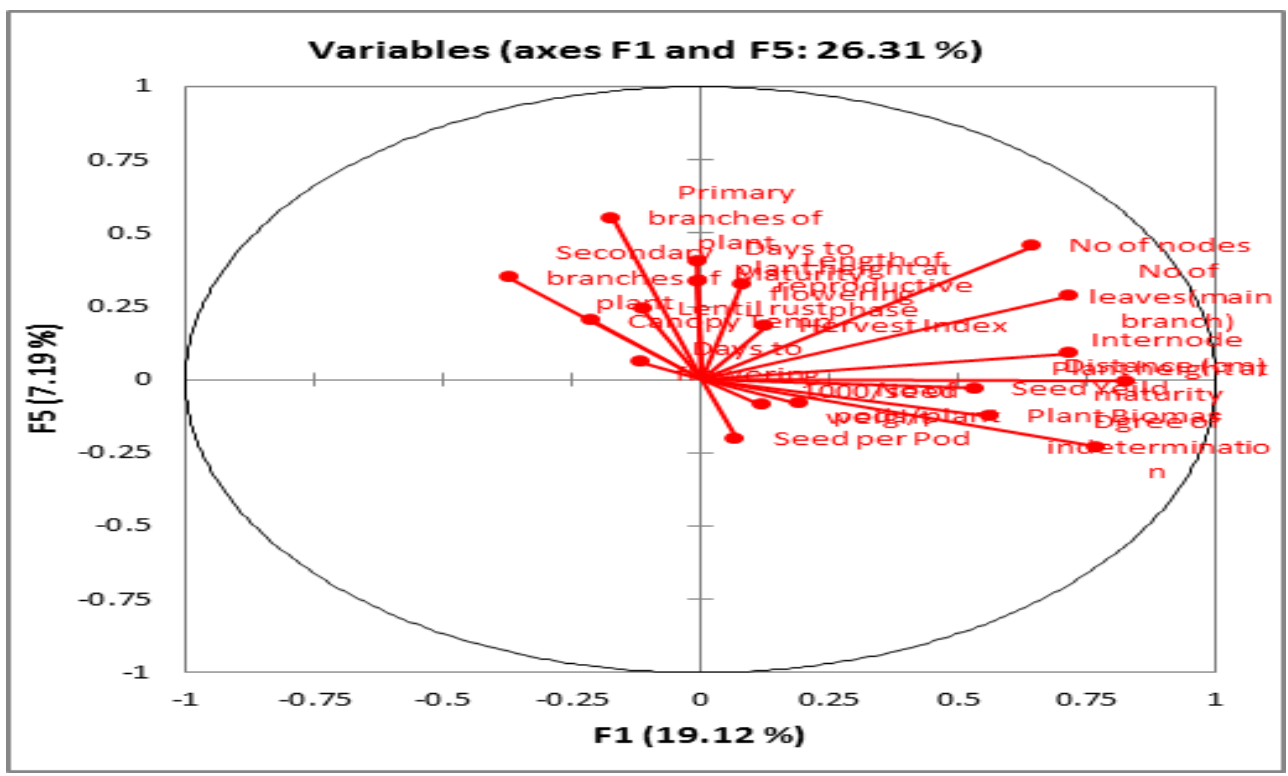

Figure 7. The correlation between the characters of two variables F1 and F5.

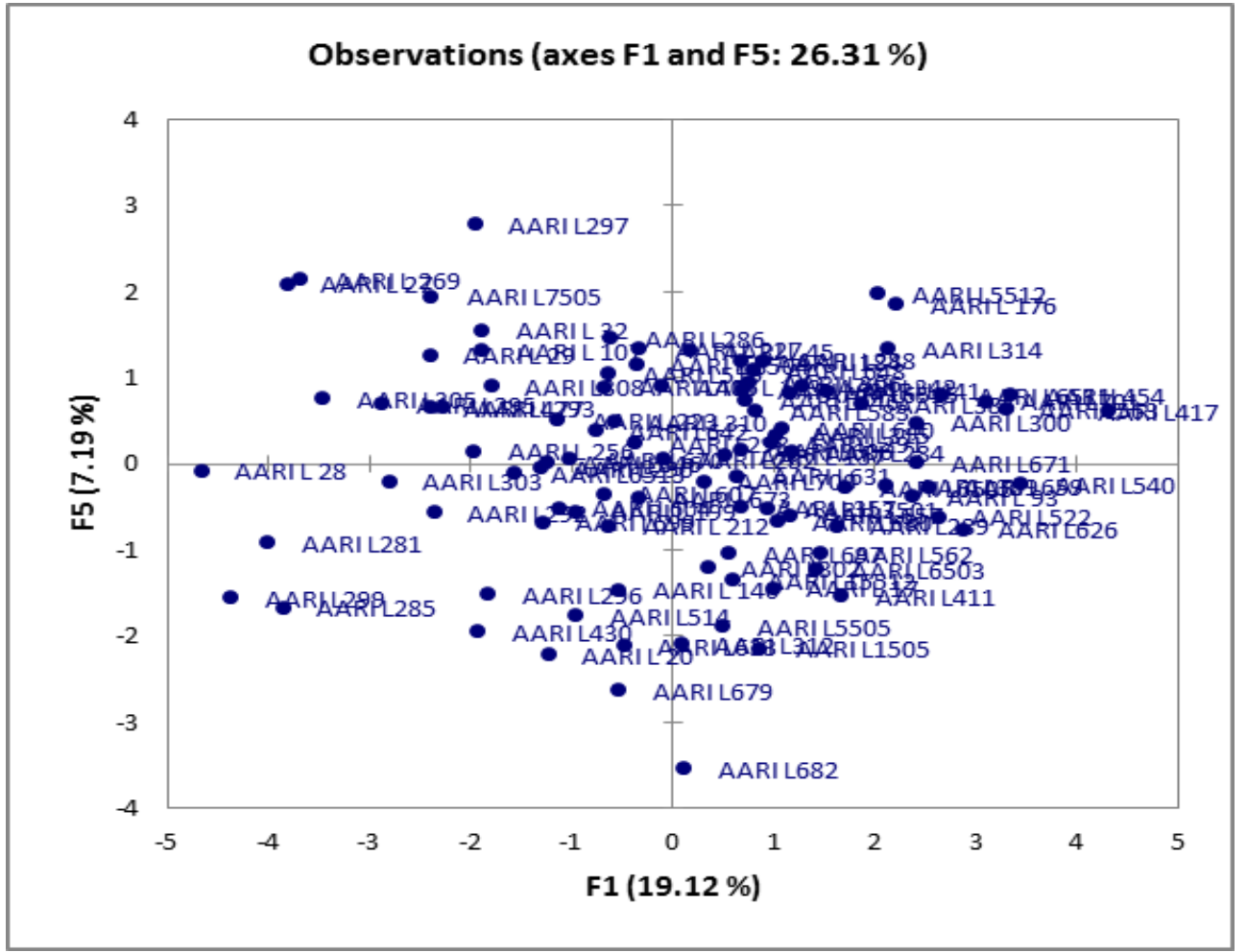

Figure 8. Two-dimensional ordination of 19 agro-morphological characters in genotypes of lentil germplasm on principal component axes. 
Principal component analysis 1 and 2 distinguished eighteen kinds of traits (Fig.9,10). The primary assembly was certainly composed to seed/pod, 1000 spore mass, pods no, crop index, length of reproductive phase, nodes fraction, time to maturation, total leaves (main stem), indetermination amount, internodes distance and plant height at maturity traits. Yield of seed, plant biomass and height of plant at flowering was detrimental association to axis two (PC2). In contrary, primary branches of plant, secondary branches of plant, lentil rust and canopy temperature exhibited the third set was fatalistically related to axis one (PC1). Days to flowering were in inverse relation to two axes. This may helpful in selection of genotypes for construction of varieties based on PC values for high elastic capacity. The outcome of analysis also determines the significance of those characters for evolution of varieties with greater yield potential.

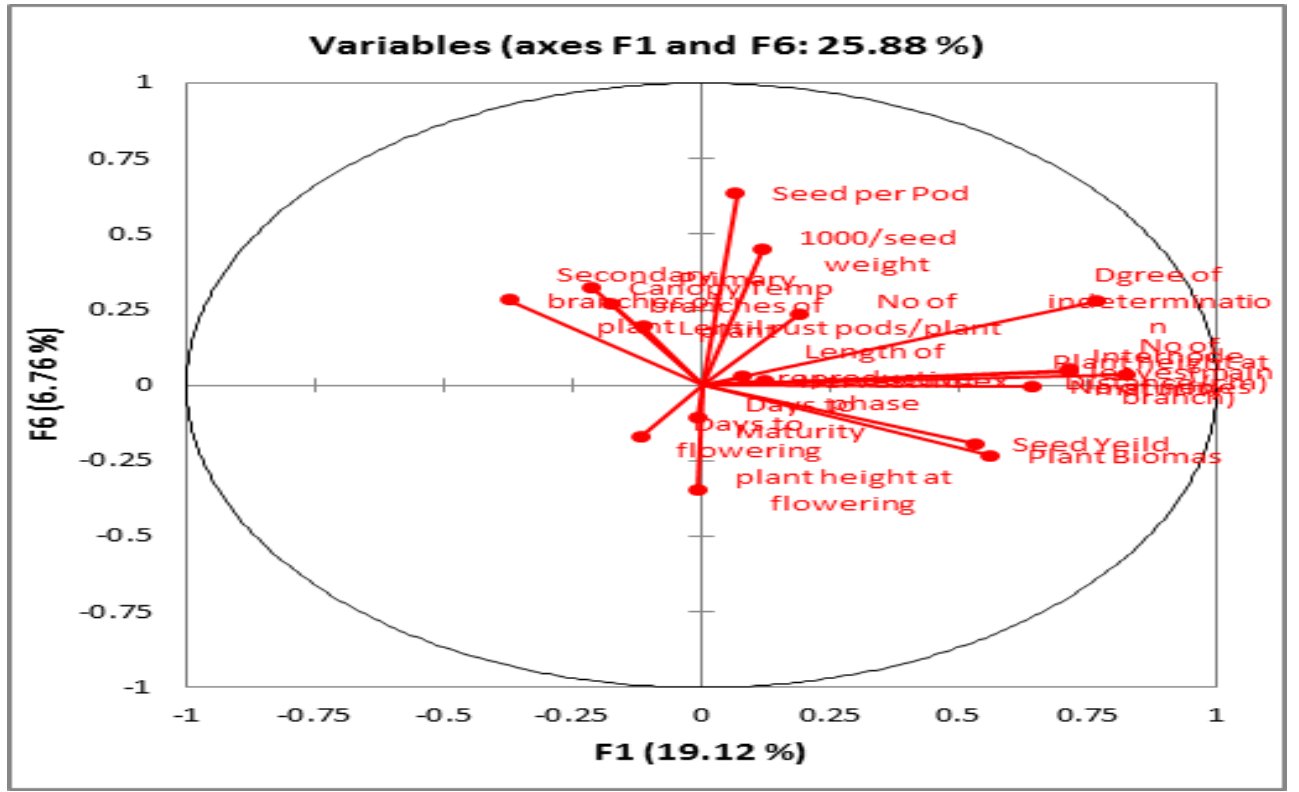

Figure 9. The correlation between the characters of two variables F1 and F6.

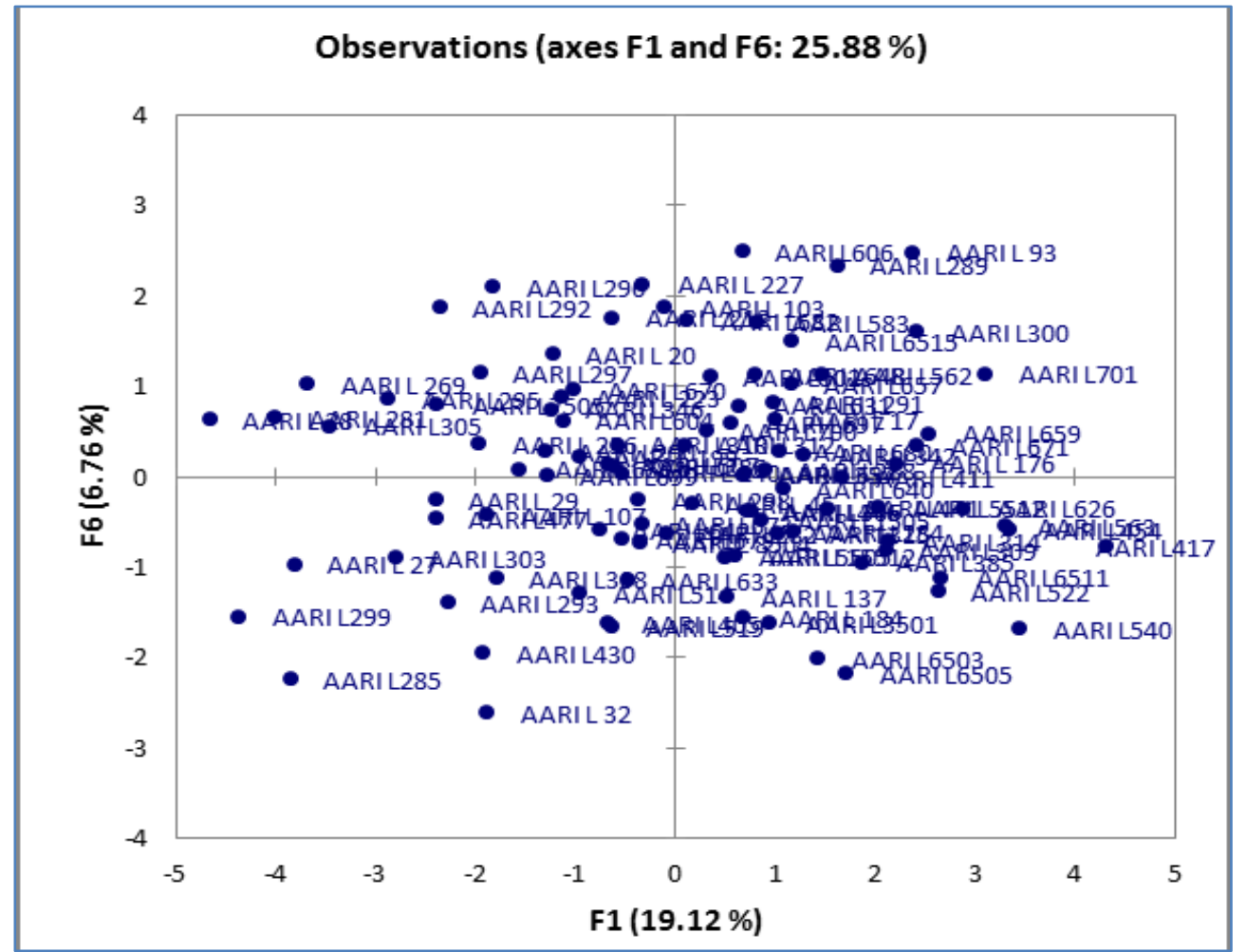

Figure 10. Two-dimensional ordination of 19 agro-morphological characters in genotypes of lentil germplasm on principal component axes. 
The graph denoted by principal component 1 along with 2 distinguished four clusters of variety (Fig.11,12). The initial accumulation was significantly associated and collected of pods in each plant, harvest index, flowering stature, period of development, spore in pod, 1000/seed weight, denominator of leaves (major branch), nodes in plant, internodes distance and harvested germ traits. Maturity height, length of reproductive phase, degree of indetermination and plant biomass was detrimentally related to axis two (PC2). In comparison, lentil rust, flowering as well as maturity duration represented third set was inversely associated to first axes (PC1). Primary twigs of plant, secondary twigs of plant and canopy temperature was in detrimental relation to two axes. This may helpful in selection of genotypes for construction of varieties based on PC values for high elastic capacity. The outcome of analysis also determines the significance of those characters for evolution of varieties with greater yield potential.

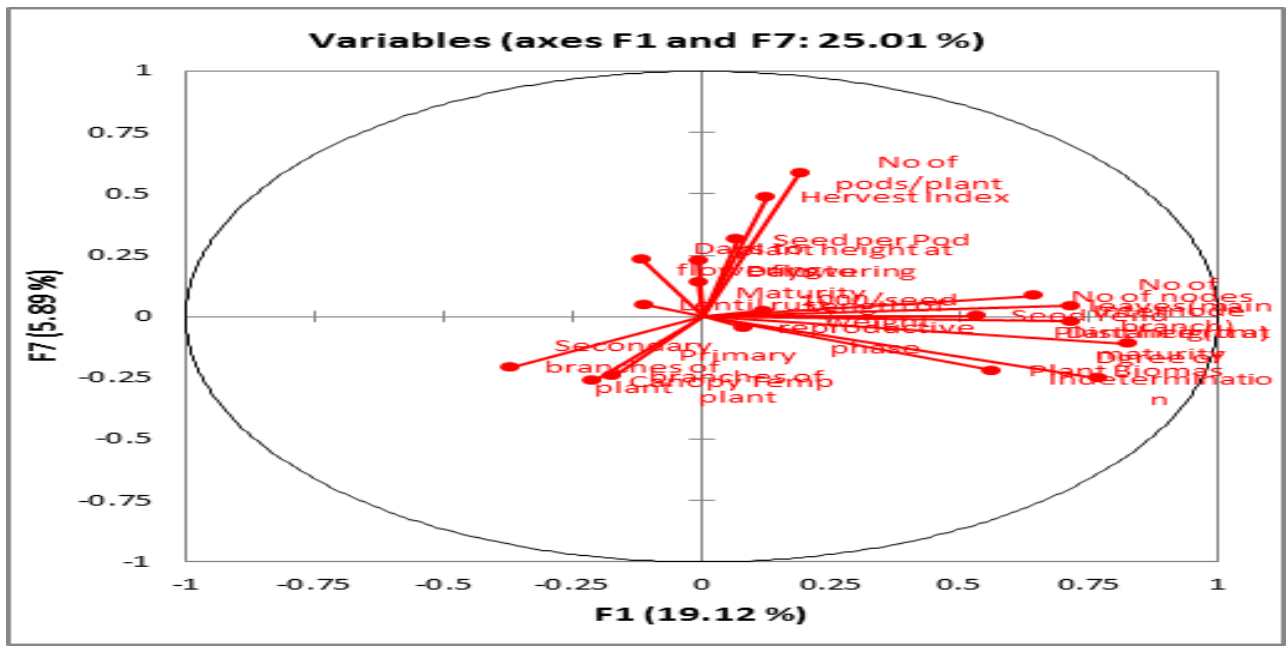

Figure 11. The correlation between the characters of two variables F1 and F7.

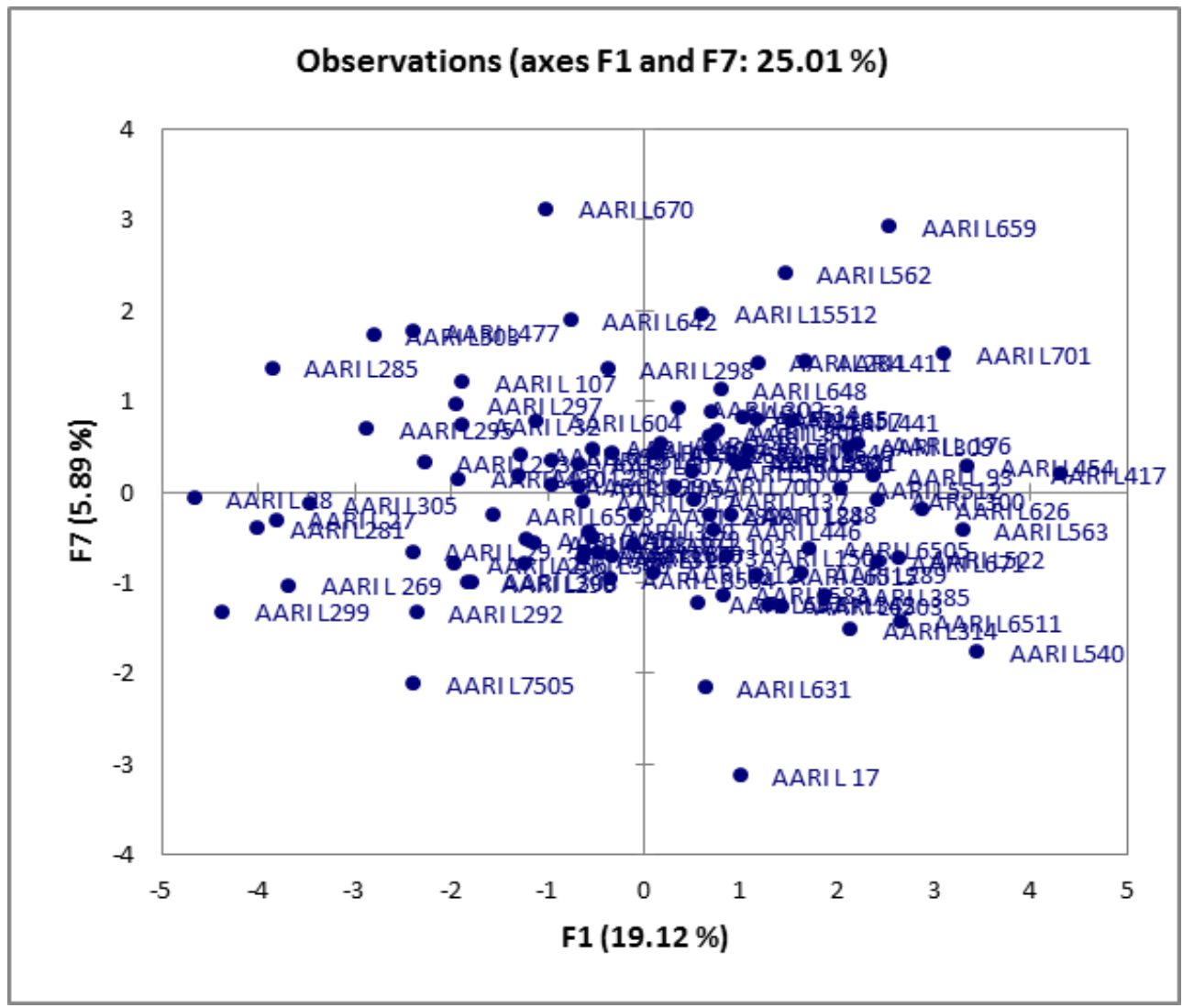

Figure 12. Two-dimensional ordination of 19 agro-morphological characters in genotypes of lentil germplasm on principal component axes. 
The plot interpret by the PC1 and PC2 differentiate four classes of parameters (Fig.13,14). Primary group was positively associated along axes and collected degree of indetermination, 1000/seed weight, height of plant at maturity, quantity of pods/plant, crop index, time to maturity, flowering height traits. Plant biomass, grain/pod, internodes distance, number of leaves (main branch), length of reproductive phase, seed yield and number of nodes was inversely correlated to axis two (PC2). In comparison, primary twig of plant, duration to flowering and secondary brushwood of plant exhibited the third set was fatalistically associated to axis one (PC1). Canopy temperature and lentil rust was inversely related to two axes. This may helpful in selection of genotypes for construction of varieties based on PC values for high elastic capacity. The outcome of analysis also determines the significance of those characters for evolution of varieties with greater yield potential.

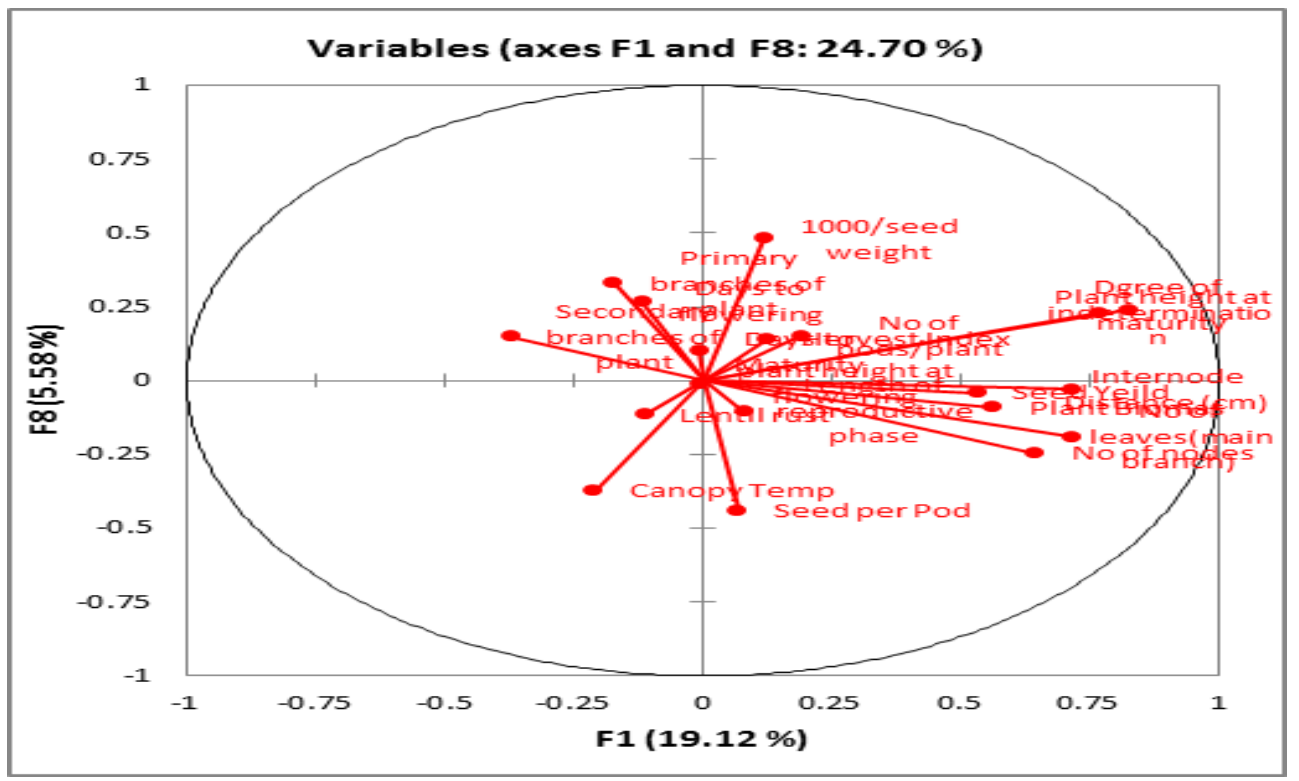

Figure 13. The correlation between the characters of two variables F1 andF8.

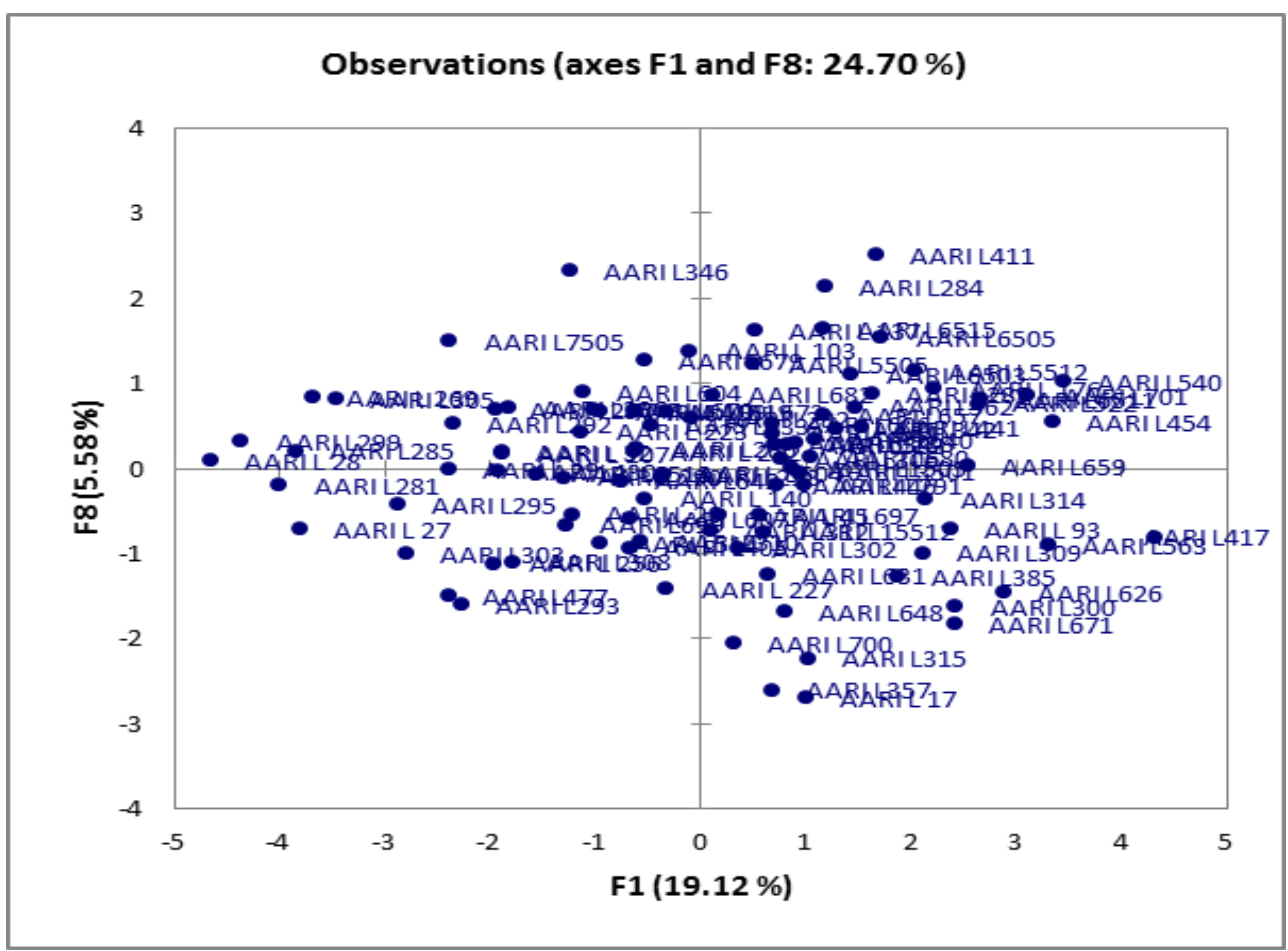

Figure 14. Two-dimensional ordination of 19 agro-morphological characters in genotypes of lentil germplasm on principal component axes. 
The plot showed by the PC2 and PC3 distinguished eighteen variety of parameters (Fig.15,16). The first group was strongly interrelated and observed length of reproductive phase, canopy temperature, days to maturity and degree of indetermination traits. Days to flowering, internodes distance, number of leaves (main branch) and number of nodes was adversely associated to axis two (PC3). In contrary, 1000/seed weight, amount of pods/plant, yield of seed, plant biomass, harvest index, seed/pod, primary along with secondary twigs of plant exhibited the third set was adversely related to axis one (PC2).Plant height at maturity, plant height at flowering and lentil rust was inversely associated to two axes. This may helpful in selection of genotypes for construction of varieties based on PC values for high elastic capacity. The outcome of analysis also determines the significance of those characters for evolution of varieties with greater yield potential.

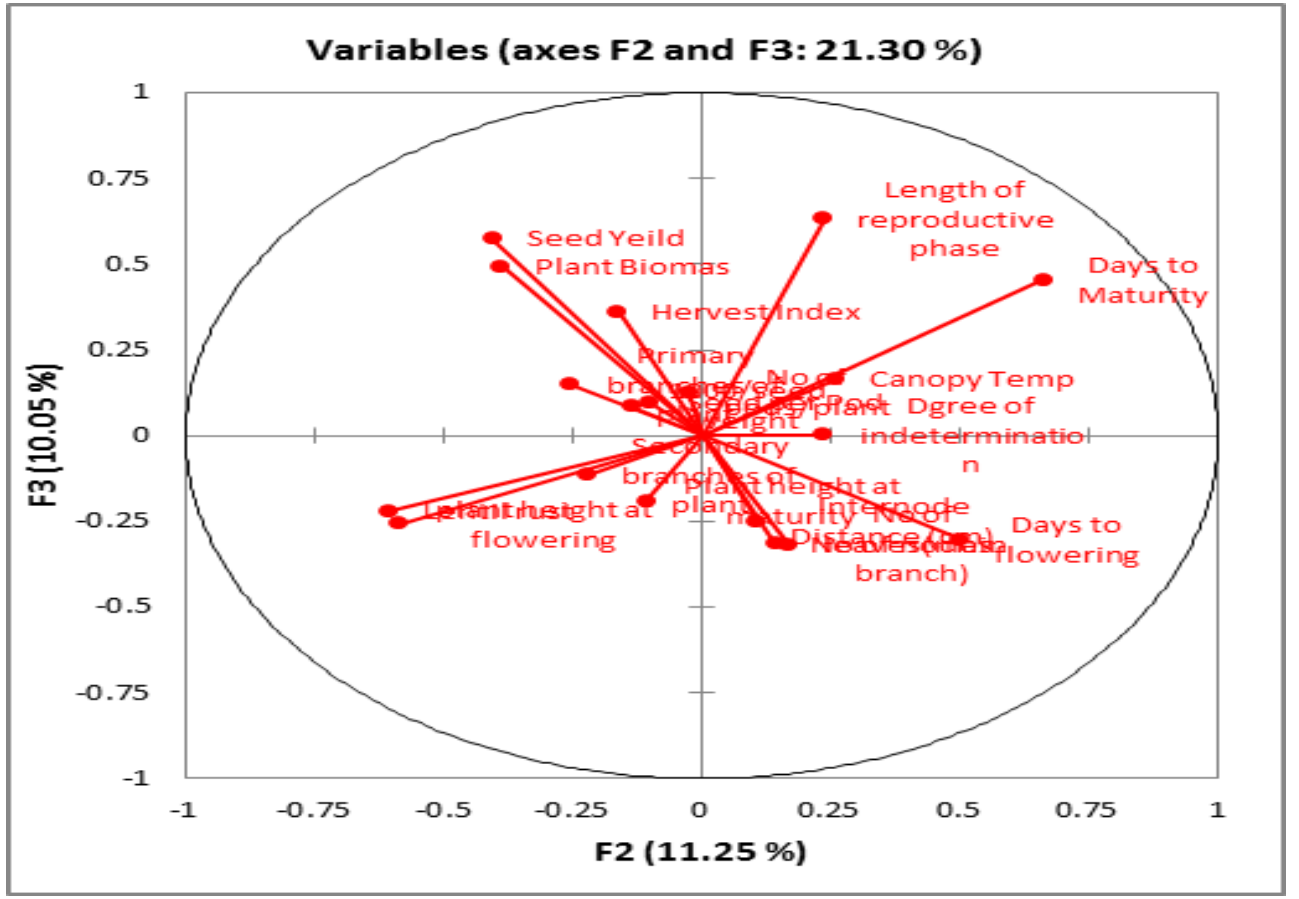

Figure 15. The correlation between the characters of two variables F2 and F3

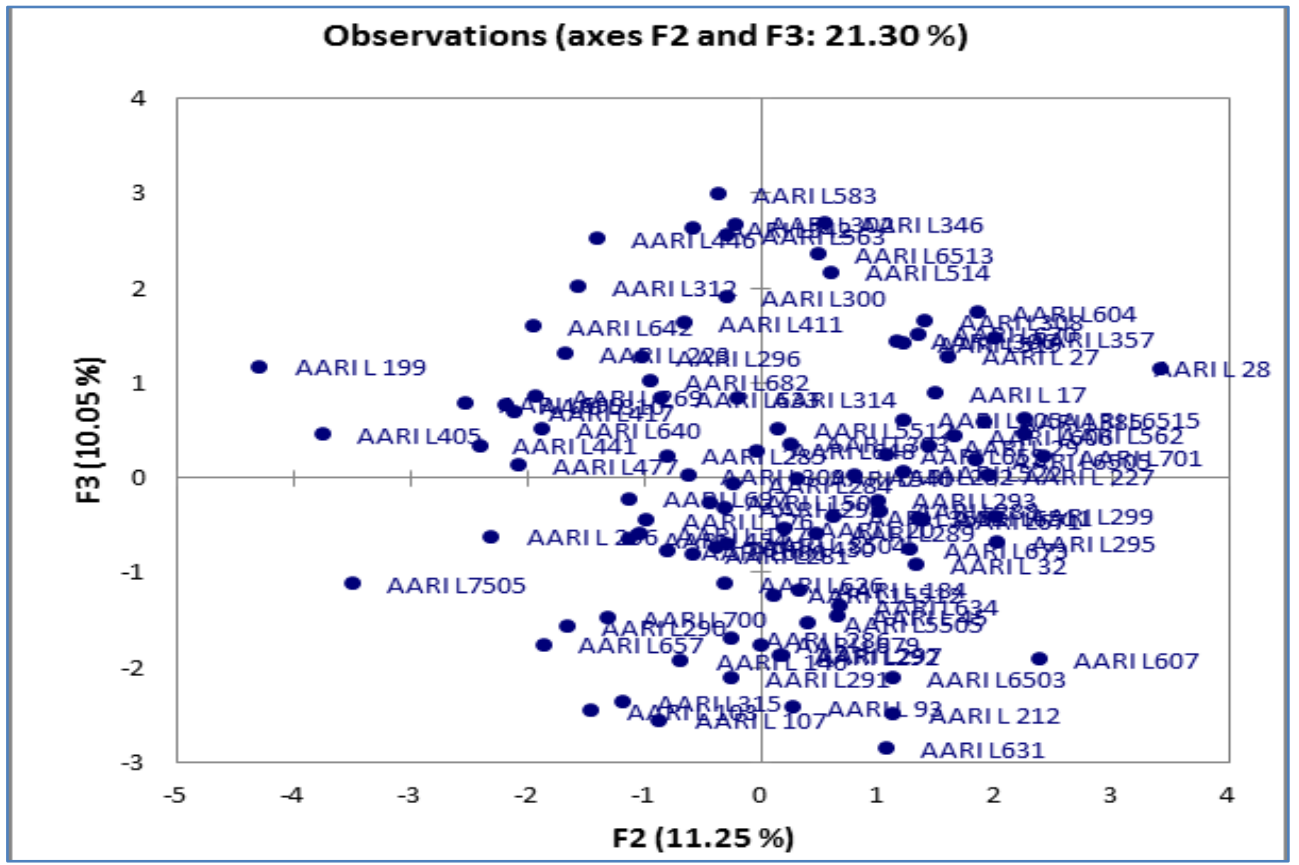

Figure 16. Two-dimensional ordination of 19 agro-morphological characters in genotypes of lentil germplasm on principal component axes. 
This graph explained PC2 and PC4 distinguished four classes of traits (Fig.17,18). Initial class was positively associated to two axes furthermore described, indetermination grade, length of reproductive phase, days to maturity and number of leaves (main branch) traits. Elevation at blossoming and development, lentil rust, seed/pod, seed yield and 1000 stone mass was harmfully linked with axis two (PC4). Internodes distance and number of nodes, blossoming time plus canopy temperature. While, pods in each plant showed the third class was adversely related to axis one (PC2). Primary and secondary twigs of plant, harvest index and plant biomass was inversely associated to two axes. This may helpful in selection of genotypes for construction of varieties based on PC values for high elastic capacity. The outcome of analysis also determines the significance of those characters for evolution of varieties with greater yield potential. Varieties.

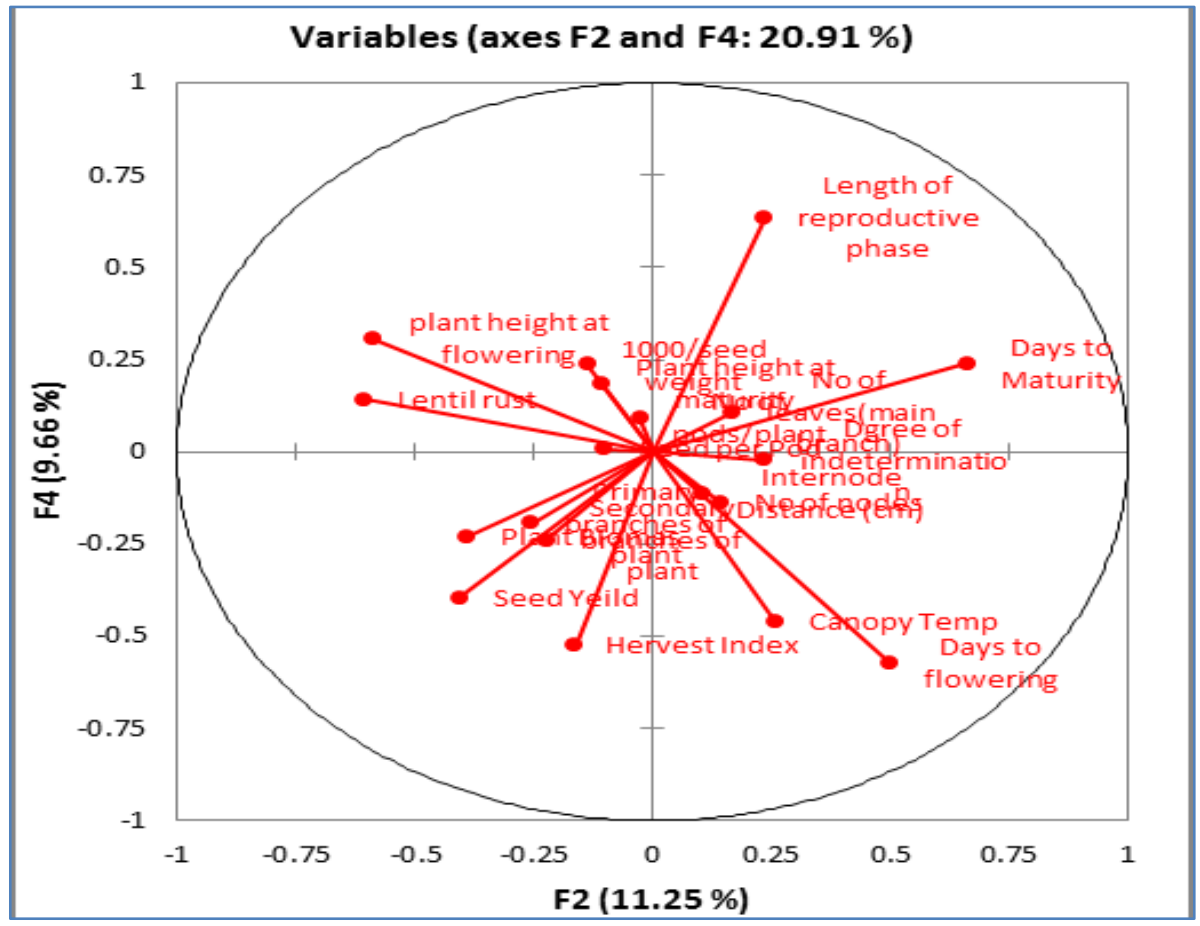

Figure 17. The correlation between the characters of two variables F2 and F4

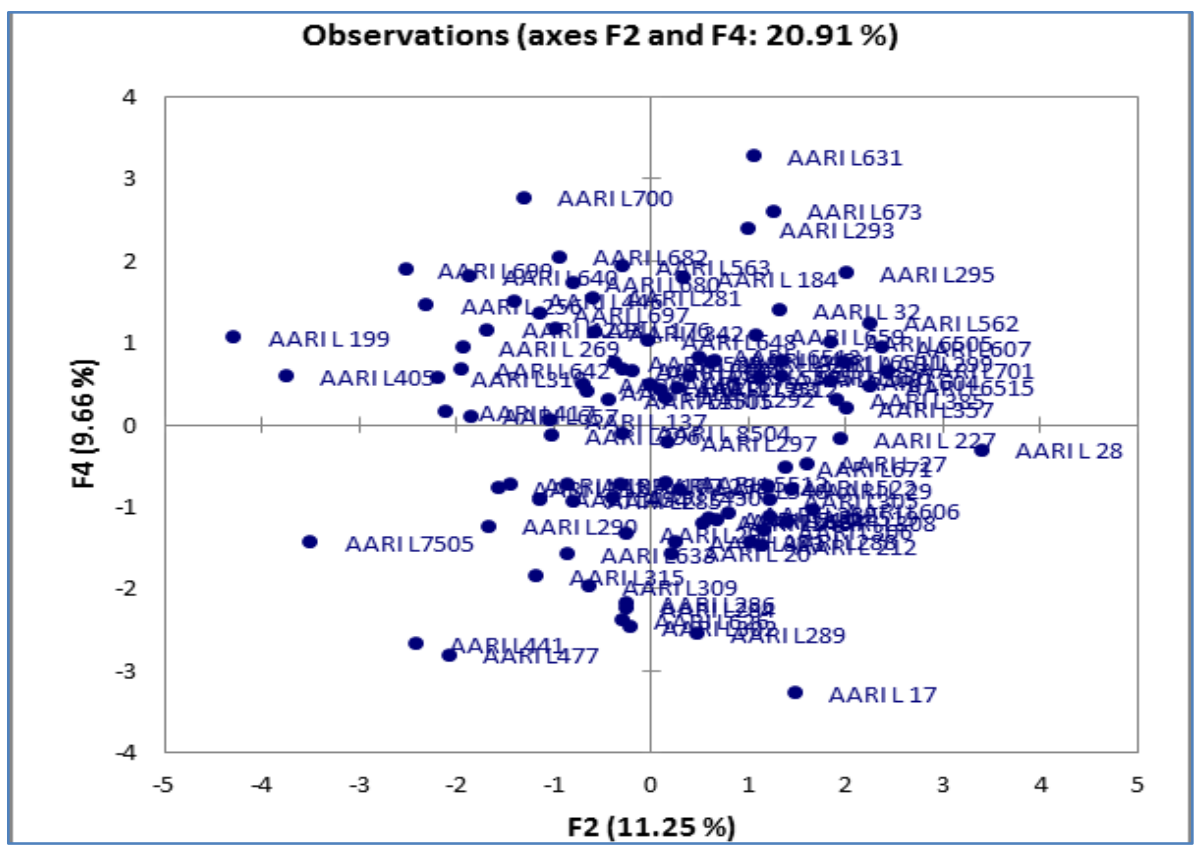

Figure 18. Two-dimensional ordination of 19 agro-morphological characters in genotypes of lentil germplasm on principal component axes. 
The plot explained by the PC2 and PC5 differentiate between eighteen sets of traits (Fig.19,20). The top most class was in positively associated to two axes and constituted to number of nodes, length of reproductive phase, number of leaves (main branch), days to maturity, days to flowering and internodes distance traits. Degree of indetermination was adversely related to axis two (PC5). In comparison, primary branches of plant, harvest index, secondary branches of plant, lentil rust, plant height at flowering showed the third set was in detrimental relation to axis one (PC2). Plant height at maturity, 1000/weight of seed, number of seeds/pod, yield of seed, plant biomass, quantity of pods/plant and canopy temperature was inversely associated to two axes. This may helpful in selection of genotypes for construction of varieties based on PC values for high elastic capacity. The outcome of analysis also determines the significance of those characters for evolution of varieties with greater yield potential.

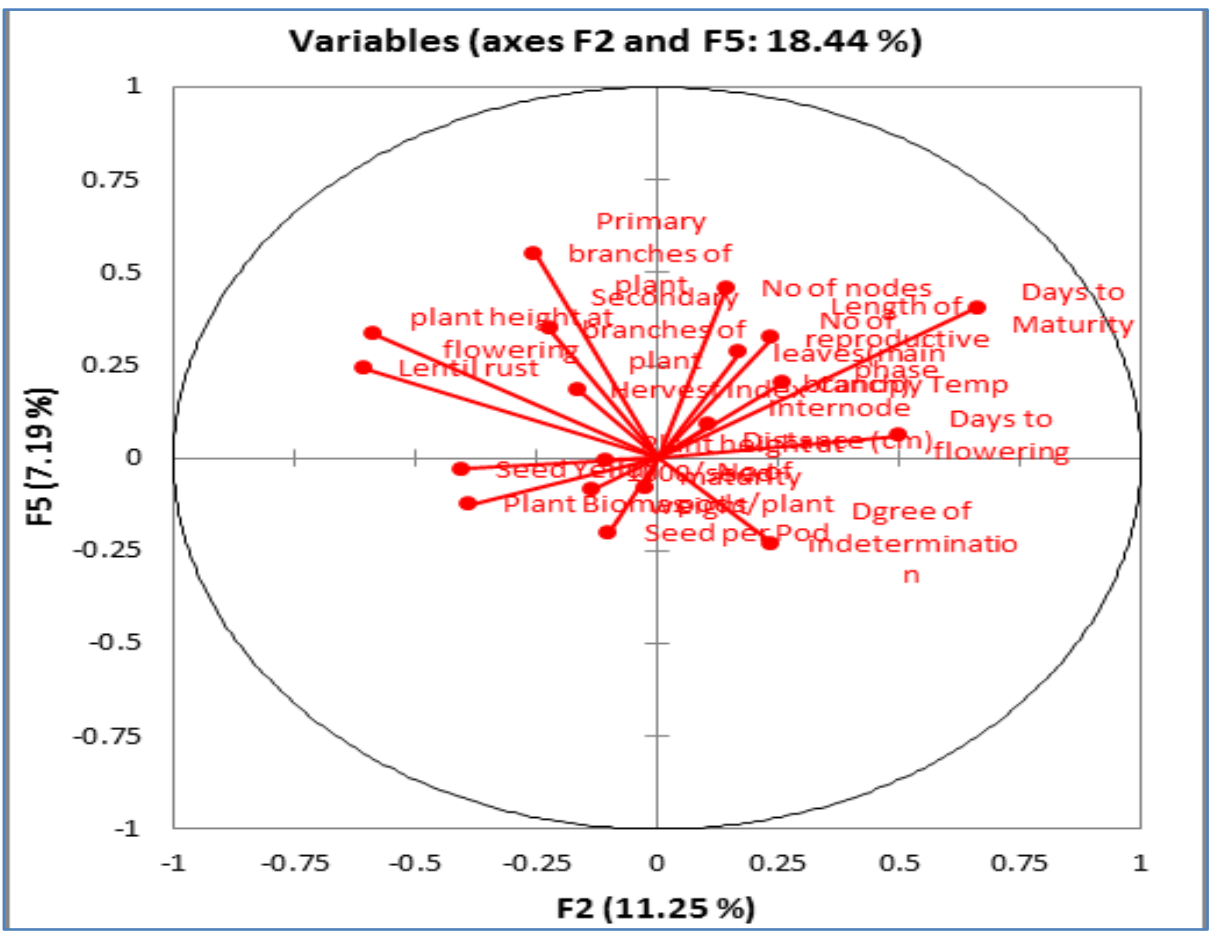

Figure 19. The between the characters of two variables F2 and F5.

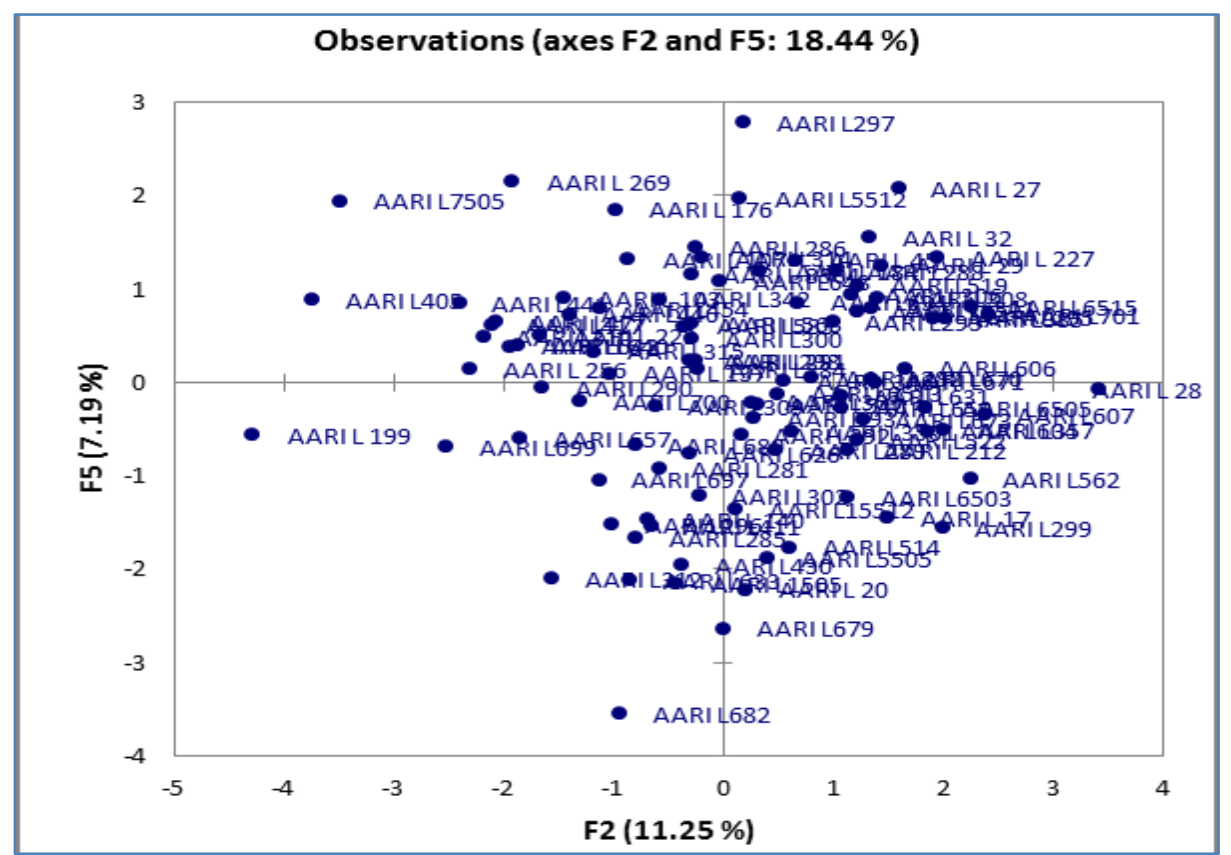

Figure 20. Two-dimensional ordination of 19 agro-morphological characters in genotypes of lentil germplasm on principal component axes. 
The plot explained by the PC2 and PC26 differentiate among eighteen classes of traits (Fig.21,22). The top most class was positively associated to two axes and constituted of quantity of leaves (main branch), internodes distance, degree of indetermination, canopy temperature, length of reproductive phase, number of nodes, seed/pod. Days to maturity and flowering was in detrimental relation to axis two (PC6). In contrary, seeds/pods, 1000/seed weight, plant primary branches, plant secondary branches, lentil rust, amount of pods/plant, harvest index, height of plant at maturity explored the third class was inversely related to axis one (PC2). Plant height at flowering plant biomass, seed yield was in detrimental relation to two axes. This may helpful in selection of genotypes for construction of varieties based on PC values for high elastic capacity. The outcome of analysis also determines the significance of those characters for evolution of varieties with greater yield capacity.

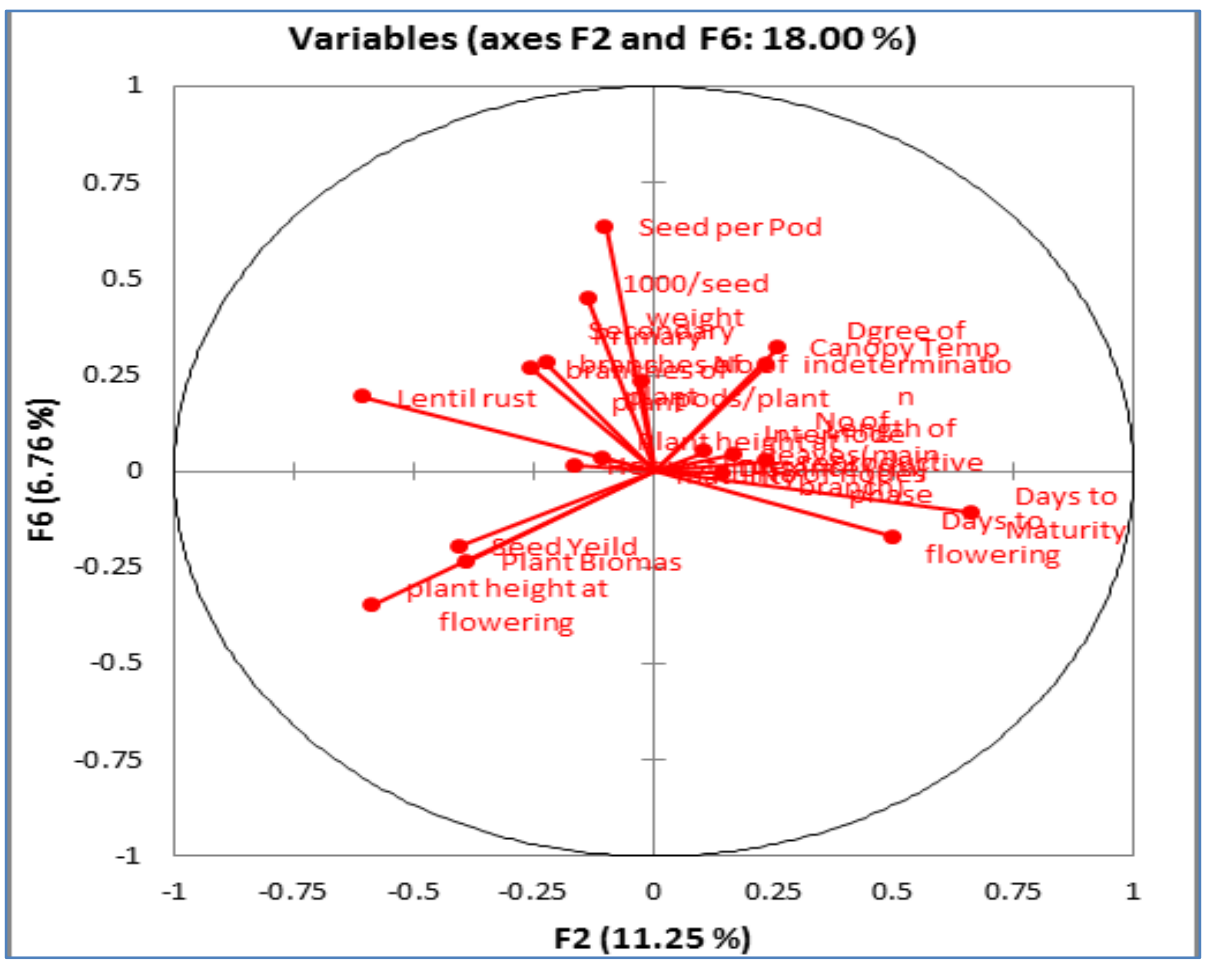

Figure 21. The correlation between the characters of two variables F2 and F6.

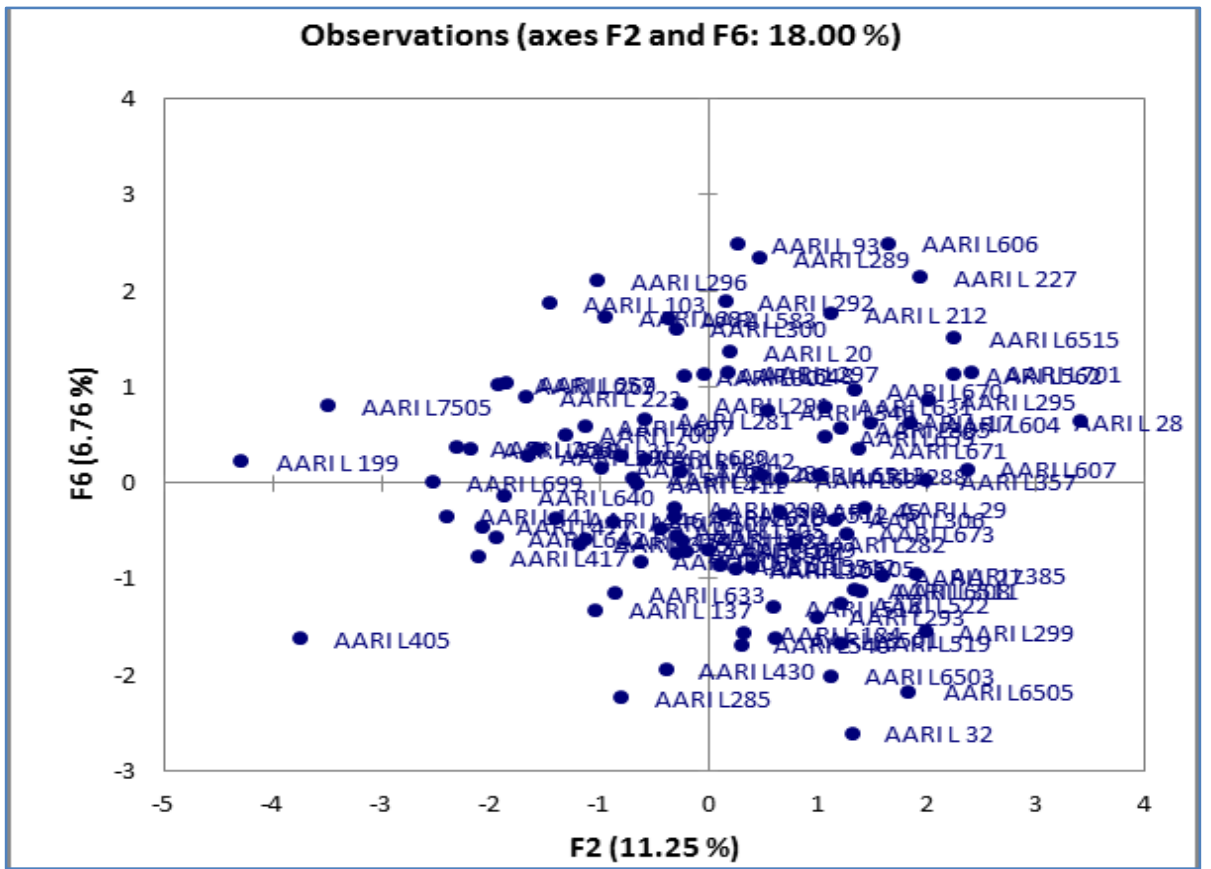

Figure 22. Two-dimensional ordination of 19 agro-morphological characters in genotypes of lentil germplasm on principal component axes. 
The plot showed by the PC2 and PC7 differentiate between eighteen sets of characters (Fig.23,24). The topmost set was positively associated to two axes and constituted to the days to maturity and flowering, number of nodes and quantity of leaves (main branch) traits. Plant height at maturity, length of reproductive phase, degree of indetermination and internodes distance was adversely related to axis two (PC7). In comparison, lentil rust, height of plant at flowering, amount of pods/plant, seeds/pod, yield of seed, harvest index and 1000/seed weight exhibited the third set was inversely related to axis one (PC2). Plant Primary Branches, secondary branches, plant biomass, and canopy temperature was in fatalistic behavior to two axes. This may helpful in selection of genotypes for construction of varieties based on PC values for high elastic capacity. The outcome of analysis also determines the significance of those characters for evolution of varieties with greater yield potential.

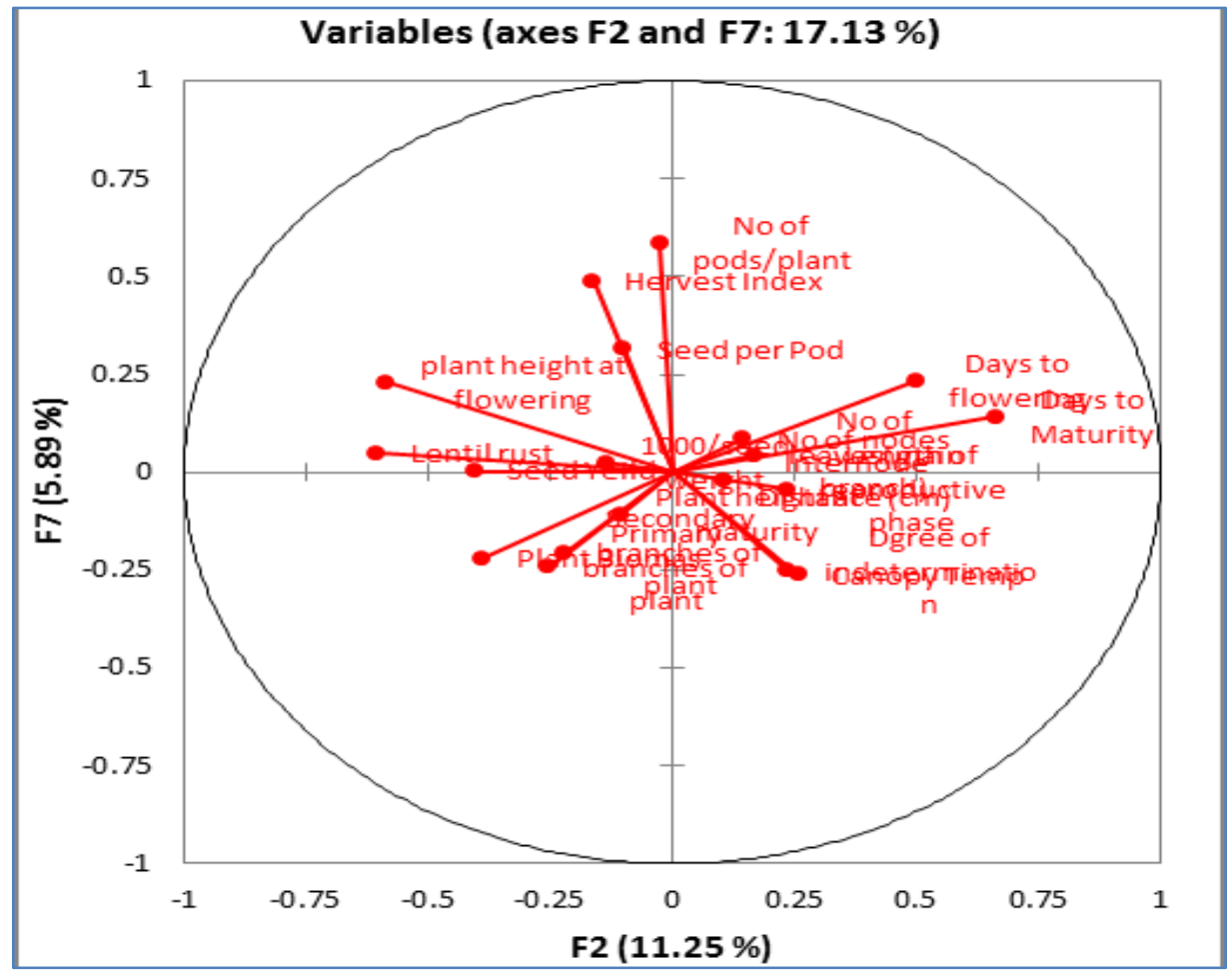

Figure 23. The correlation between the characters of two variables F2 andF7.

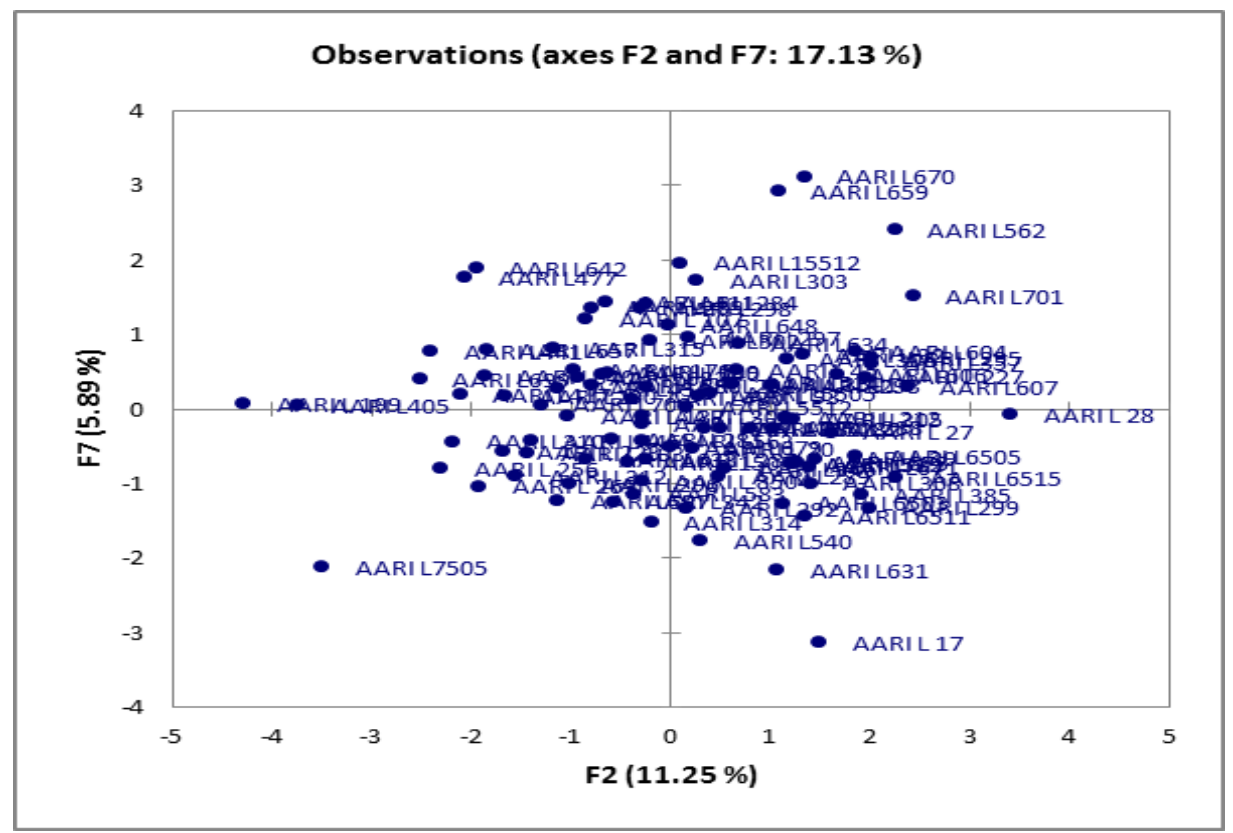

Figure 24. Two-dimensional ordination of 19 agro-morphological characters in genotypes of lentil germplasm on principal component axes. 
The plot described by the PC2 and PC8 differentiate between eighteen classes of traits (Fig.25,26). The initial class was positively associated to two axes and constituted to degree of indetermination, days to maturity and flowering traits. Quantity of leaves (main branch), amount of nodes and length of reproductive phase, internodes distance and canopy temperature was adversely related to axis two (PC8). In contrary, Height of plant at maturity, 1000 seed weight, quantity of pods/plant, primary and secondary branches of plant explored the third class was adversely related to axis one (PC2). Harvest index, seed/pod, plant biomass, seed yield and lentil rust and plant height at flowering was detrimental in relation to two axes. This may helpful in selection of genotypes for construction of varieties based on PC values for high elastic capacity also determine the significance of those characters for evolution of varieties with greater yield potential

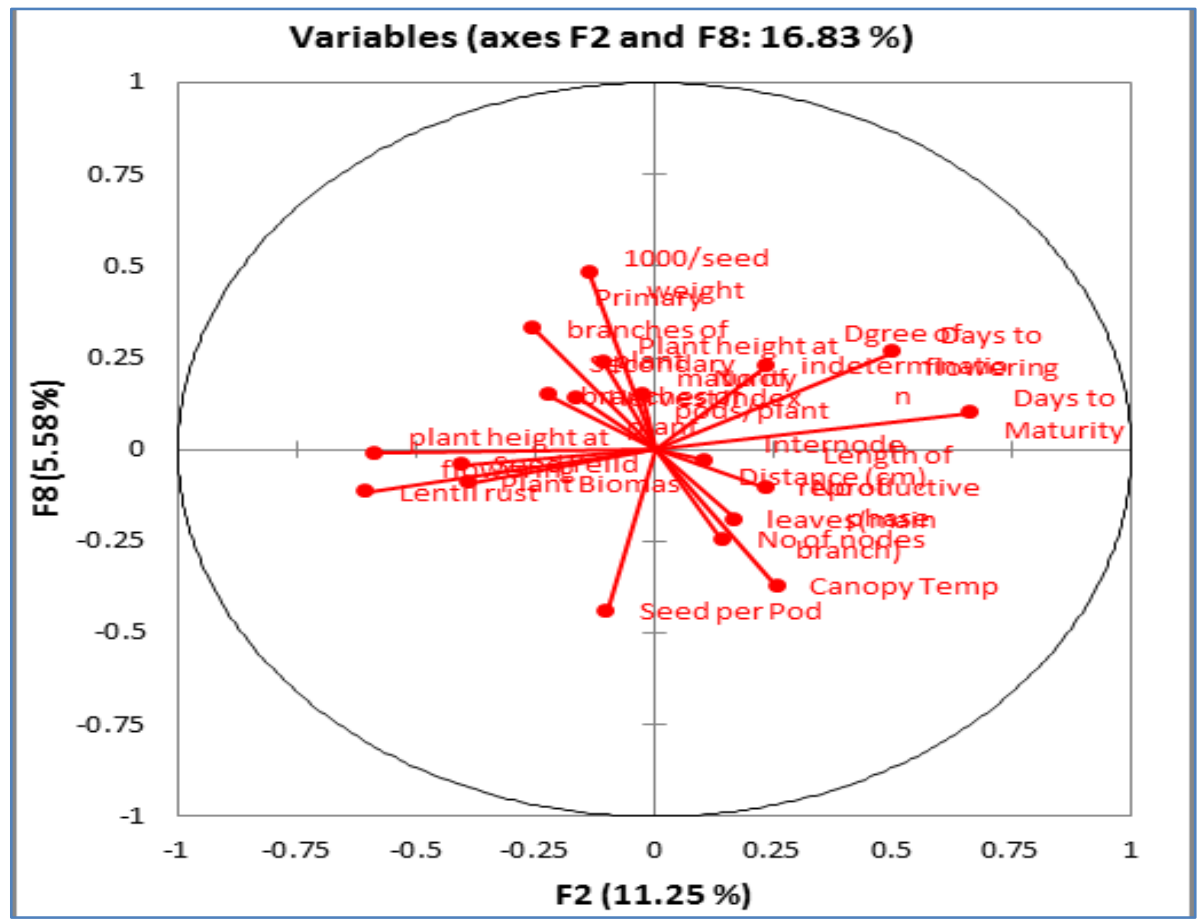

Figure 25. The correlation between the characters of two variables F2 and F8.

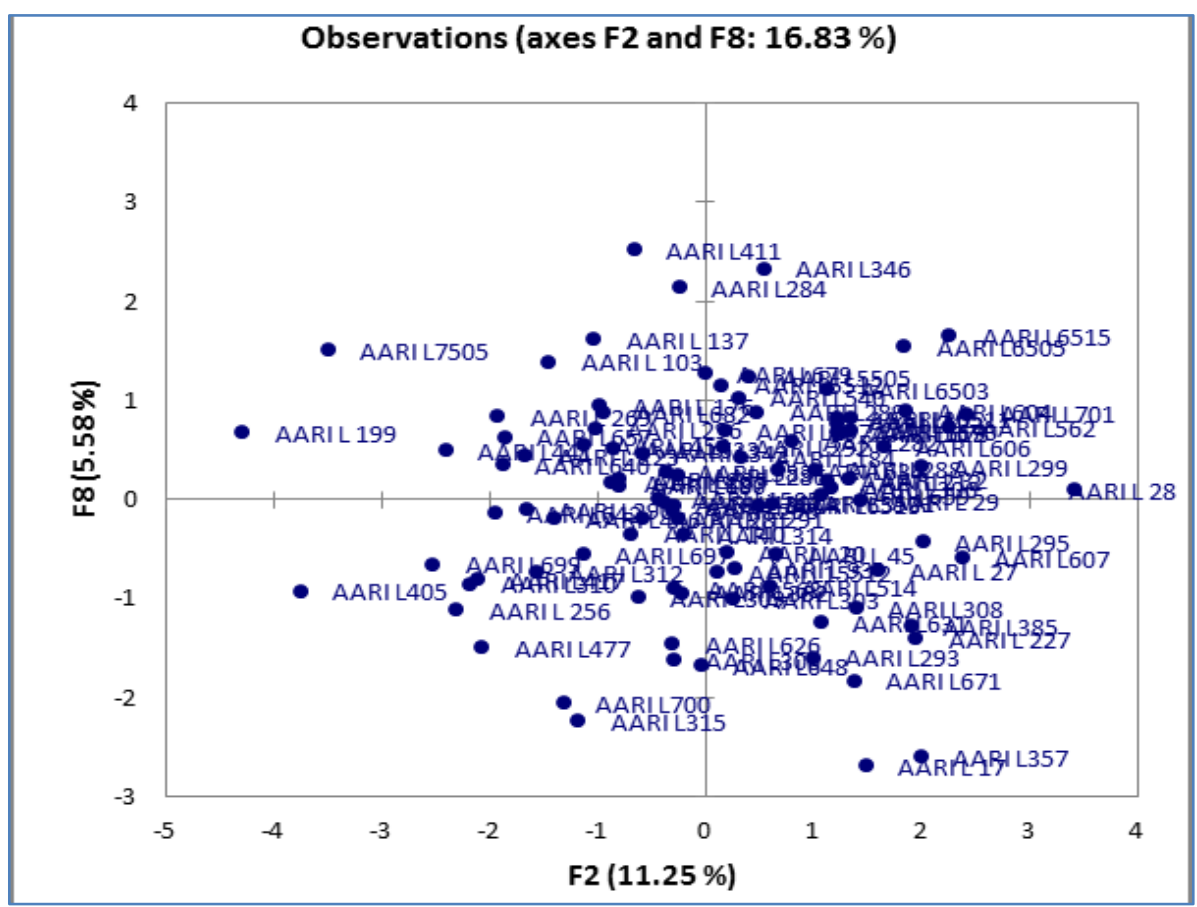

Figure 26. Two-dimensional ordination of 19 agro-morphological characters in genotypes of lentil germplasm on principal component axes. 
The plot explained by the PC3 and PC2 differentiate among eighteen sets of traits (Fig.27,28). The topmost set was positively related to two axes and constituted to length of reproductive phase, degree of indetermination, days to maturity and canopy temperature traits. Quantity of pods/plant, 1000 seed weight, seeds/pod, seed produce, plant biomass and harvest index was inversely related to axis two (PC2). In contrary, quantity of leaves (main branch), primary branches of plant, time to initiate flowering, internodes distance and amount of nodes exhibited the third set was fatalistic behavior to axis one (PC3). Plant height at maturity, secondary branches of plant, lentil rust, plant height at flowering was adversely associated to two axes. This may helpful in selection of genotypes for construction of varieties based on PC values for high elastic capacity. The outcome of analysis also determines the significance of those characters for evolution of varieties with greater yield potential.

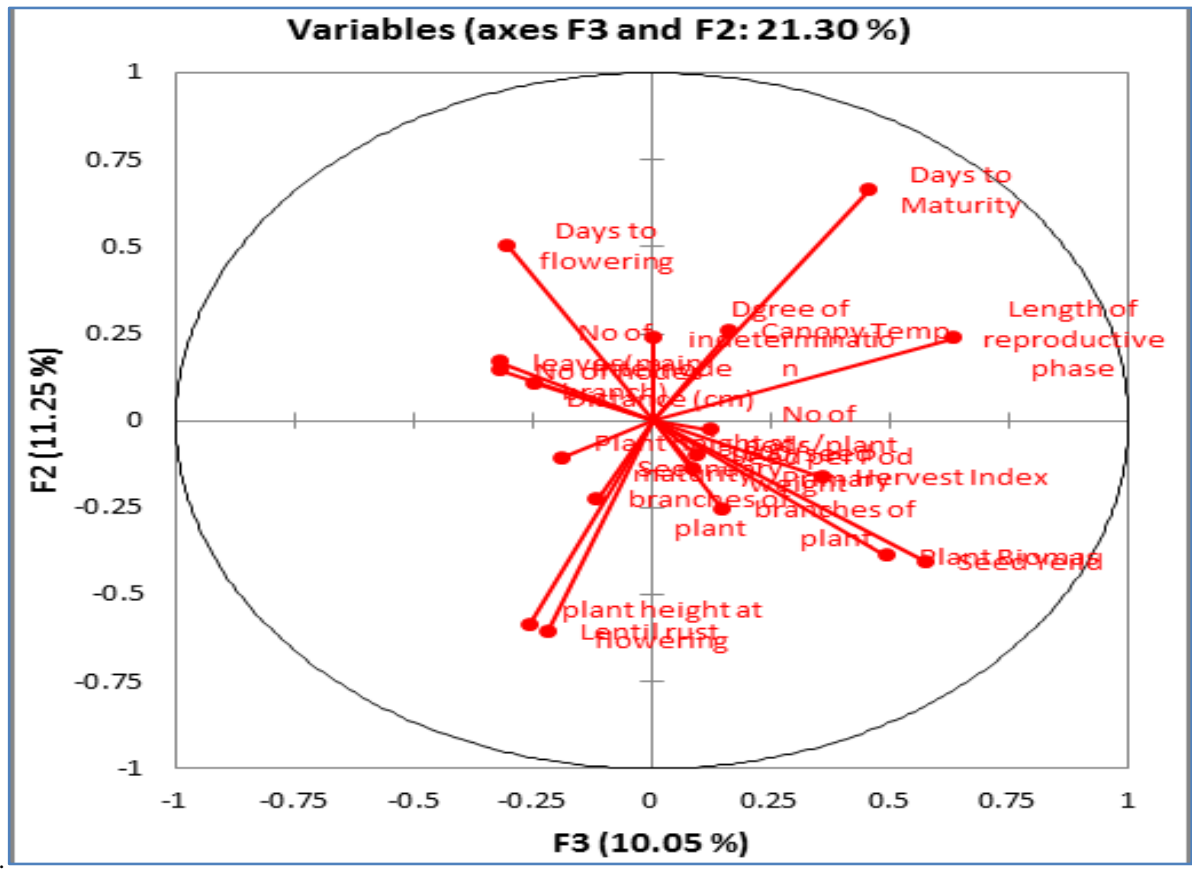

Figure 27. The correlation between the characters of two variables F3 and F2.

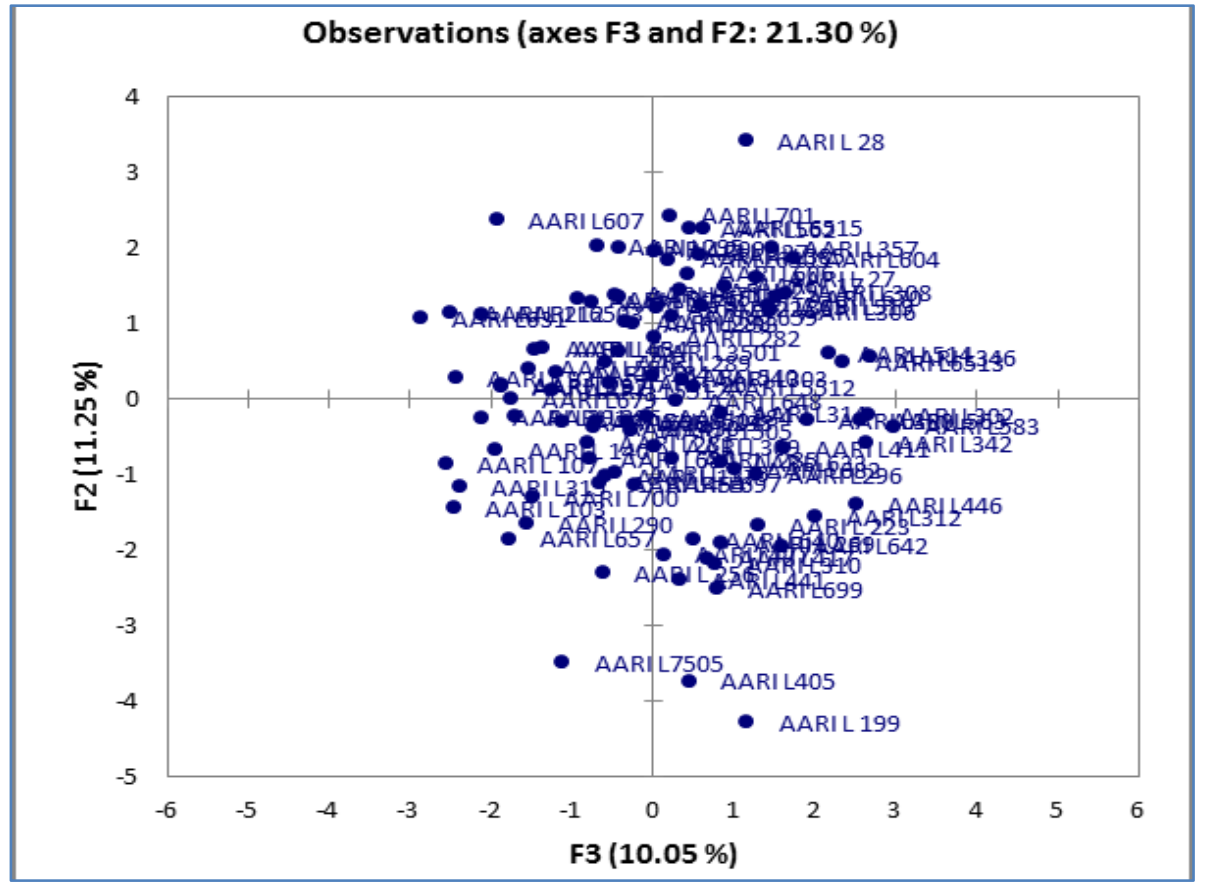

Figure 28. Two-dimensional ordination of 19 agro-morphological characters in genotypes of lentil germplasm on principal component axes. 
The plot explained by the PC3 and PC4 differentiate between eighteen sets of traits (Fig.29,30). The initial set was positively associated to two axes and comprised to maturity duration, length of reproductive phase, 1000/seed weight, degree of indetermination and quantity of pods/plant traits. Primary branches of plant, plant biomass, seed yield, canopy temperature and harvest index was adversely associated to axis two (PC4). In comparison, Height of plant at maturity, plant height at flowering, lentil rust, number of leaves(main branch) and seed/pod showed the third set was inversely related to axis one (PC3). Days to flowering, internodes distance, number of nodes and secondary branches of plant was in detrimental relation to two axes. This may helpful in selection of genotypes for construction of varieties based on PC values for high elastic capacity. The outcome of analysis also determine the significance of those characters for evolution of varieties with greater yield potential

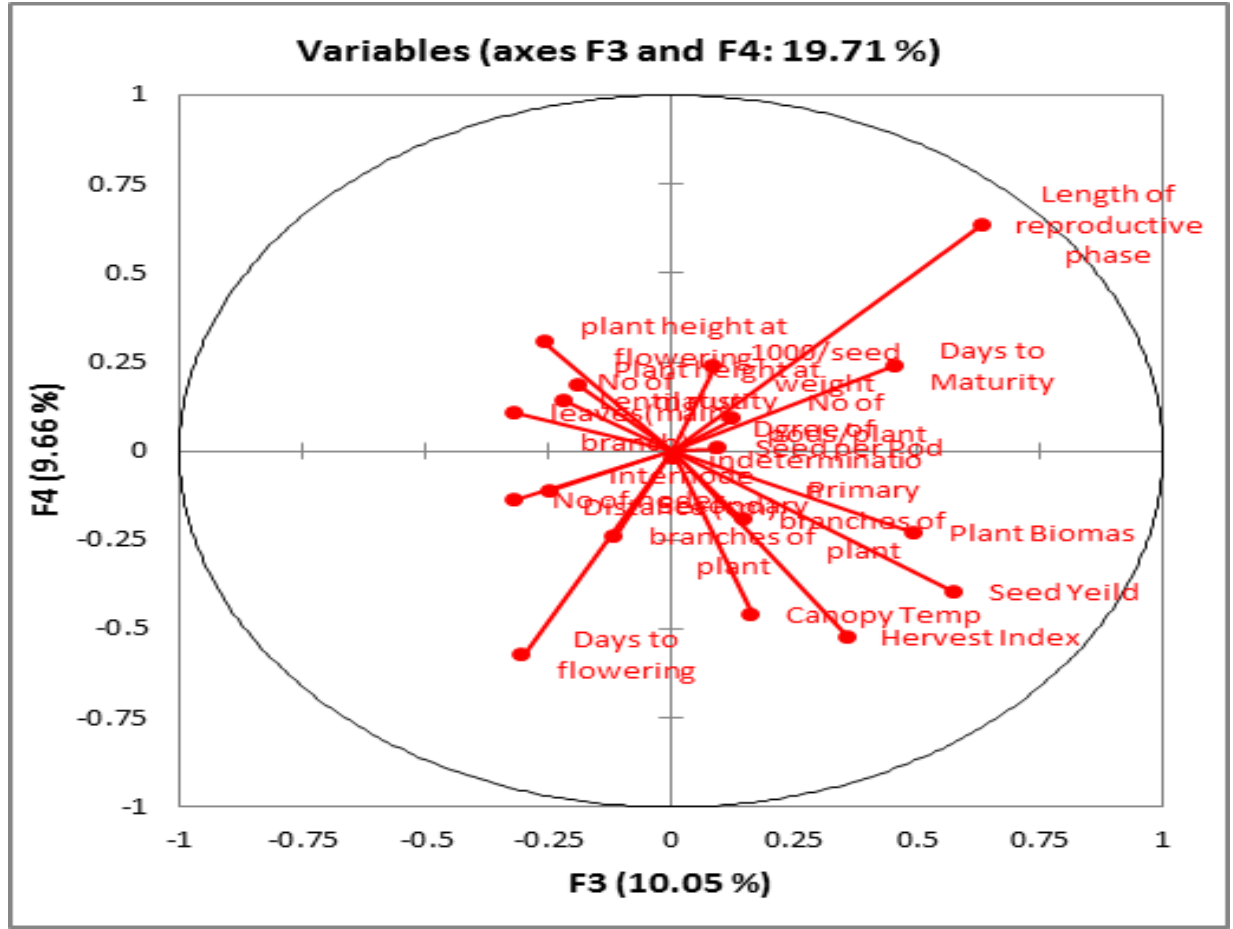

Figure 29. The correlation between the characters of two variables F3 andF4.

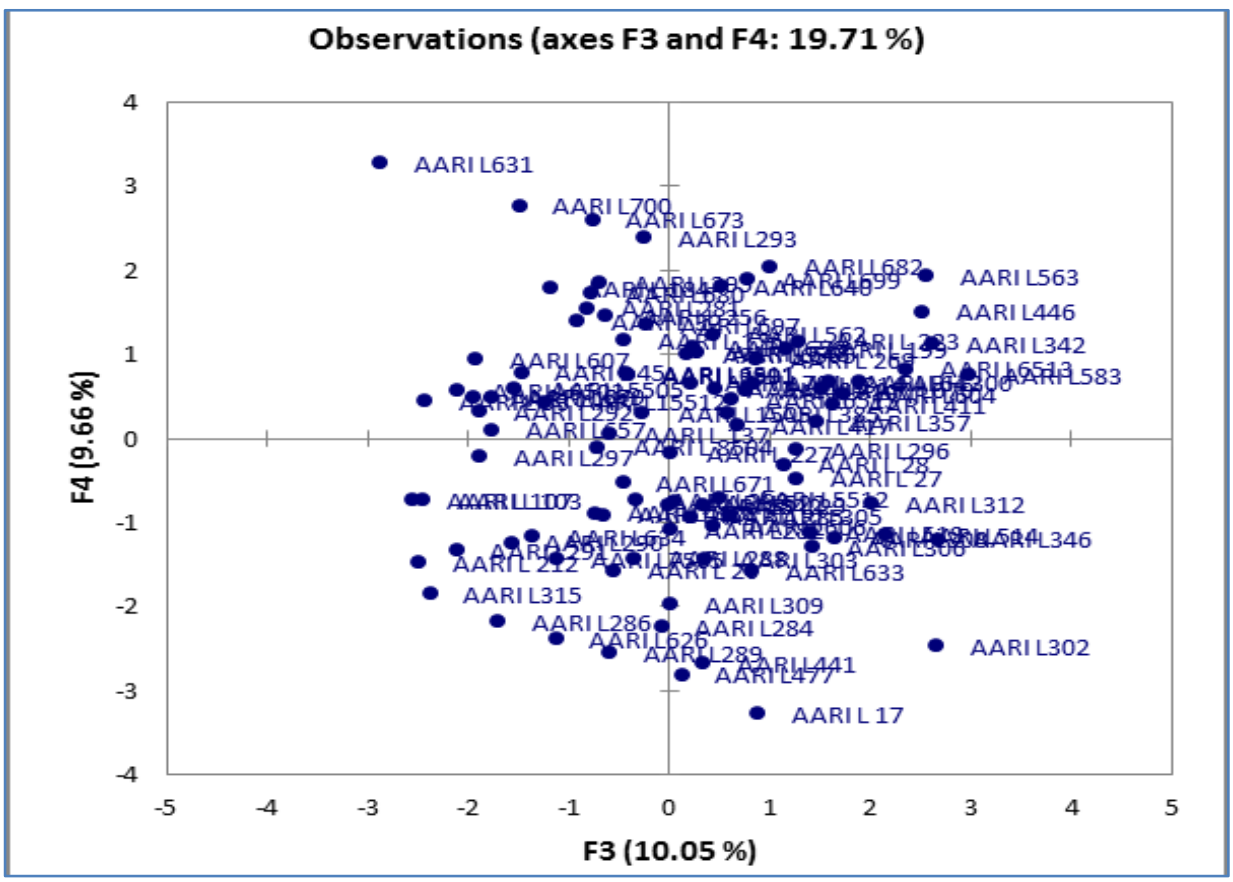

Figure 30. Two-dimensional ordination of 19 agro-morphological traits in genotypes of lentil germplasm on principal component axes. 
The plot described by the PC3 and PC5 differentiate among eighteen classes of traits (Fig.31,32). The topmost class was positively associated to two axes and comprised of primary branches of plant, days to maturity, length of reproductive phase, harvest index and canopy temperature traits. Plant height at maturity, seed yield, seed/pod, and plant biomass, degree of indetermination and 1000/seed weight was adversely related to axis two (PC5). In contrast, lentil rust, secondary branches of plant, number of leaves(main branch), plant height at flowering, internodes distance, number of nodes, number of pods/plant, flowering time, exhibited the third class was inversely associated to axis one (PC3). No traits were in detrimental relation to two axes. This may helpful in selection of genotypes for construction of varieties based on PC values for high elastic capacity. The outcome of analysis also determines the significance of those characters for evolution of varieties with greater yield potential.

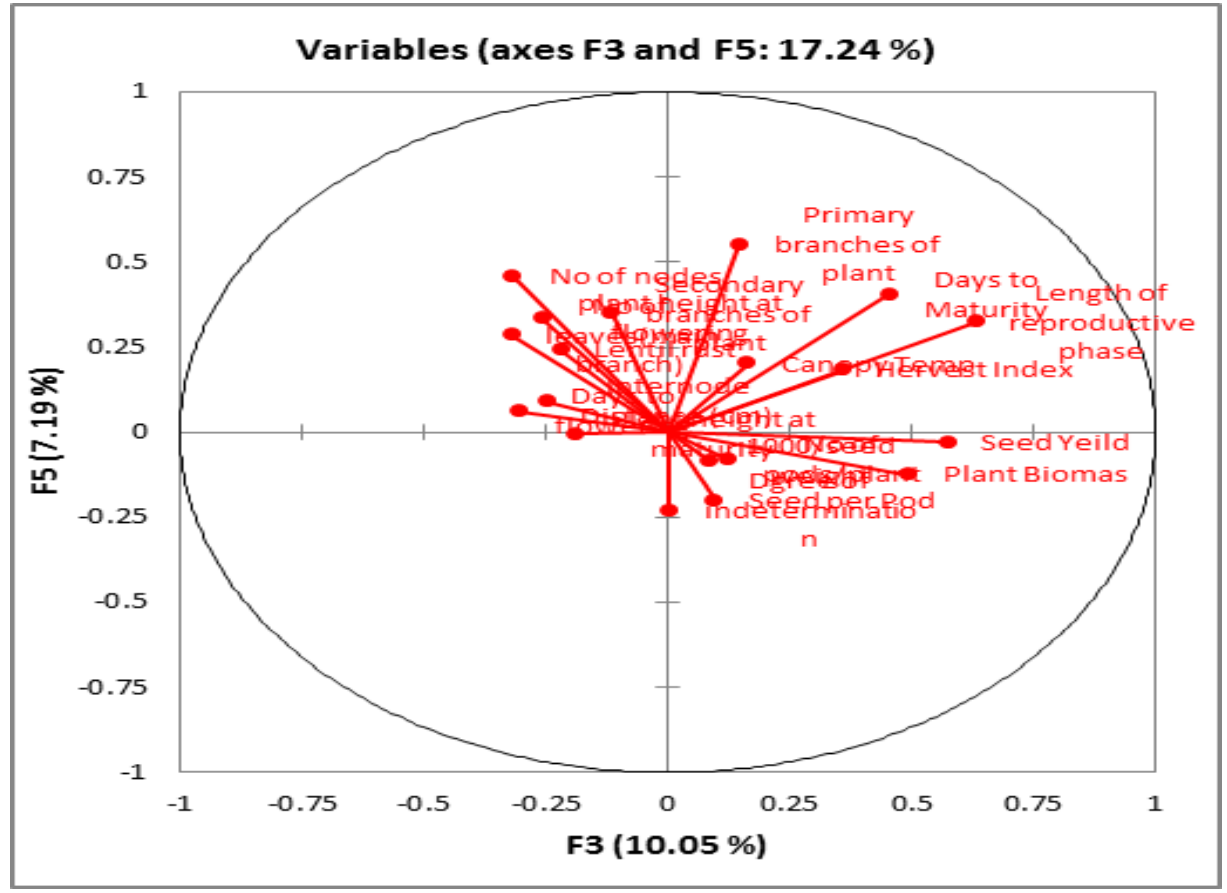

Figure 31. The correlation between the characters of two variables F3 and F5.

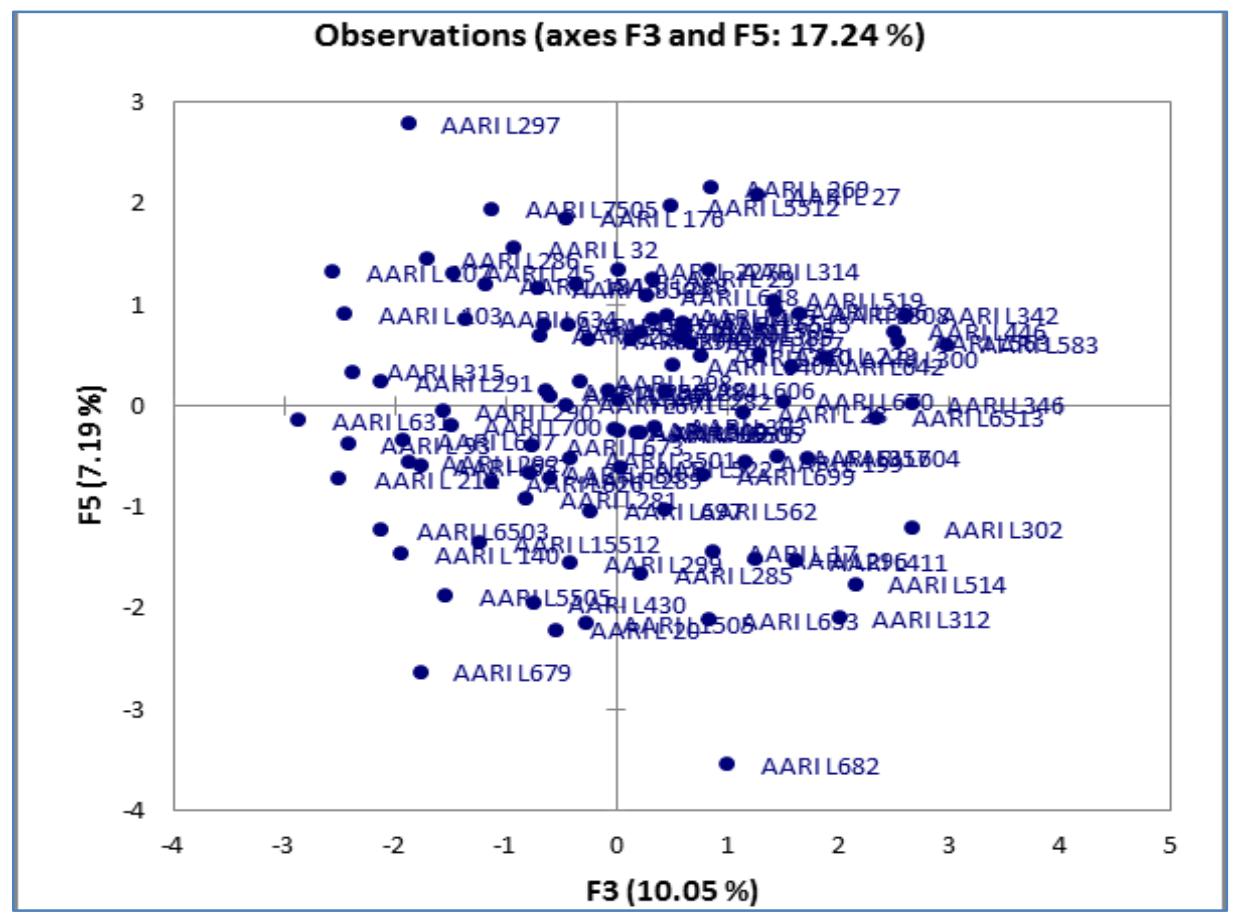

Figure 32. Two-dimensional ordination of 19 agro-morphological characters in genotypes of lentil germplasm on principal component axes. 
The plot explored by the PC3 and PC6 differentiate among eighteen groups of traits (Fig.33,34). The first group was positively associated to two axes and comprised of seed/pod, 1000/seed weight, canopy temperature, amount of pods/plant, secondary branches of plant and degree of indetermination traits. Harvest index, length of reproductive phase, maturity duration, seed produce and plant biomass was adversely related to axis two (PC6). In comparison, quantity of leaves(main branch), lentil rust, number of nodes, plant height at maturity, primary branches of plant and internodes distance showed the third group was adversely related to axis one (PC3). time to flowering and height of plant at flowering was inversely associated to two axes. This may helpful in selection of genotypes for construction of varieties based on PC values for high elastic capacity. The outcome of analysis also determines the significance of those characters for evolution of varieties with greater yield potential.

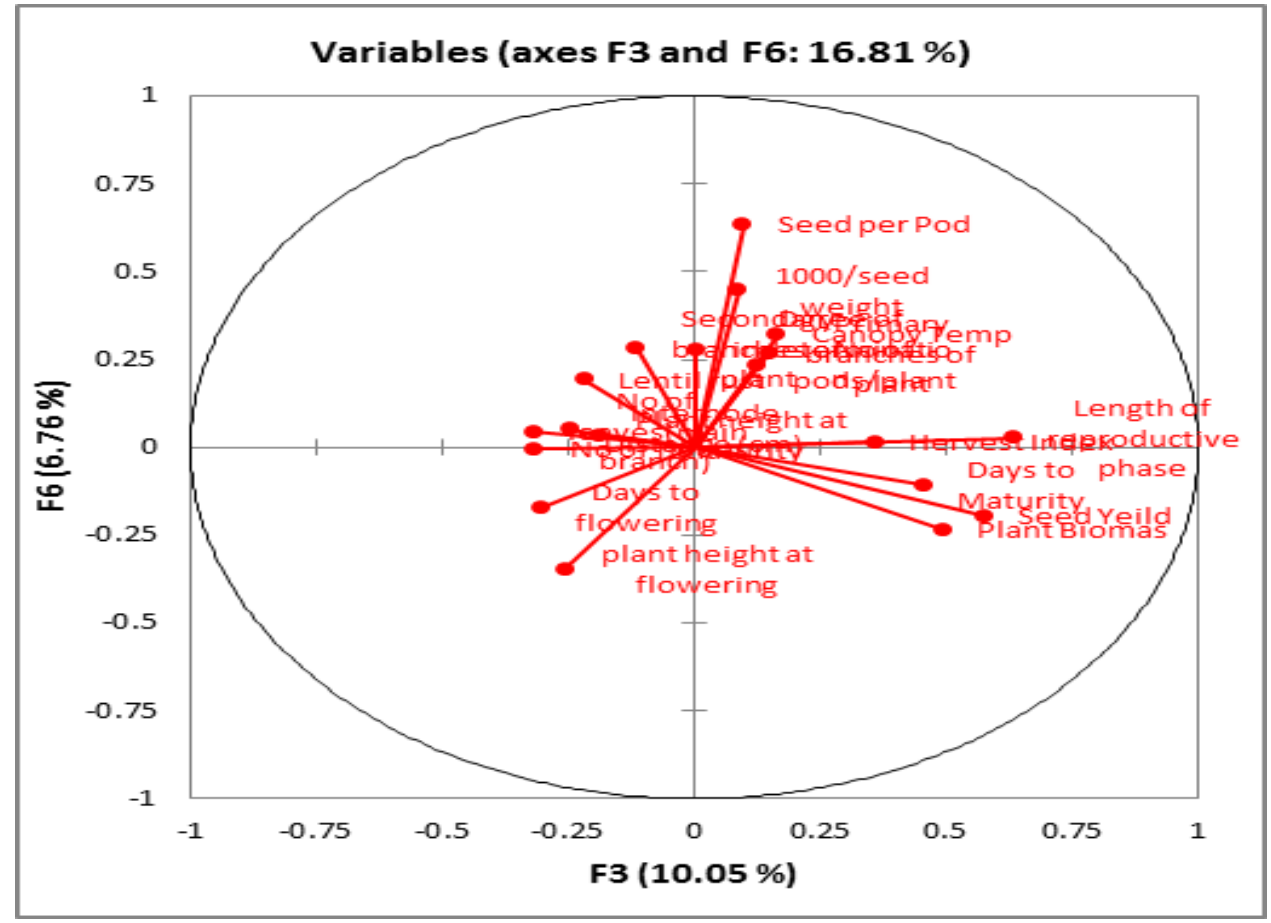

Figure 33. The correlation between the characters of two variables F3 and F6.

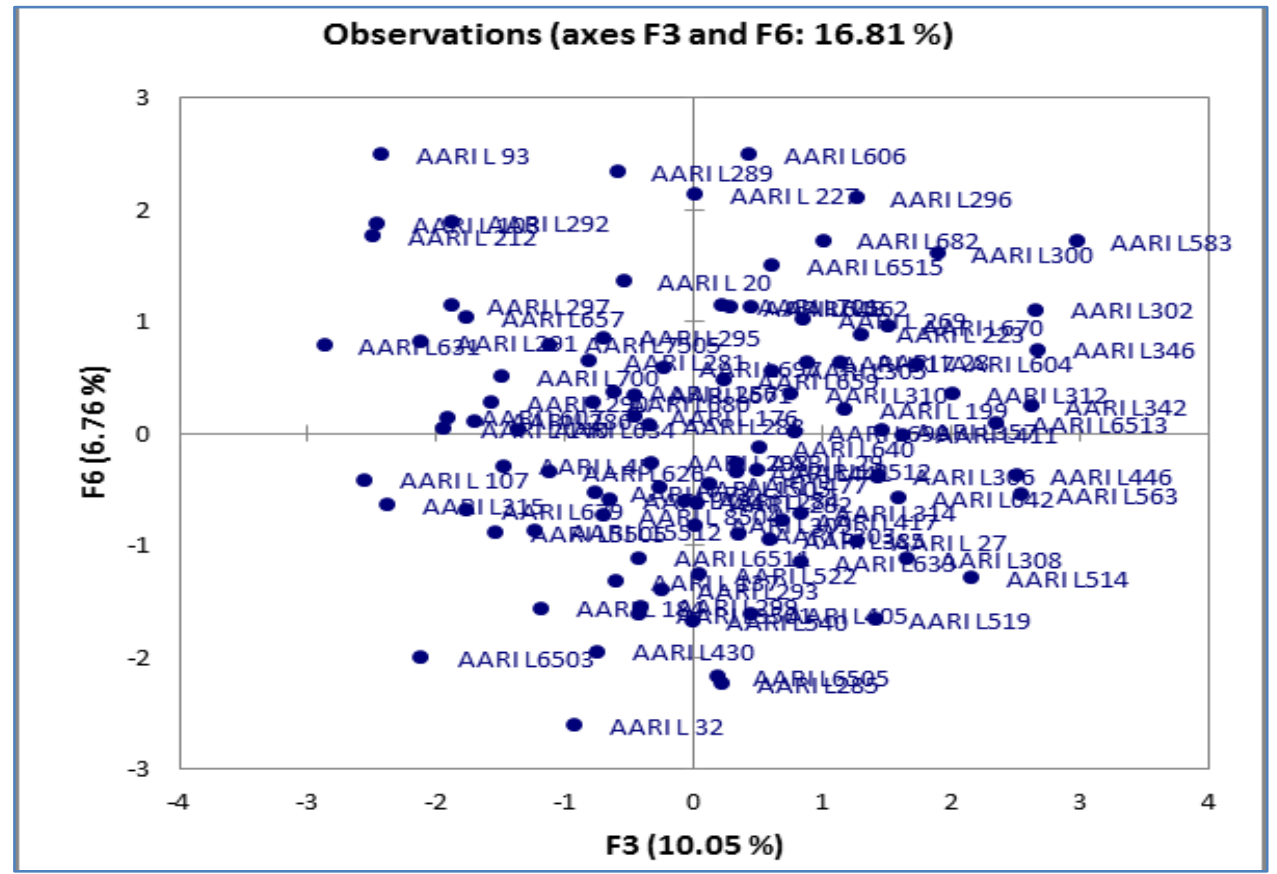

Figure 34. Two-dimensional ordination of 19 agro-morphological characters in genotypes of lentil germplasm on principal component axes. 
The plot showed by the PC3 and PC7 differentiate among eighteen collections of traits (Fig.35,36). The chief assembly was certainly connected along two cleavers and exposed of seed/pod, pods in each plant, index production, 1000/kernel mass, and days to maturity traits. Plant biomass, internodes distance, canopy temperature, degree of indetermination, seed yield and length of reproductive phase was fatalistic relation to axis two (PC7). In contrast, lentil rust, days to flowering, number of nodes, number of leaves (main branch), showed the third group was adversely to axis one (PC3). Plant height at maturity, primary branches of plant, plant height at flowering and secondary branches of plant was detrimentally associated to two axes. This may helpful in selection of genotypes for construction of varieties based on PC values for high elastic capacity. The outcome of analysis also determines the significance of those characters for evolution of varieties with greater yield potential.

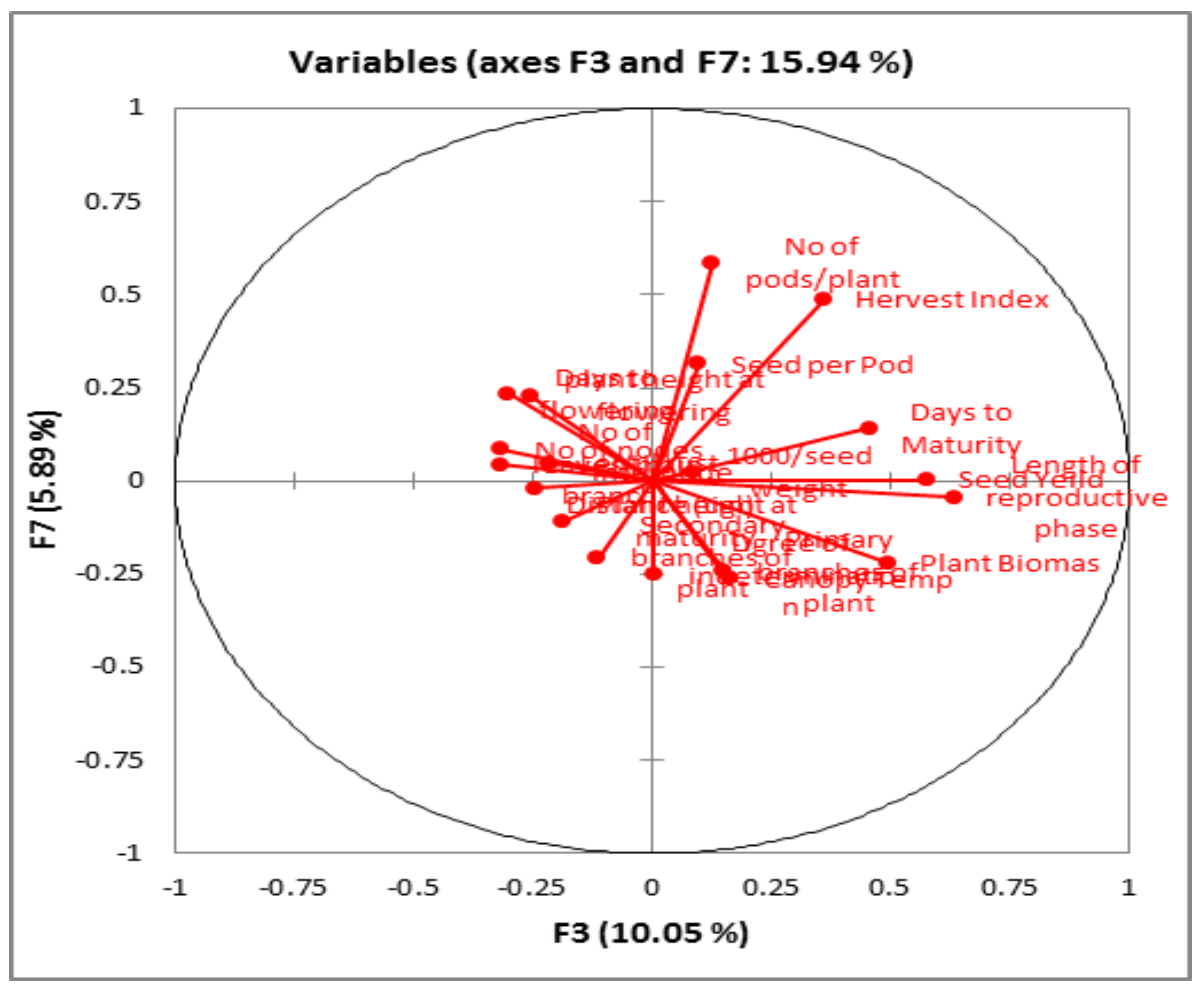

Figure 35. The correlation between the characters of two variables F3 andF7.

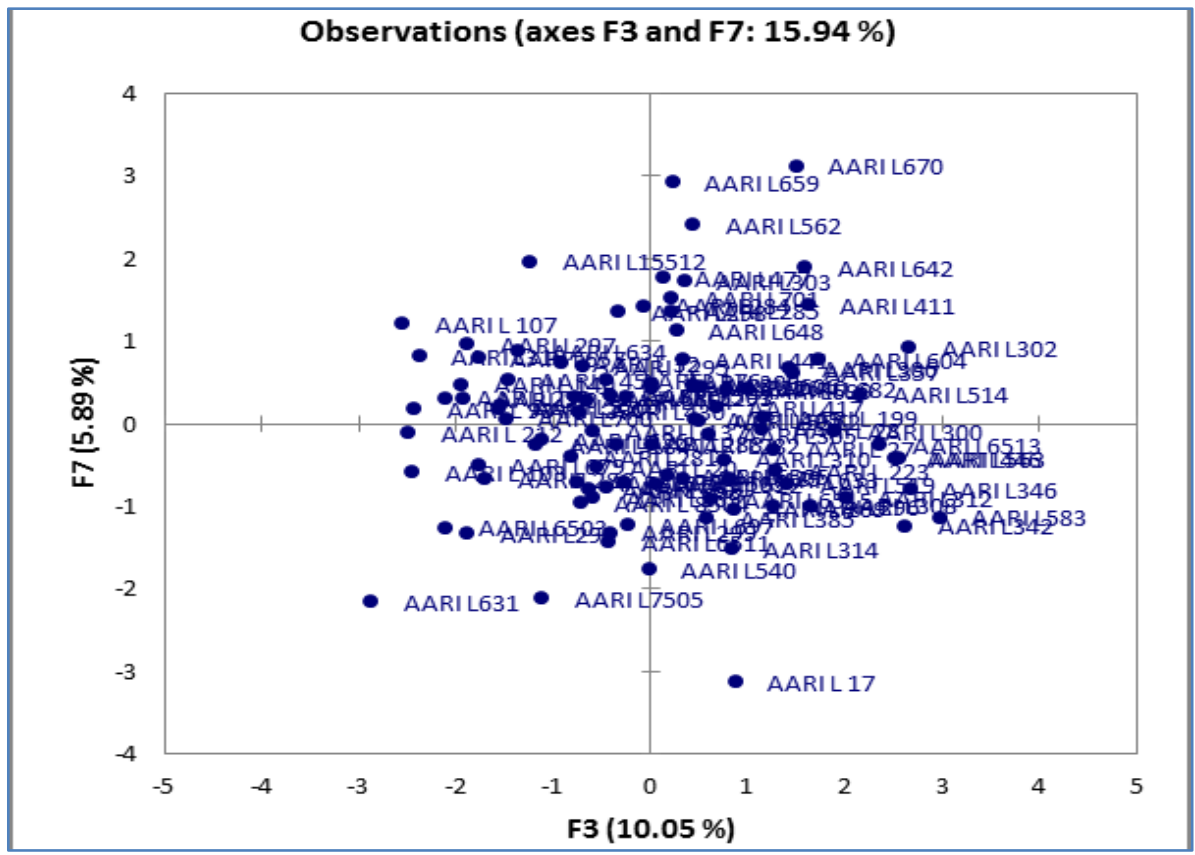

Figure 36. Two-dimensional ordination of 19 agro-morphological characters in genotypes of lentil germplasm on principal component axes. 
This plot explained by the PC3 and PC8 differentiate four sets of traits (Fig.37,38). The leading assembly was confidently associated along axis and composed of days to maturity, 1000/ germ mass, fruitage index, prime twigs plus total pods traits. Length of reproductive phase, seed/pod, plant biomass, seed yield and canopy temperature was inversely related to axis two (PC8). In comparison, plant height at maturity, secondary branches of plant, time to flowering and degree of indetermination showed the third set was adversely associated to axis one (PC3). Number of nodes, number of leaves (main branch), lentil rust, internodes distance and plant height at flowering was in fatalistic to two axes. This may helpful in selection of genotypes for construction of varieties based on PC values for high elastic capacity. The outcome of analysis also determines the significance of those characters for evolution of varieties with greater yield potential.

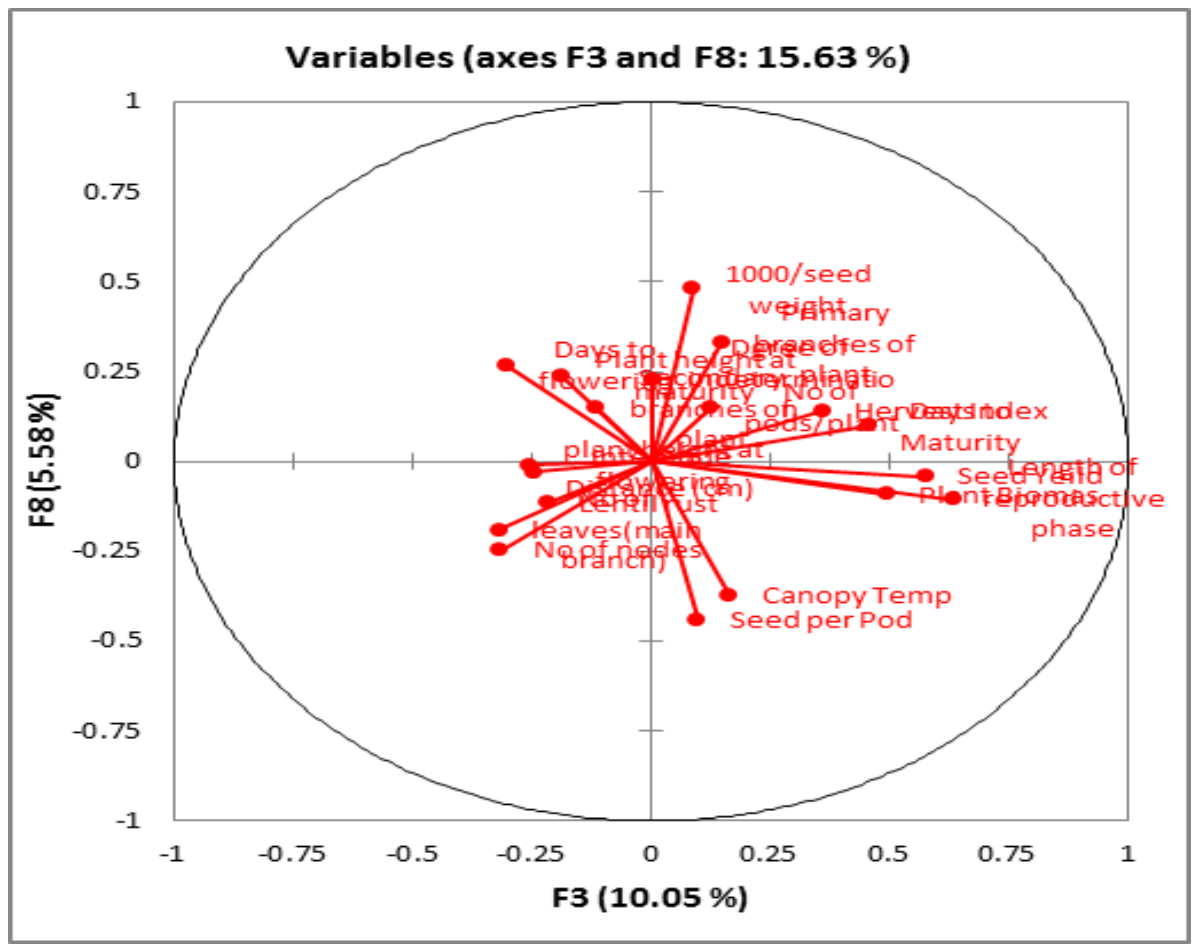

Figure 37. The correlation between the characters of two variables F3 and F8.

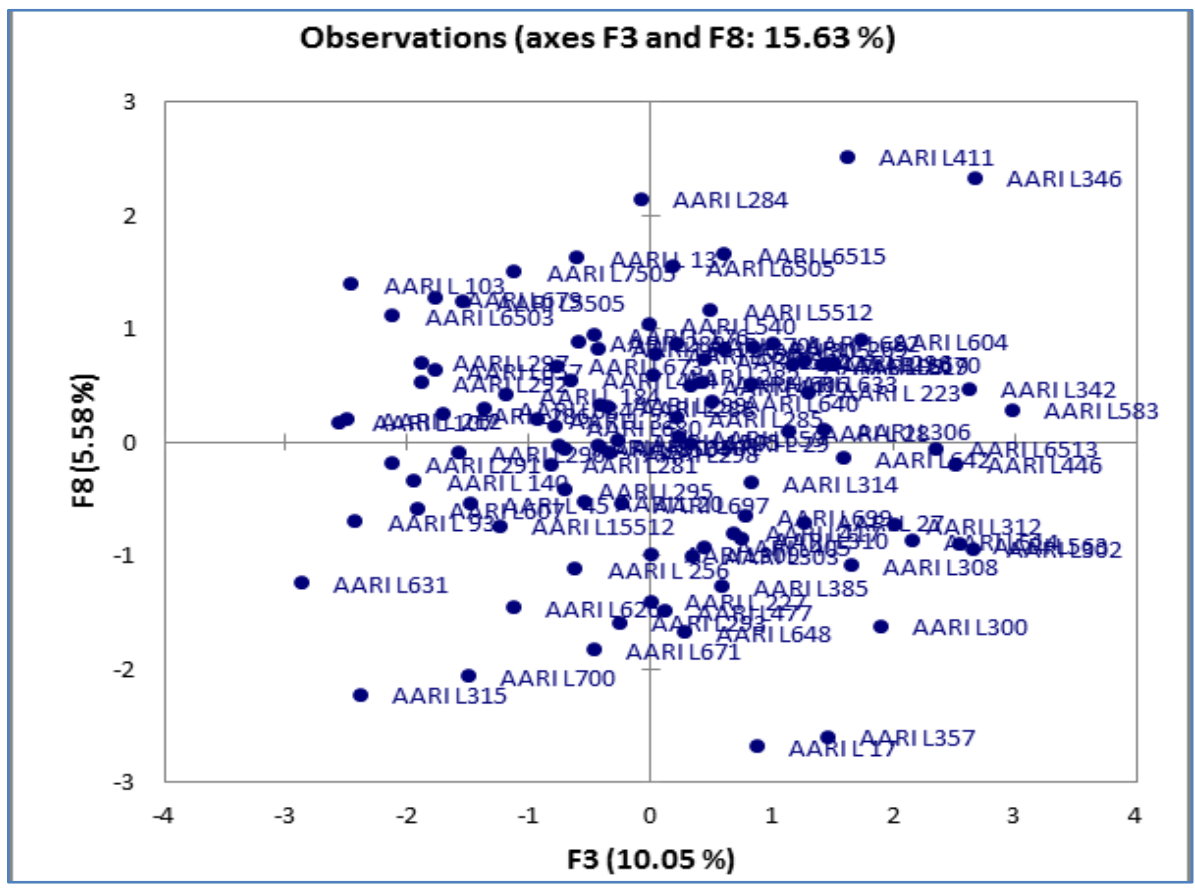

Figure 38. Two-dimensional ordination of 19 agro-morphological characters in genotypes of lentil germplasm on principal component axes. 
This Plot defined by the PC4 and PC5 differentiate among eighteen clusters types (Fig.39,40). The leading individual was confidently associated along axis and composed of internodes distance, length of reproductive phase, number of leaves (main branch), maturity time, development elevation, lentil rust as well as blossoming altitude traits. Quantity of pods/plant, 1000 seed weight, degree of indetermination, was inversely related to axis two (PC5). In contrary, canopy temperature, Plant primary branches, harvest index, Plant secondary branches, flowering period and total nodes represented third group was adversely associated to axis one (PC4). Seed yield, plant biomass and seed/pod were inversely related to two axes. This may helpful in selection of genotypes for construction of varieties based on PC values for high elastic capacity. The outcome of analysis also determines the significance of those characters for evolution of varieties with greater yield potential.

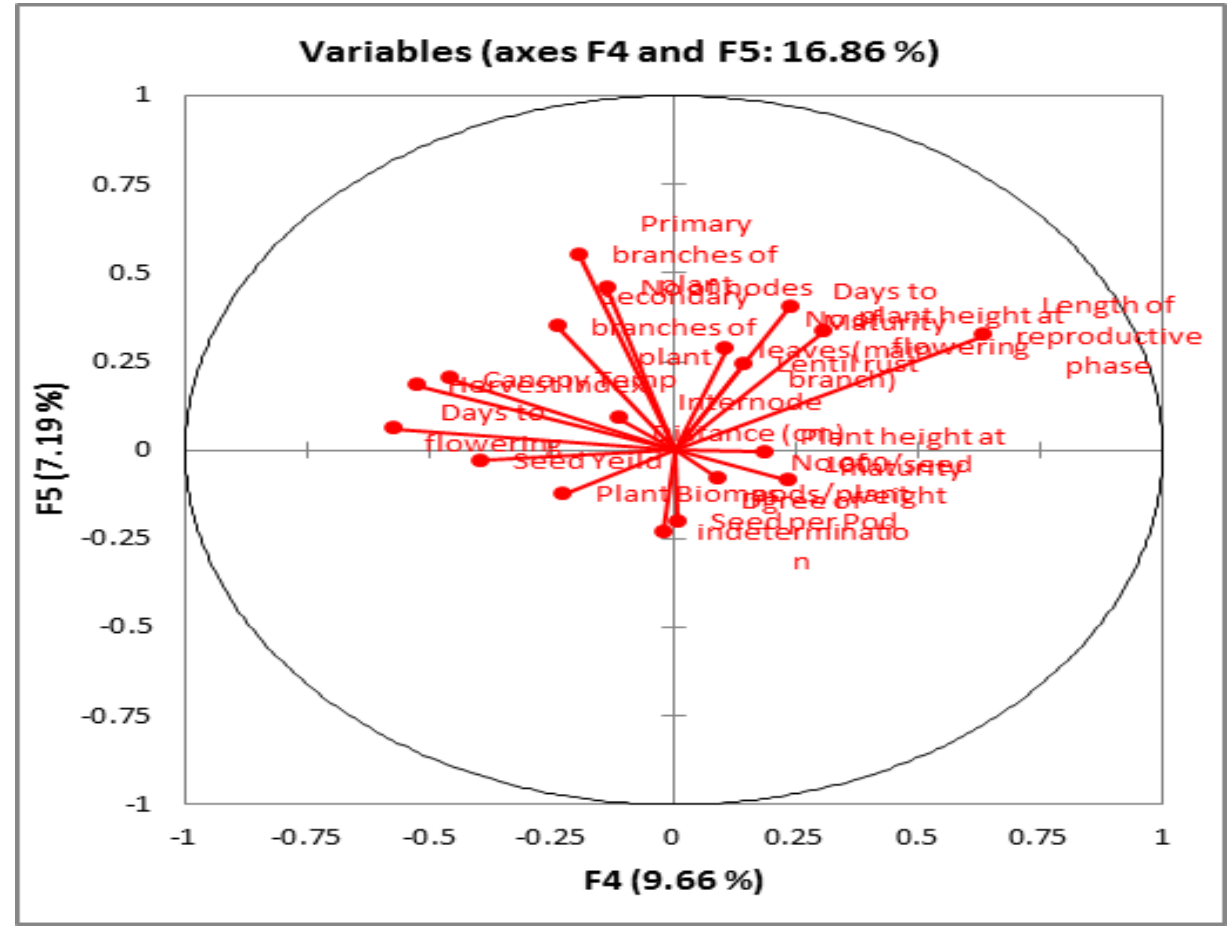

Figure 39. The correlation between the characters of two variables F4 and F5..

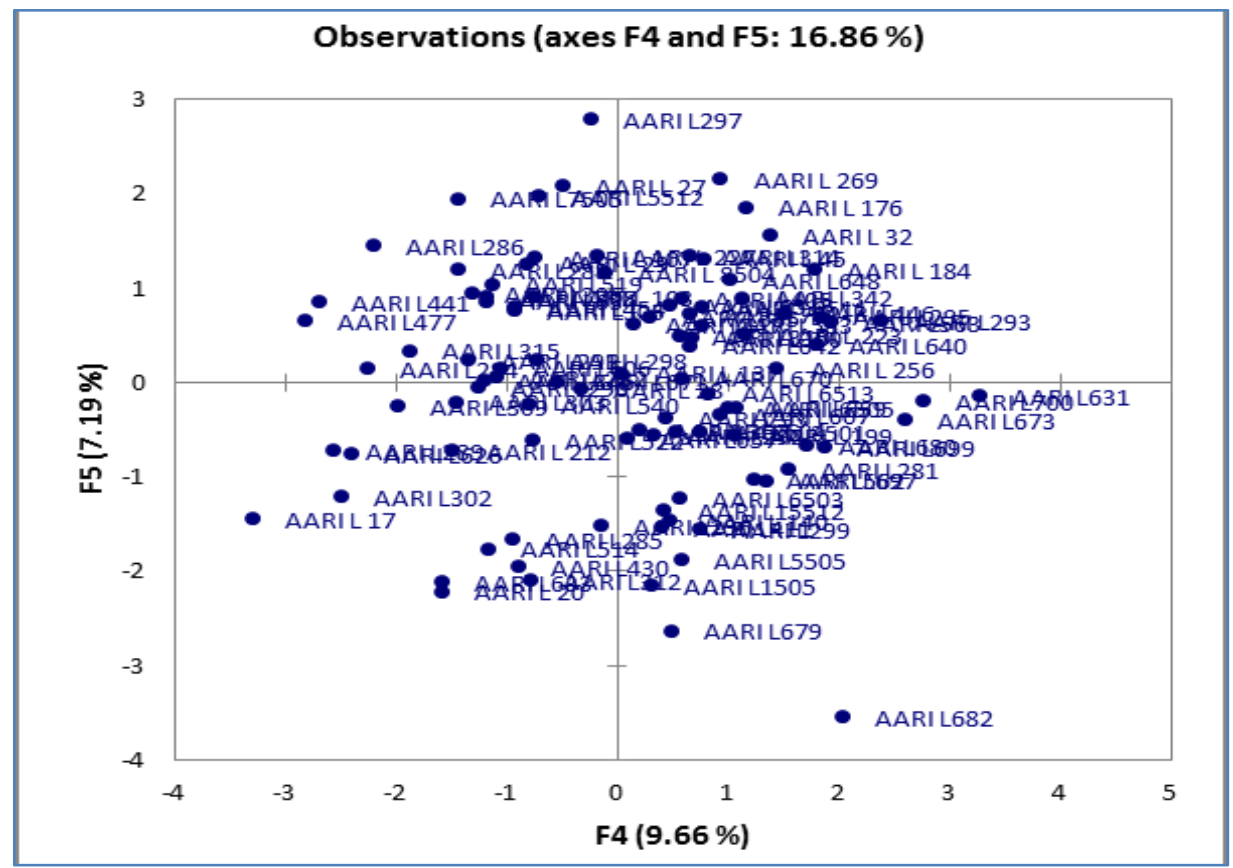

Figure 40. Two-dimensional ordination of 19 agro-morphological characters in genotypes of lentil germplasm on principal component axes 
Plot explained by the PC4 and PC6 differentiate among eighteen groups of traits (Fig.41,42). The major crowd was highly interconnected on the way of two hatchets and composed of 1000 germ mass, numeral leaves (main branch), spore in each pod, degree of indetermination, height at maturity, length of reproductive phase and number of pods/plant and lentil rust traits. Blossoming as like maturity altitude was adversely associated to axis two (PC6). In comparison, Primary branches of plant, harvest index, secondary branches of plant, canopy temperature and internodes distance, showed the third group was inversely related to axis one (PC4). Number of nodes, flowering period, plant biomass and grain harvest was adversely interconnected to two axes. This may helpful in selection of genotypes for construction of varieties based on PC values for high elastic capacity. The outcome of analysis also determines the significance of those characters for evolution of varieties with greater yield capability.

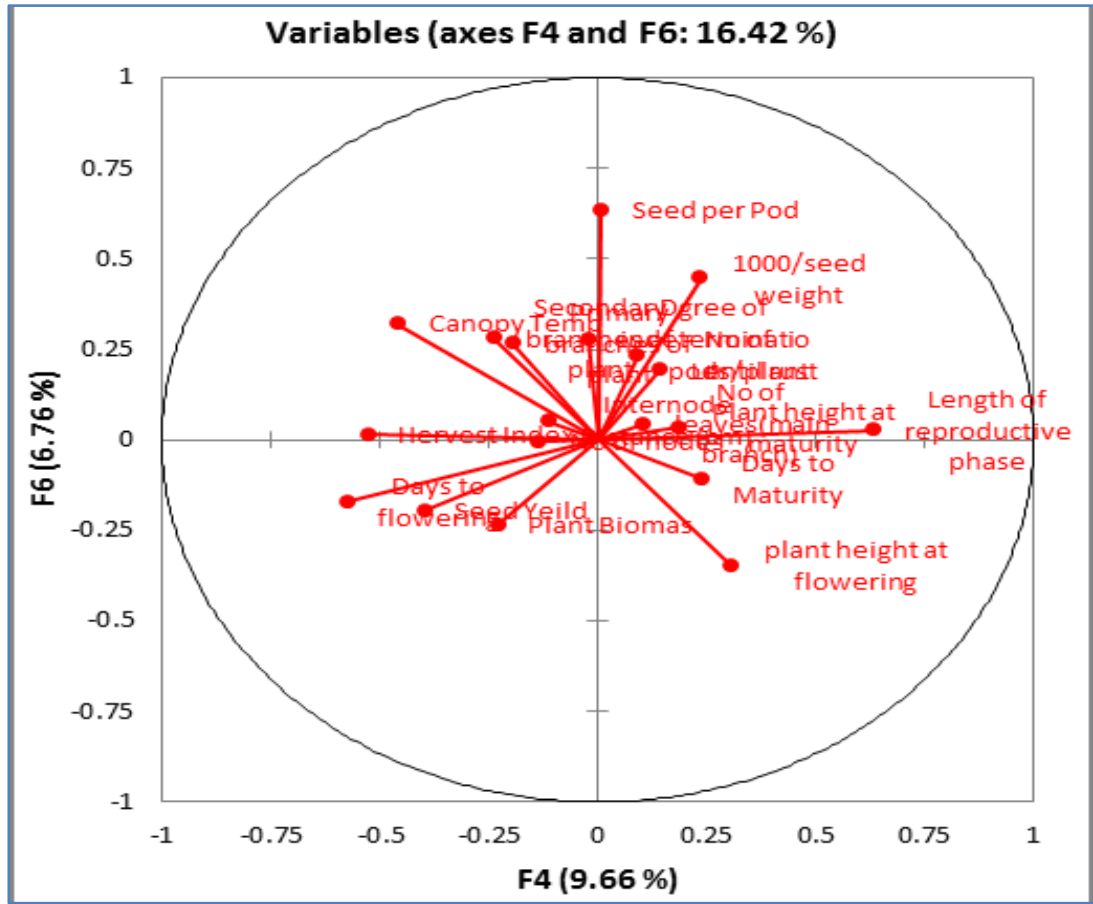

Figure 41. The correlation between the characters of two variables F4 and F6.

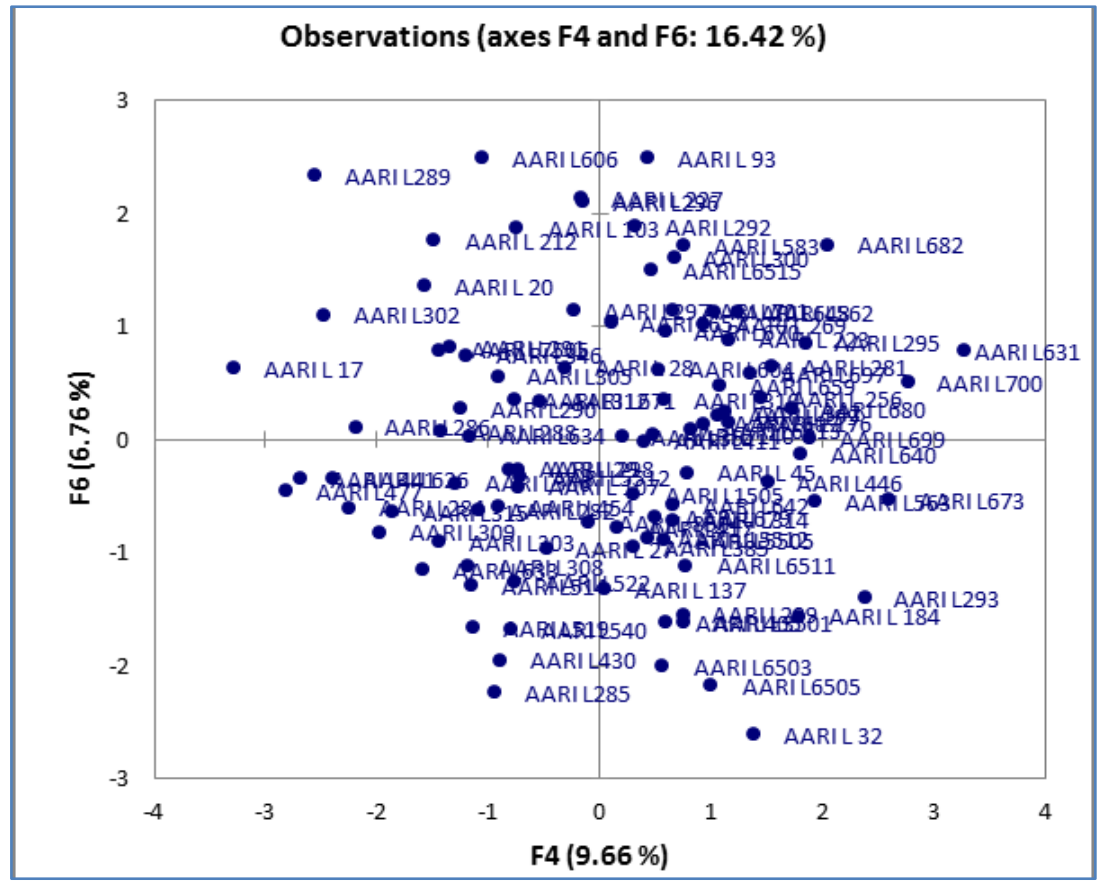

Figure 42. Two-dimensional ordination of 19 agro-morphological characters in genotypes of lentil germplasm on principal component axes. 
The plot showed by the PC4 and PC7 differences in eighteen collection of traits (Fig.43,44). The head group was really allied to two hatchets and collected of vegetal stature at flowering seed/pod, integer of pods/plant, total of leaves (main branch), lentil rust, days to maturity and 1000/seed weight traits. Plant elevation at maturity and length of reproductive phase was negatively affiliated to axis two (PC7). In contrary, harvest index, days to blossoming, number of nodes, kernel yield as well as internodes distance exhibited the third group was inversely associated to axis one (PC4). Primary branches of plant, canopy temperature, secondary branches of plant and degree of indetermination and plant biomass was in detrimental relation to two axes. This may helpful in selection of genotypes for construction of varieties based on PC values for high elastic capacity. The outcome of analysis also determines the significance of those characters for evolution of varieties with greater yield potential.

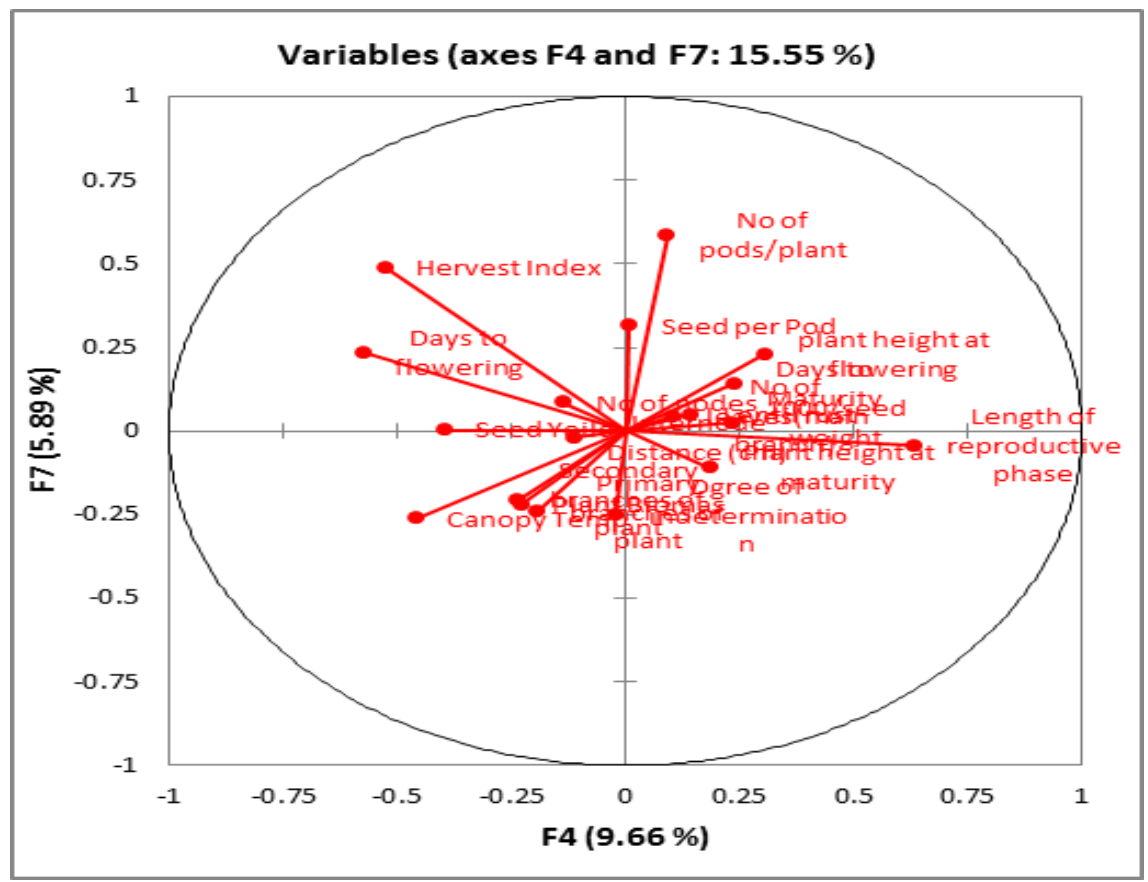

Figure 43. The correlation between the characters of two variables F4 and F7

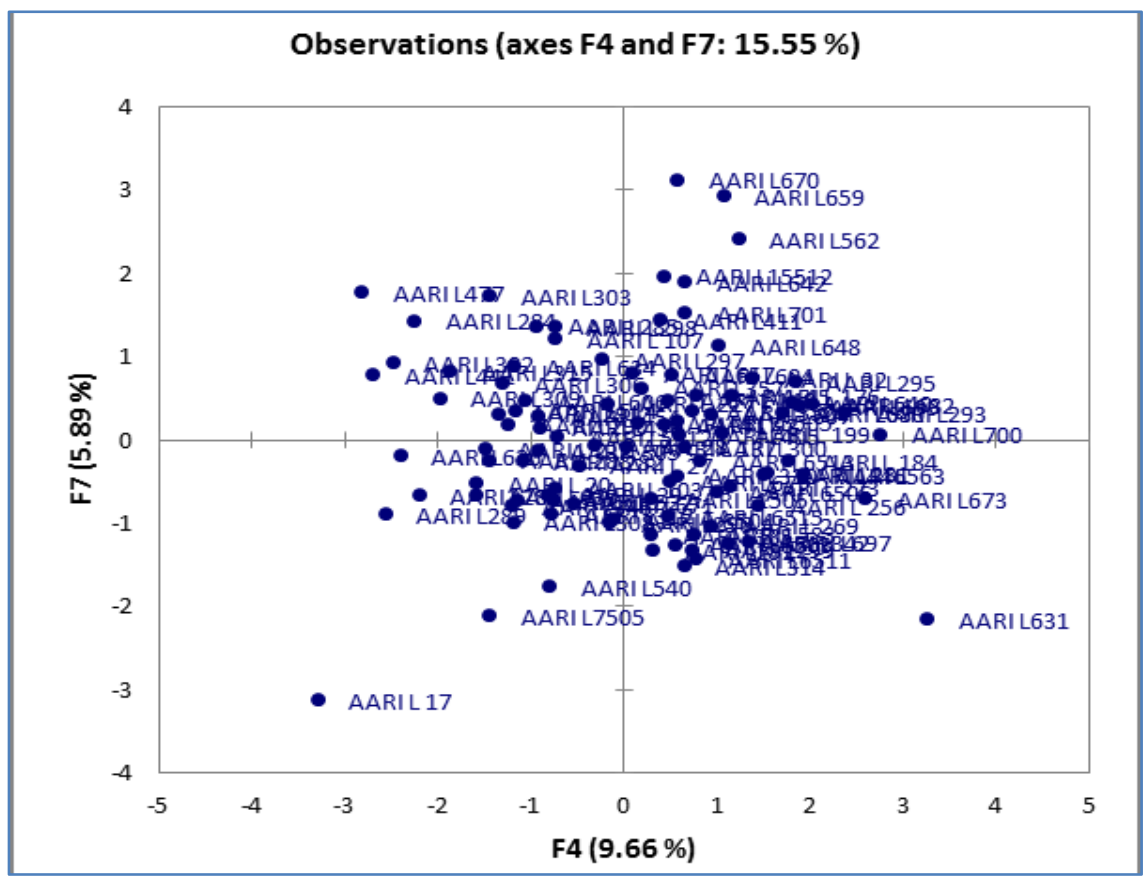

Figure 44. Two-dimensional ordination of 19 agro-morphological characters in genotypes of lentil germplasm on principal component axes. 
The plot described by the PC5 and PC6 differentiate between eighteen classes of traits (Fig.45,46). The major group was completely linked to two downsizes and constituted of length of reproductive phase, harvest index and Plant primary branches, plant height at maturity, number of leaves (main branch), internodes distance, lentil rust, canopy temperature and subordinate brushwood of plant, traits. Numeral of nodes, bush elevation at blossoming, times to flowering and duration of maturity was adversely affiliated to axis two (PC6). In comparison, seed/pod, 1000/seed weight, degree of indetermination and number of pods/plant exhibited the third group was inversely associated to axis one (PC5). Plant biomass and seed yield was adversely affiliated to two axes. This may helpful in selection of genotypes for construction of varieties based on PC values for high elastic capacity. The outcome of analysis also determines the significance of those characters for evolution of varieties with greater yield potential.

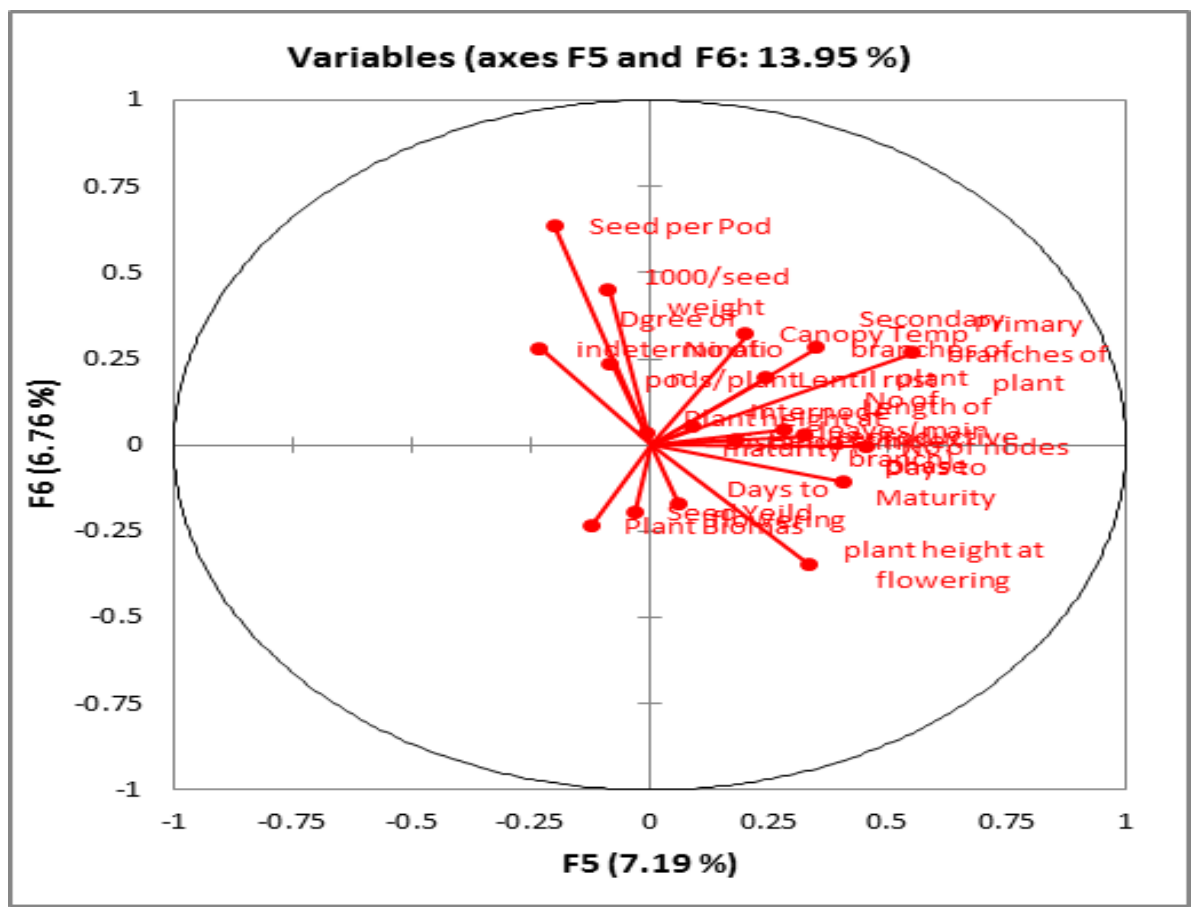

Figure 45. The correlation between the characters of two variables F5 and F6.

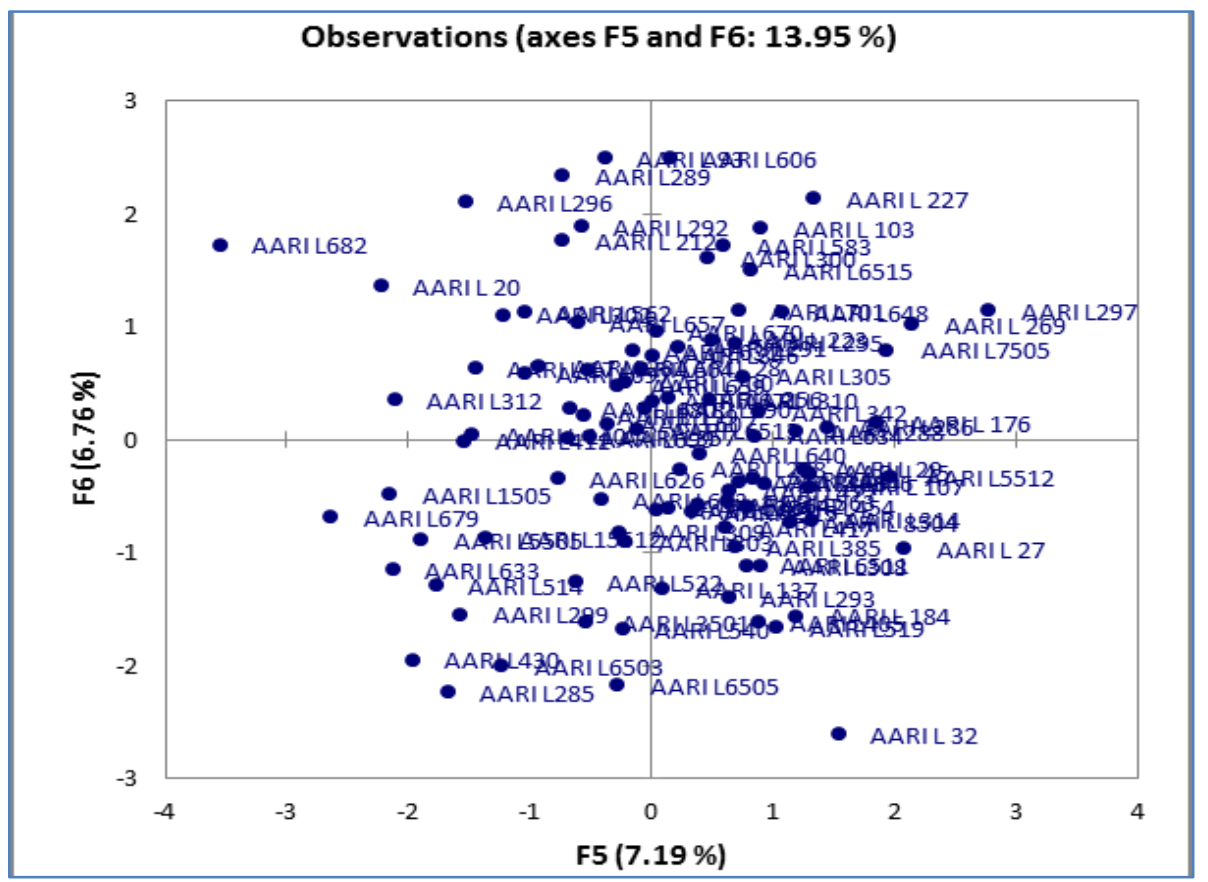

Figure 46. Two-dimensional ordination of 19 agro-morphological characters in genotypes of lentil germplasm on principal component axes. 
The plot explained by the PC5 and PC7 exhibited eighteen sets of traits (Fig.47,48). The leading group was certainly associated to two hatchets and constituted to plant height at maturity, harvest index, eras to flowering, maturity level, most important twigs of plant as well as less important twigs traits of plant. Extent of reproductive phase, internodes distance, number of nodes, number of leaves (main branch), lentil rust, canopy temperature, plant height at flowering was negatively associated to axis two
(PC7). In contrary, 1000/seed weight, degree of indetermination and number of pods/plant exhibited the third set was inversely affiliated to axis one (PC5). Seed yield, plant biomass and seed/pod, was adversely associated to two axes. This may helpful in selection of genotypes for construction of varieties based on PC values for high elastic capacity. The outcome of analysis also determines the significance of those characters for evolution of varieties with greater yield potential.

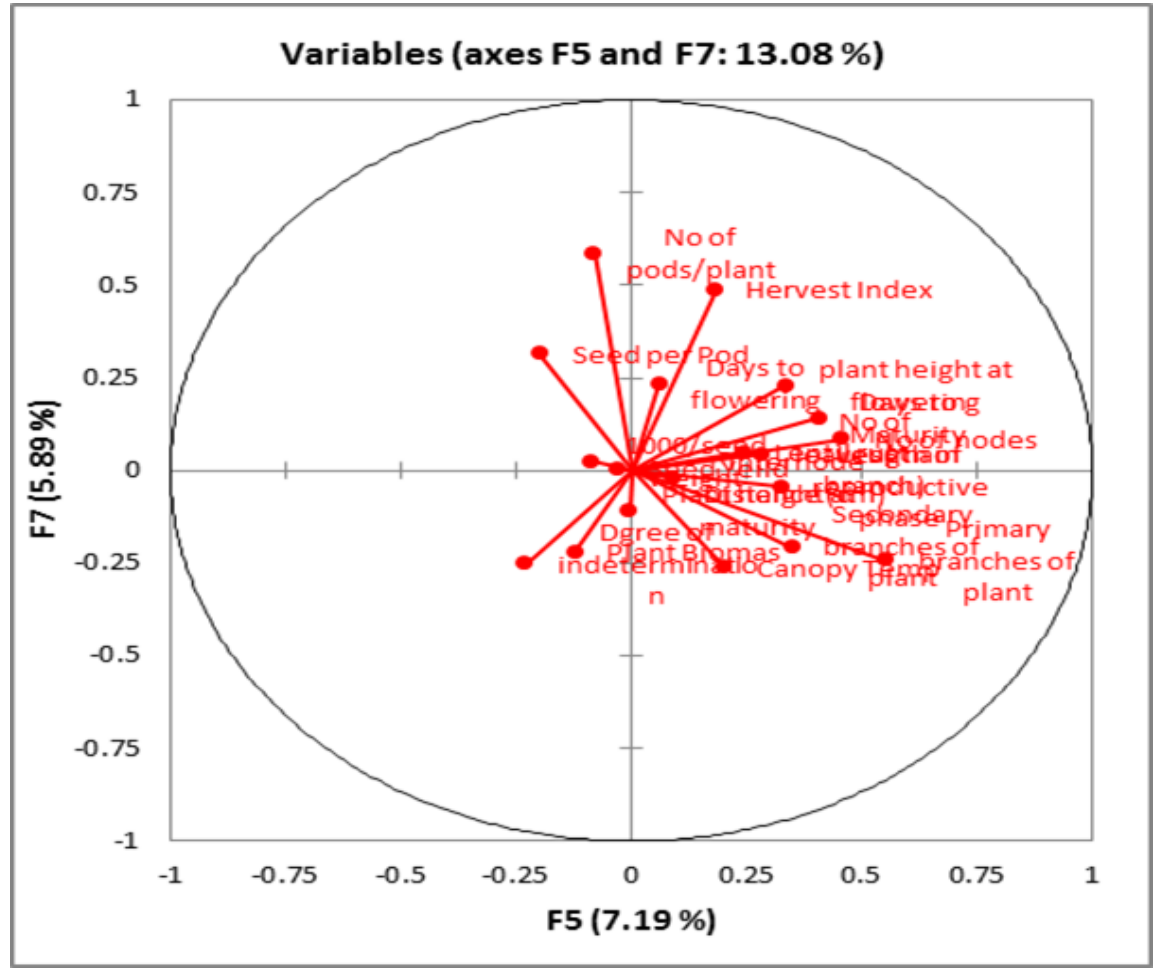

Figure 47. The correlation between the characters of two variables F5 and F7. Each dot in this cloud shows a particular character.

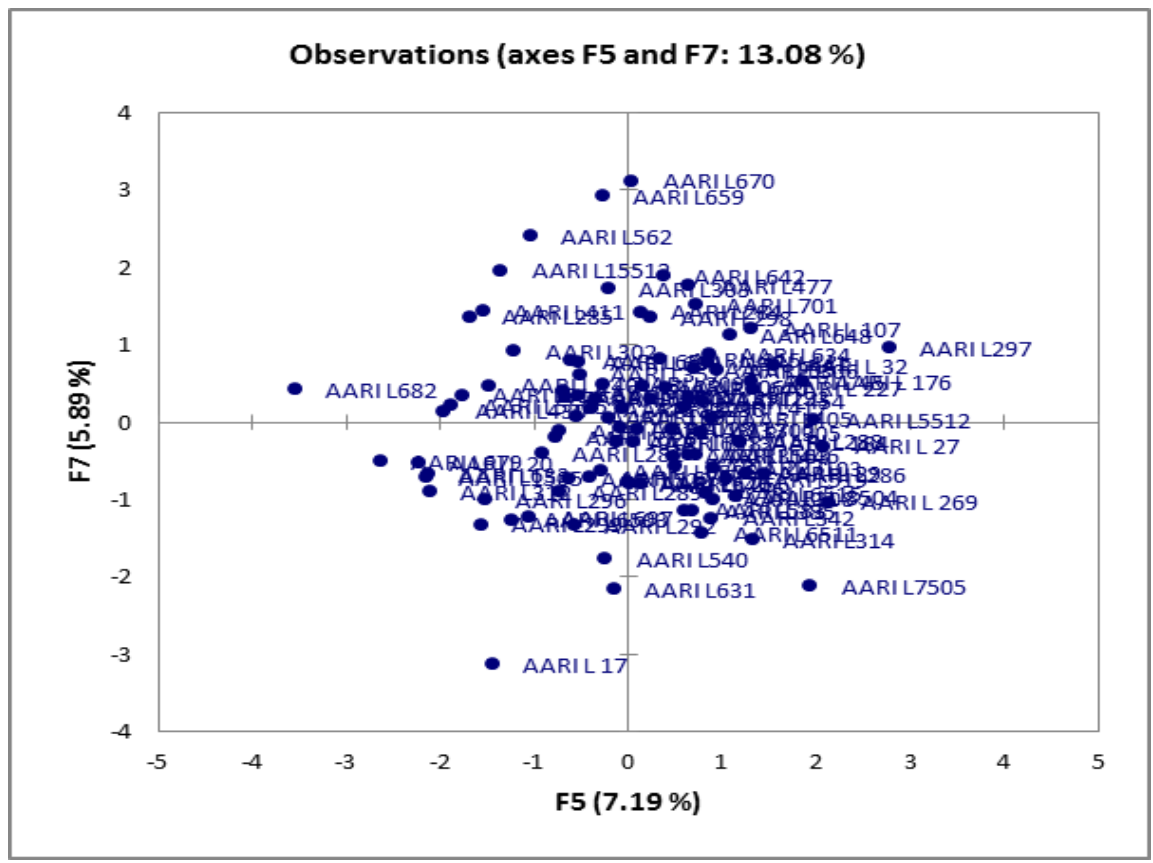

Figure 48. Two-dimensional ordination of 19 agro-morphological characters in genotypes of lentil germplasm on principal component axes. 
The plot explained by the PC6 and PC7 differences among eighteen collections of traits (Fig.49,50). The topmost class was positively associated to two axes and constituted to quantity of pods/plant, 1000 seed weight, harvest index, days to flowering, seeds/pod, quantity of leaves(main branch), number of nodes traits. Length of reproductive phase, Primary branches of plant, secondary branches, lentil rust, canopy temperature, degree of indetermination, internodes distance was inversely related to axis two (PC7). In comparison, height of plant at maturity, plant height at flowering, maturity duration, seed yield explored the third set was inversely affiliated to axis one (PC6). Plant biomass was adversely associated to two axes. This may helpful in selection of genotypes for construction of varieties based on PC values for high elastic capacity. The outcome of analysis also determines the significance of those characters for evolution of varieties with greater yield potential.

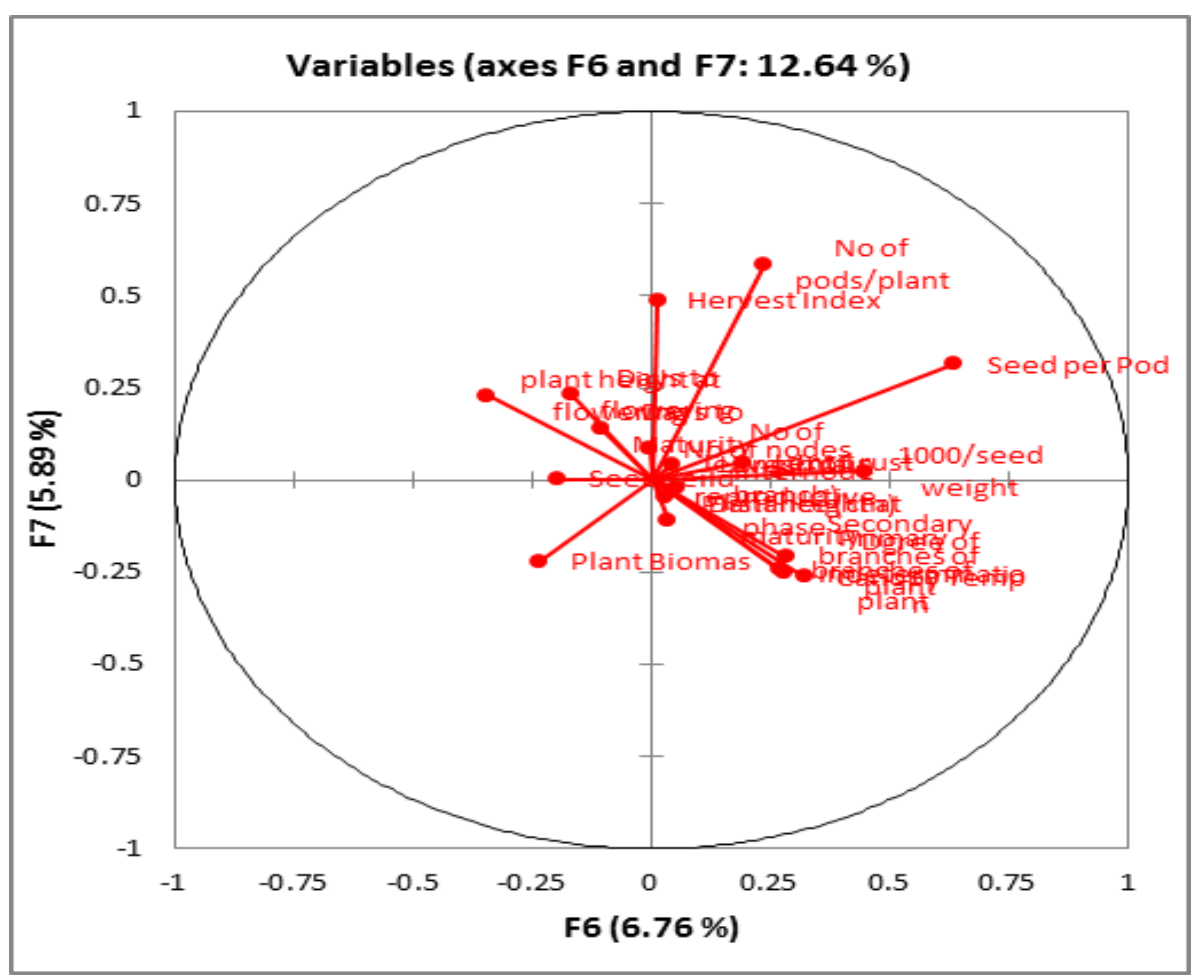

Figure 49. The correlation between the characters of two variables F6 and F7.

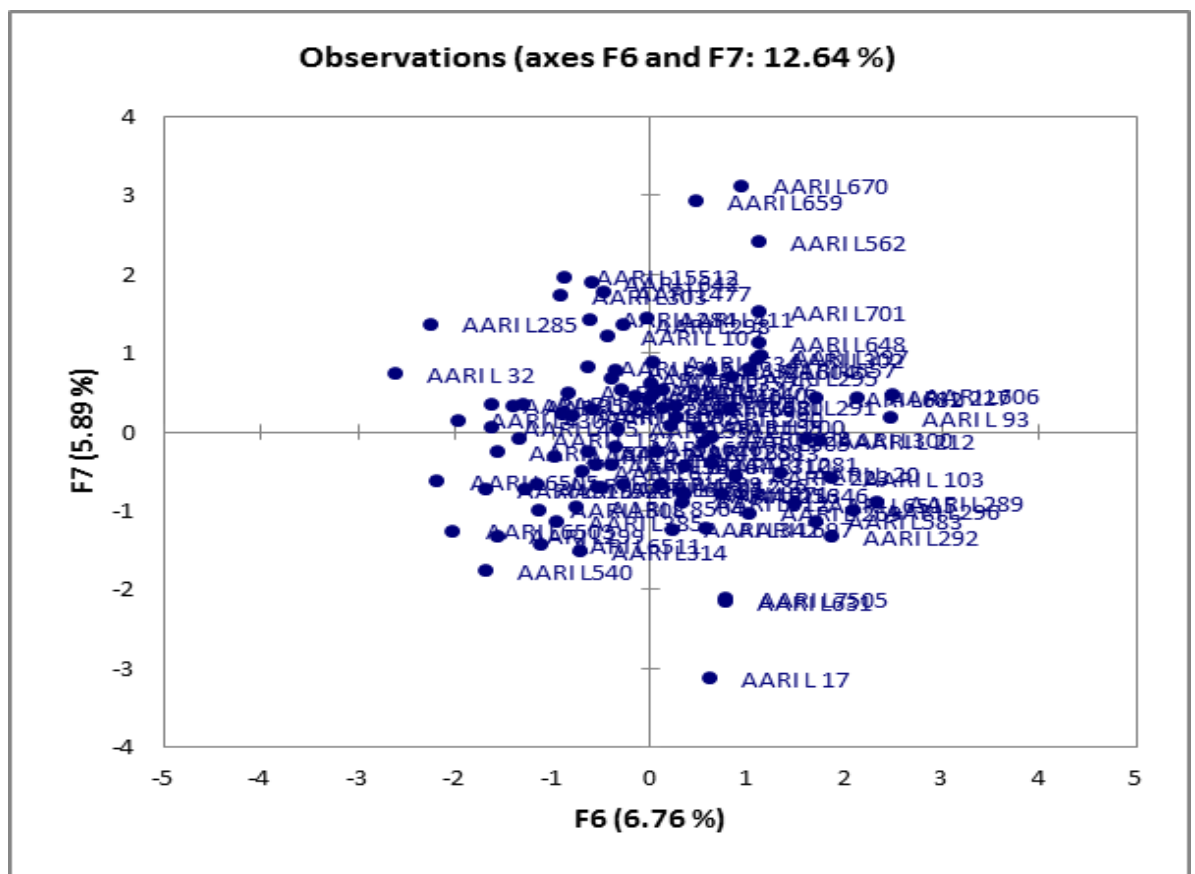

Figure 50. Two-dimensional ordination of 19 agro-morphological characters in genotypes of lentil germplasm on principal component axes. 
The plot explained by the PC6 and PC8 distinguished eighteen groups of characters (Fig.51,52). The initial group was completely correlated to two cuts and composed of1000/seed weight, Plant height at maturity, amount of plant/pods, also times to maturity, and grade of in determination, subordinate brushwood of plant plus primary kindling of plant traits. Seed/pod, canopy temperature, number of leaves(main branch), , sum of nodes or internodes distance, length of reproductive phase represented the third group was negatively correlated to axis one (PC).In contrast, days to flowering, plant height at flowering was negatively correlated to axis one (PC6). Harvest index, plant biomass, seed yield was negatively correlated to two axes. This could help in genotype mixture based on PC values for high yielding potential. The results also suggest importance of these traits in development of high yielding varieties.

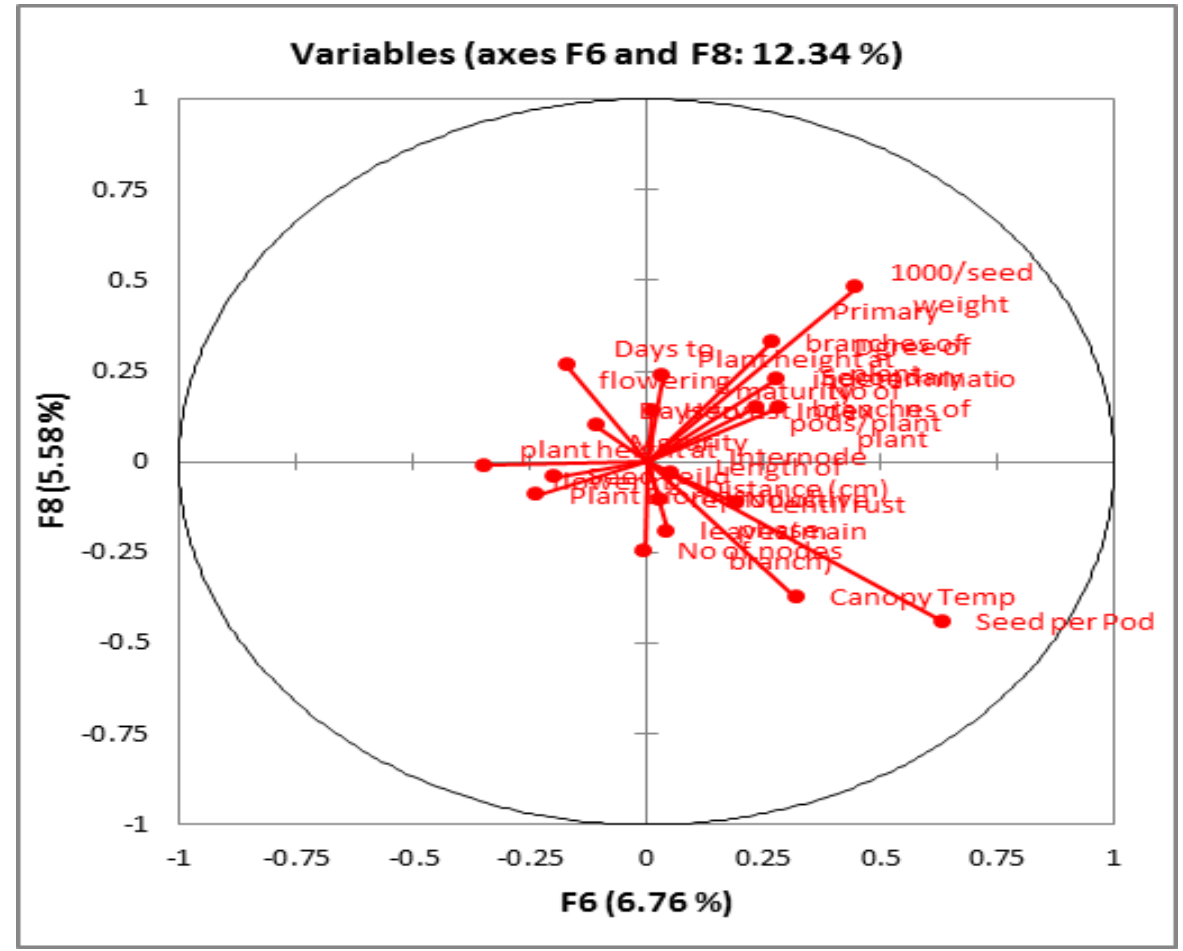

Figure 51. The correlation between the characters of two variables F6 and F8.

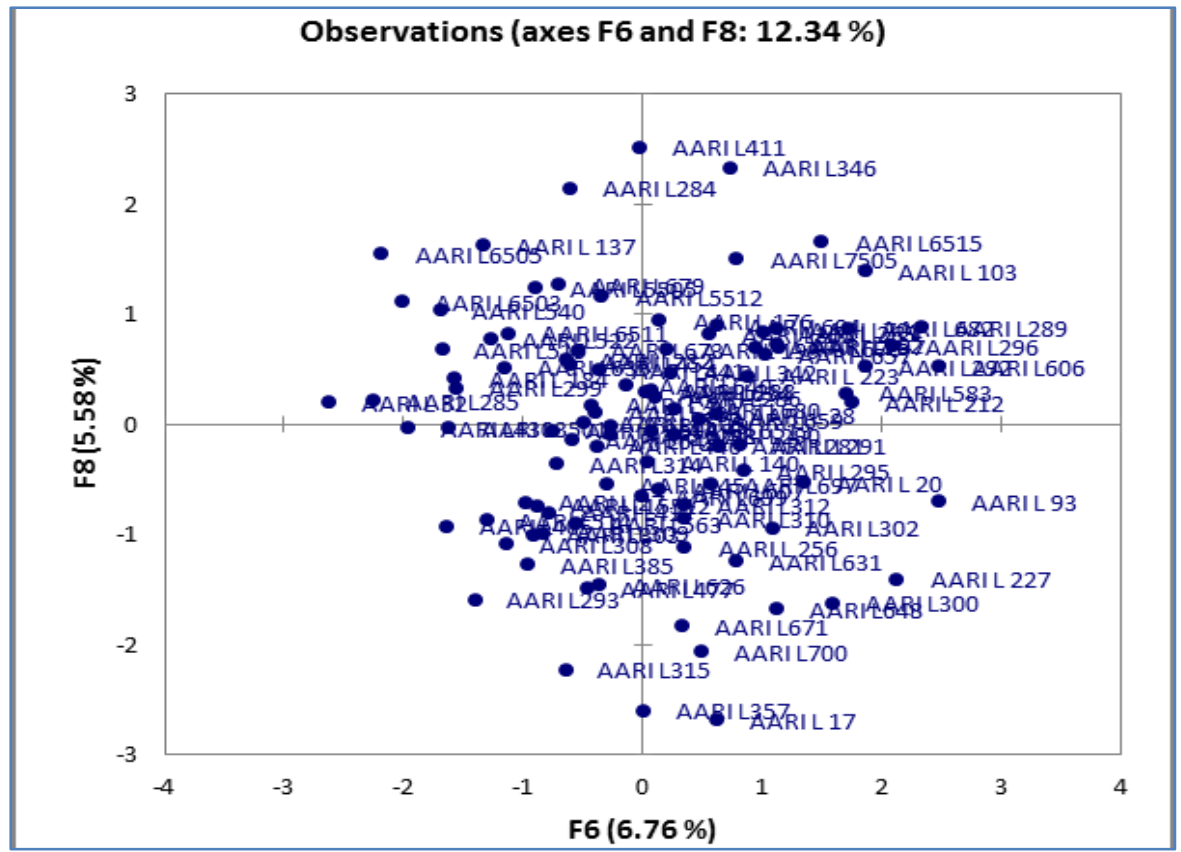

Figure 52. Two-dimensional ordination of 19 agro-morphological characters in genotypes of lentil germplasm on principal component axes. 
The plot explained by the PC7 and PC8 differentiate among eighteen groups of traits (Fig.53,54). The initial cluster was strongly associated toward two cleavers and composed of 1000 grain mass, blossoming times, crop index, pods in every plant, maturation period and internodes distance traits. Spore production, flowering height, length of reproductive phase, sum of leaves, total nodes, pod in every germ was inversely associated to axis one (PC7). In comparison, Primary plus secondary twigs, indetermination grade, harvest index was negatively correlated to axis two (PC8). Plant biomass and canopy temperature was indirect proportion to two axes. This may helpful in selection of genotypes for construction of varieties based on PC values for high elastic capacity. The outcome of analysis also determines the significance of those characters for evolution of varieties with greater yield potential.

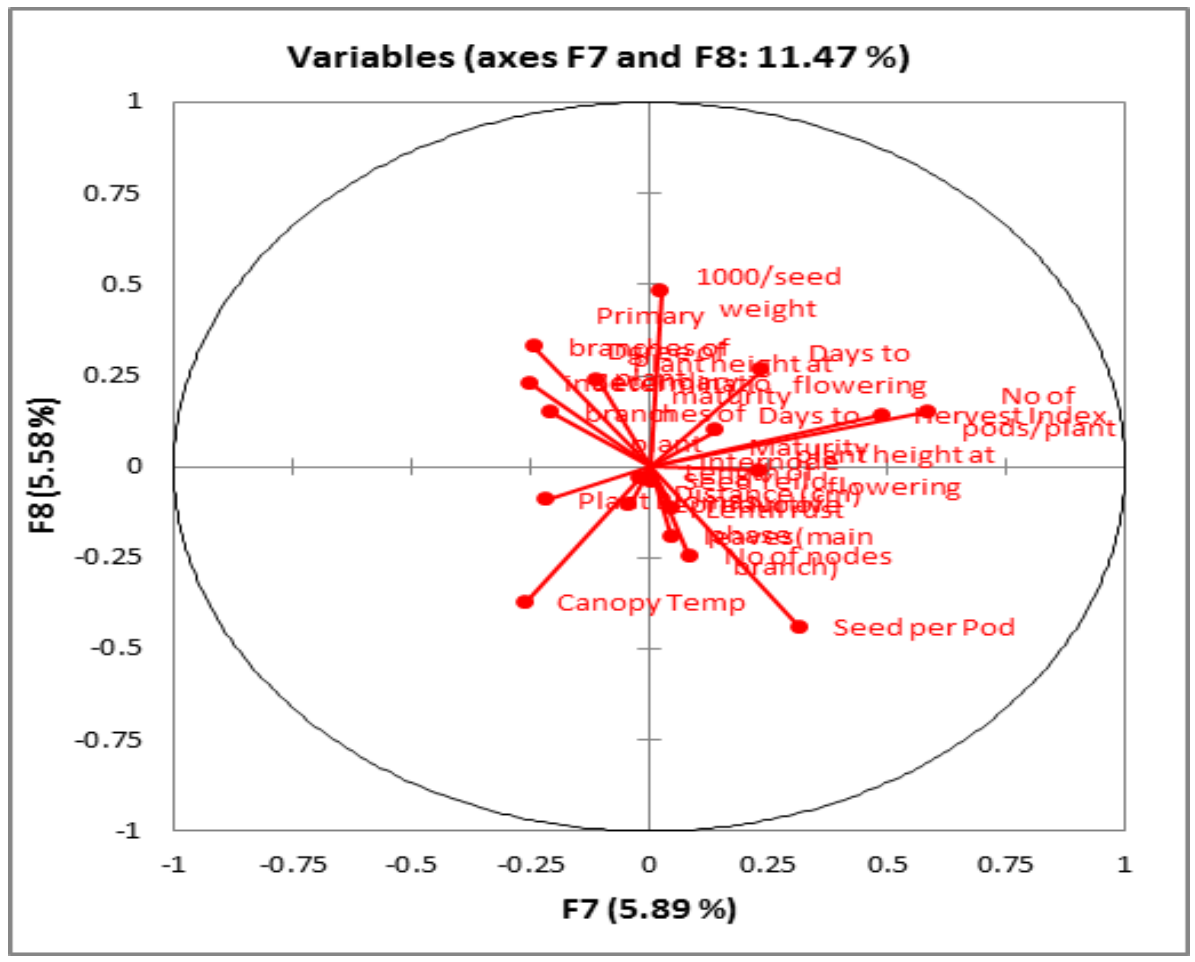

Figure 53. The correlation between the characters of two variables F7 and F8.

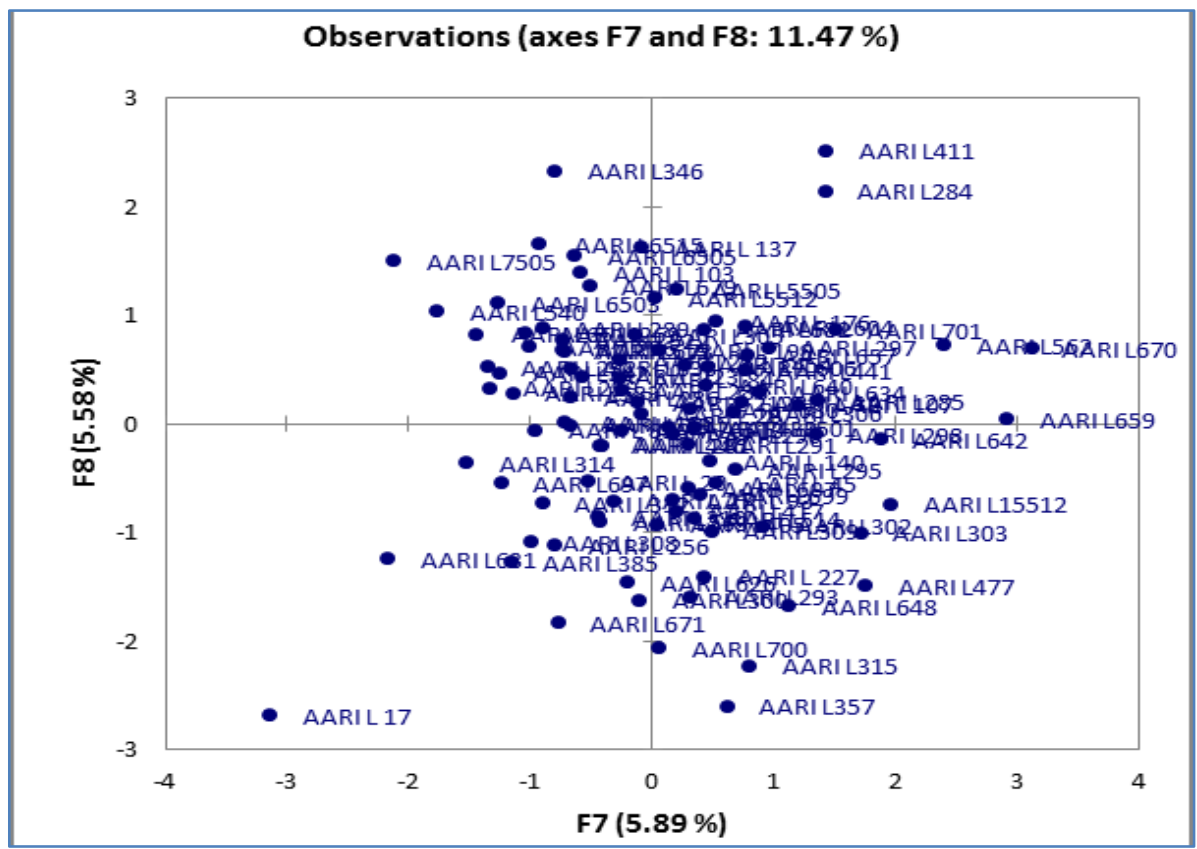

Figure 54. Two-dimensional ordination of 19 agro-morphological traits in genotypes of lentil germplasm on principal component axes. 


\section{Conclusions}

An experiment was planned to estimate the "Evaluation of lentil germplasm for morphological traits and yield performance” one hundred genotypes of lentil germplasm were used for experimentation. Seeds were grown in the field of research area of Ayub Agriculture Research Institute of Faisalabad. Growth attributes as plant biomass, seed yield, 1000 seed weight, length of reproductive phase, degree of indetermination, plant height at flowering, plant height at maturity, days to flowering, days to maturity, number of pods per plant, number of nodes per plant, seeds per pod, primary branches of plant, secondary branches of plant, number of leaves (main branch), canopy temperature, internode distance, lentil rust, lentil blight were calculated. All these characters were statistically analyzed by principle component analysis. Results revealed that certain characters like plant biomass, seed yield, days to maturity and flowering etc. showed positive correlation with each other while other characters such as lentil rust, canopy temperature, internode distance, length of reproductive phase, etc. depicts negative correlation with each other.

\section{REFERENCES}

[1] Ahamed, K. U., B. Akhter, M. R. Islam, M. R. Humaun and M. J. Alam. 2014. Morphological characterization and genetic diversity in lentil (Lens culinarisMedikus ssp. culinaris) germplasm. Int. J. Agric. Res. Innov. Tech., 4: 70-76.

[2] Erskine, W. 1996. Seed-size effects on lentil (Lens culinaris) yield potential and adaptation to temperature and rainfall in West Asia. J. Agri. Sci., 126:335-341.

[3] Erskine, W., S. Chandra, M. Chaudhry, I. A. Malik, A. Sarker, B. Sharma, M. Tufail, and M.C. Tyagi, 1998. A bottleneck in lentil: widening its genetic base in South Asia. Euphytica., 101: 207-211.

[4] Goa, Y., 2015. Performance evaluation and adaptation of lentil varieties in lemu, gumur and damot gale districts of southern Ethiopia. Current research in agricultural sciences. 2: 53-59.

[5] Khatun, S., M. Monjurul, A. Mondal, M. I. Khalil, M. M. I. Mollah, M. Kamruzzaman. 2016. Impact of Morpho-Physiological Traits on Seed Yield of Lentil (Lens culinarisMedik.). Int. J. Agri. Innovations and Res., 5: 168-172.

[6] Kumar, A., D. P. Singh. and B. B. Singh. 2015. Association analysis in lentil. Indi. J. Pulses Res.,1: 20-24.

[7] Majumdar, D. K., 2011. Lentil. In: Pulse Crop Production: Principles and Technologies. 398-436

[8] Rehman, A., M. A. Ali, B. M. Atta, M. Saleem, A. Abbas and A. R. Mallahi. 2009. Genetic studies of yield related traits in mungbean (Vigna radiata L. Wilczek). Aust. J. Crop. Sci., 3:352-360.
[9] Rehman, A., M. Saleem and M. A. Ali. 2013. Inheritance pattern of degree of indetermination in mungbean [Vigna radiata(L.) Wilczek].Plant. Knowledge. Journal. 2: 163-171.

[10] Singh, S., I. Singh, R. K. Gill, S. Kumar and A. Sarker. 2009. Genetic studies for yield and component characters in large seeded exotic lines of lentil. J. Food. Legumes, 22:229-232.

[11] Singh, K., and T.S. Sandhu. 1988. Screening of cultivars of lentil for resistance to rust. Lens 15: 28-29.

[12] Tickoo, J. L., C. S. Ahn, H. K. Chen and S, Shanmuga sundaram. 2005. Utilization of the genetic variability from AVRDC germplasm. Mungbean. Proc 2nd int. symp AVRDC Taipei Thailand, 103-110. 